\title{
Advanced Test Reactor National Scientific User Facility 2010 Annual Report
}

May 2011

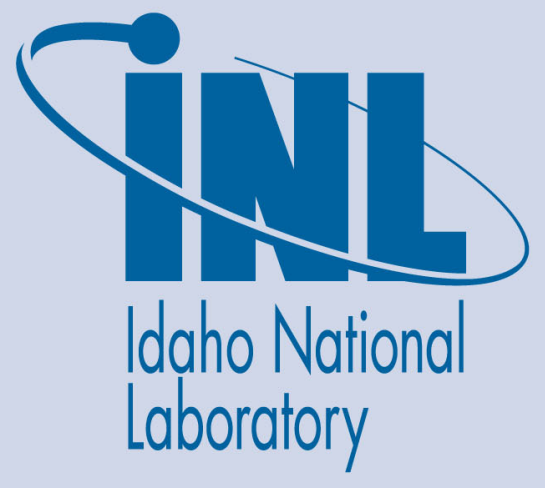

The INL is a U.S. Department of Energy National Laboratory operated by Battelle Energy Alliance 
INL/EXT-11-21785

\title{
Advanced Test Reactor National Scientific User Facility 2010 Annual Report
}

May 2011

\author{
Idaho National Laboratory \\ Idaho Falls, Idaho 83415
}

http://www.inl.gov

Prepared for the

U.S. Department of Energy

Office of Nuclear Energy

Under DOE Idaho Operations Office

Contract DE-AC07-05ID14517 


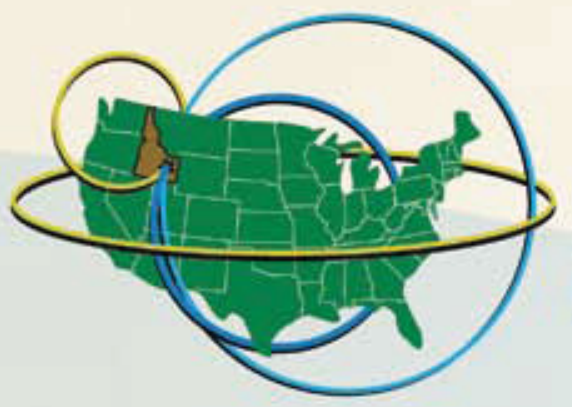

ATR

National Scientific User Facility

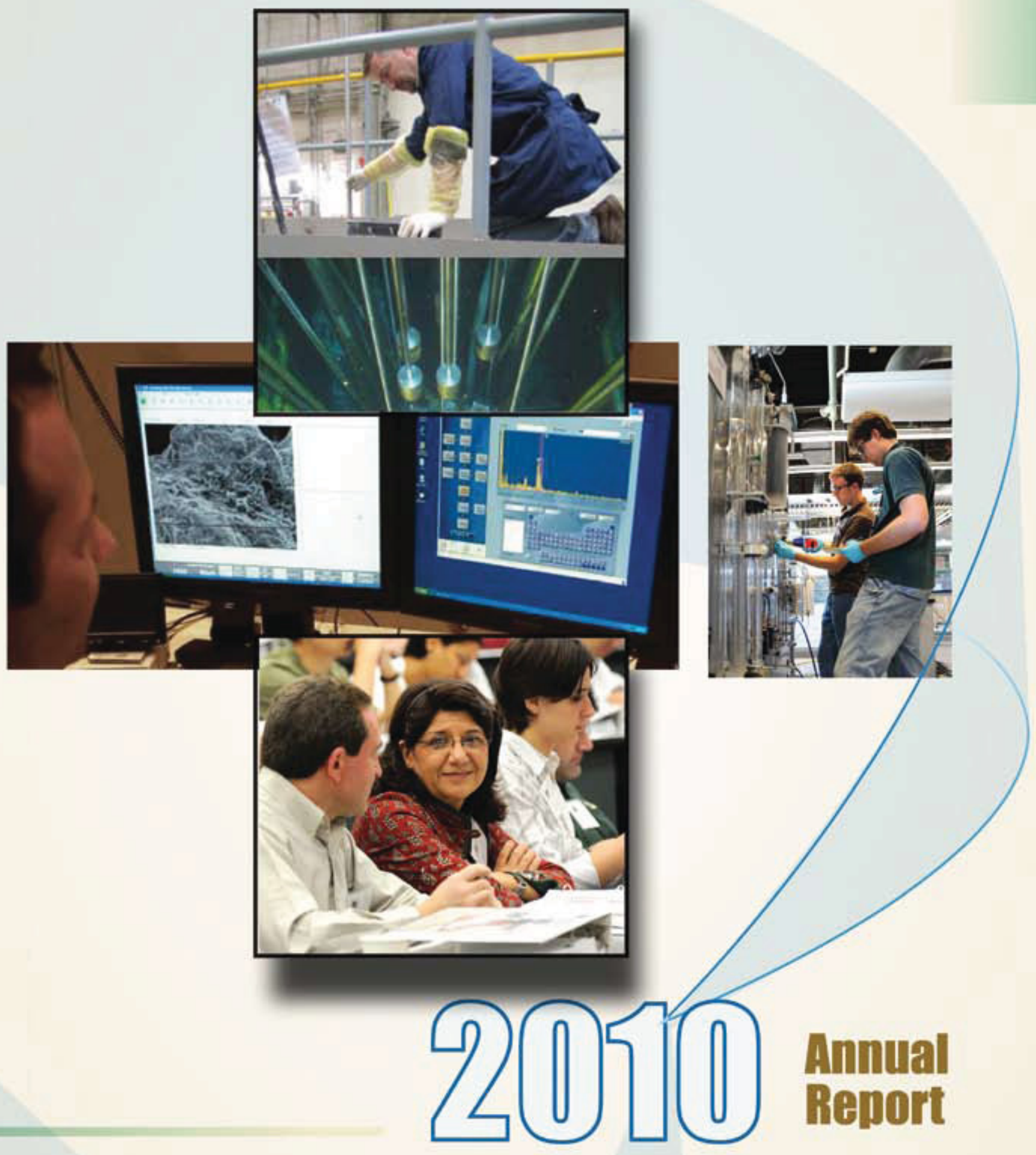


Todd Allen

Scientific Director

(608) 265-4083

allen@engr.wisc.edu

Frances Marshall

Manager, Program Operations

(208) 526-8947

frances.marshall@inl.gov

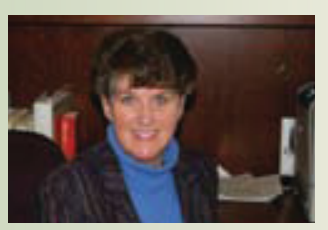

\section{ATR NSUF Contact Information}

\section{Jeff Benson \\ Education Coordinator \\ (208) 526-3841 \\ jeff.benson@inl.gov \\ John Jackson \\ Industry Program Lead \\ (208) 526-0293 \\ john.jackson@inl.gov}

Collin Knight

Project Manager

Post-irradiation Examination

(208) 533-7707

collin.knight@inl.gov
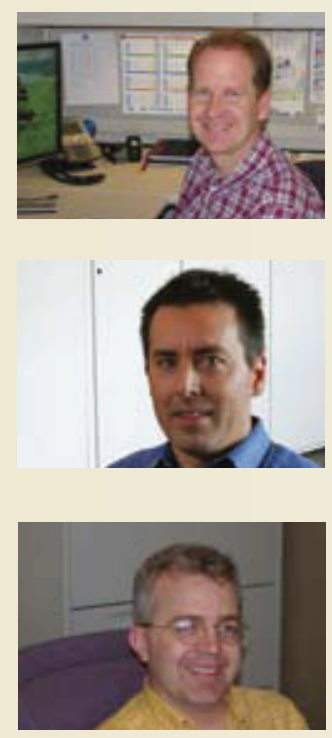

Dan Ogden

Project Manager Irradiation Experiments

(208) 526-4400 dan.ogden@inl.gov

Renae Soelberg Administrative Assistant (208) 526-6918 renae.soelberg@inl.gov
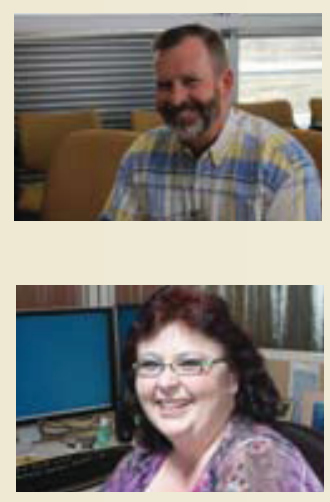

Mary Catherine Thelen

Program Administrator

(208) 526-5209 mary.thelen@inl.gov

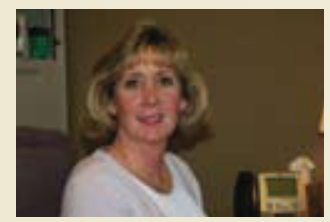

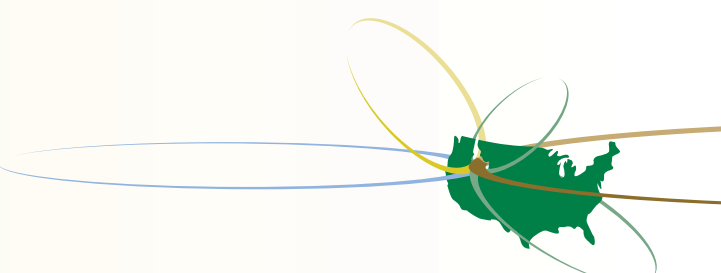





\section{Table of Contents}

Welcome and Introduction ............................................................ 1

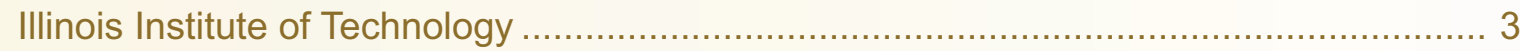

Massachusetts Institute of Technology ...............................................................

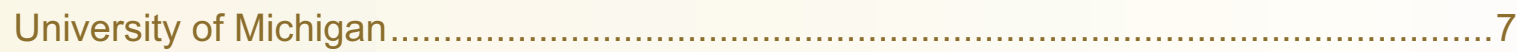

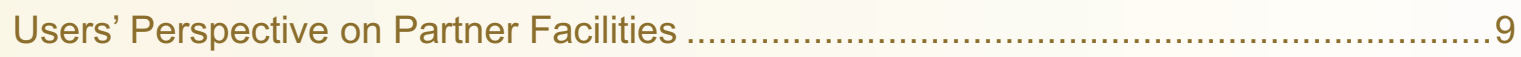

John Jackson-Idaho National Laboratory .......................................................... 13

Collin Knight-Idaho National Laboratory ........................................................... 15

\section{ATR NSUF Program Information}

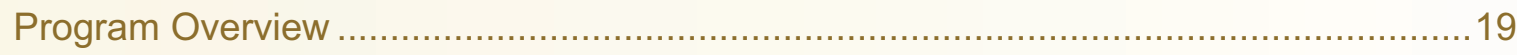

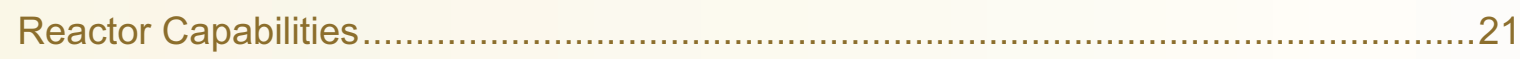

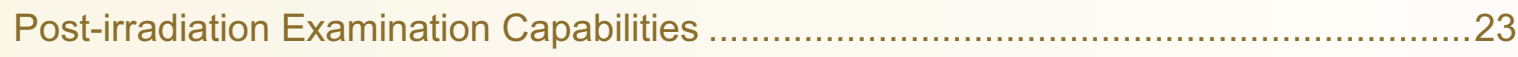

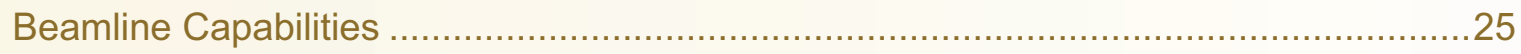

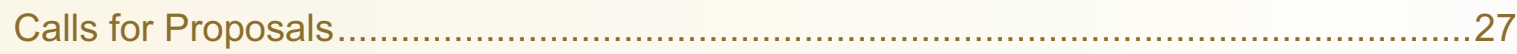

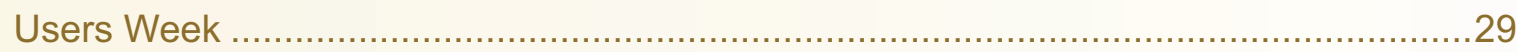

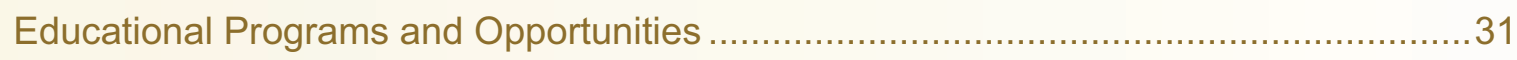

Distributed Partnership at a Glance ............................................. 33

\section{Awarded Projects Reports}

Irradiation Effect on Thermophysical Properties of Hf3Al-Al Composite:

A Concept for Fast Neutron Testing at ATR

Heng Ban, Ph.D., Utah State University

Project Awarded in 2009

Advanced Damage Tolerant Ceramics: Candidates for Nuclear Structural Applications......37

Michel W. Barsoum, Ph.D., Drexel University

Project Awarded in 2009

Development and Validation of an ATR-C Radiation Transport Model

Denis Beller, Ph.D., University of Nevada, Las Vegas

Project Awarded in 2010

Radiation Effects on Ceramic Coating of Advanced Cladding for Fast Reactors 
Measurement of Actinides Neutron Transmutation (MANTRA)....

George Imel, Ph.D., Idaho State University

Project Awarded in 2010

Irradiation Behavior of Triplex SIC/SIC Tubing Under PWR Conditions.

Mujid S. Kazimi, Ph.D., Massachusetts Institute of Technology

Project Awarded in 2009

Irradiation Behavior of Nanostructured Metals and Aloys.

K. L. Murty, Ph.D., North Carolina State University

Project Awarded in 2008

Inert Matrix Ceramic Fuel for Destruction of Plutonium and Minor Actinides

Juan C. Nino, Ph.D., University of Florida

Project Awarded in 2008

Characterization of Advanced Structural Alloys under Irradiation

G. Robert Odette, Ph.D., University of California, Santa Barbara

Project Awarded in 2008

High Fluence Embrittlement Database and ATR Irradiation Facility for

LWR Vessel Life Extension.

G. Robert Odette, Ph.D., University of California, Santa Barbara

Project Awarded in 2009

Synchrotron X-ray Diffraction Measurements of Spatially Resolved Strain Fields in

Nuclear Fuel Plates.

Maria A. Okuniewski, Ph.D., Idaho National Laboratory

Project Awarded in 2009

Hydride LWR Fuel Rod Irradiation

Donald Olander, Ph.D., Retired, and Mehdi Balooch, Ph.D., University of California, Berkeley

Project Awarded in 2010

Advanced Nondestructive Assessment Technology to Determine the Aging of

Silicon-Containing Materials for Generation IV Nuclear Reactors

David L. Olson, Ph.D., Colorado School of Mines

Project Awarded in 2008

Investigation of the Thermodynamics of Plutonium/Iron Solubility in Brines

Using X-ray Absorption Spectroscopy....

Donald Reed, Ph.D., Los Alamos National Laboratory

Project Awarded in 2009

Radiation Stability of Structural Materials for Nuclear Energy Systems

Kumar Sridharan, Ph.D., University of Wisconsin

Project Awarded in 2008

Fundamental Investigations of the Irradiation Behavior of Iron-Chromium Alloys

James F. Stubbins, Ph.D., University of Illinois

Project Awarded in 2008

Microstructural and Irradiation Effects on Ag and Cs Diffusion in CVD-SiC

Izabela Szlufarska, Ph.D., University of Wisconsin

Project Awarded in 2010

Radiation Stability of Ceramics for Advanced Fuel Applications

Yong Yang, Ph.D., University of Wisconsin

Project Awarded in 2009 


\section{Acronyms}

ANIAC

ANL

APS

ATR

ATRC

BWR

CAES

DOE.

EML

EPRI

FIB

HFEF

INL

IIT

IMC

ISU.

LANL

LWR.

MaCS

MFC.

MIT

MITR

MIBL

MRCAT
ATR NSUF Industry Advisory Committee Argonne National Laboratory Advanced Photon Source Advanced Test Reactor Advanced Test Reactor Critical Boiling Water Reactor Center for Advanced Energy Studies Department of Energy Electron Microscopy Laboratory Electric Power Research Institute Focused lon Beam Hot Fuels Examination Facility Idaho National Laboratory . Illinois Institute of Technology Irradiated Materials Complex Idaho State University Los Alamos National Laboratory Light Water Reactor Microscopy and Characterization Suite Materials and Fuels Complex Massachusetts Institute of Technology Massachusetts Institute of Technology Reactor Michigan Ion Beam Laboratory Materials Research Collaborative Access Team

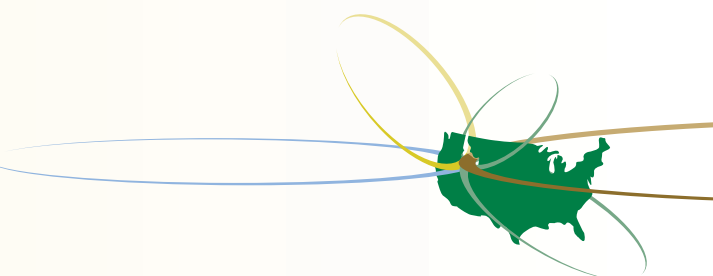


NCSU

North Carolina State University

NE.

Nuclear Energy

NIST

National Institute of Standards and Technology

ORNL Oak Ridge National Laboratory

PI Principal Investigator

PWR Pressurized Water Reactor

ORNL Oak Ridge National Laboratory

PNNL Pacific Northwest National Laboratory

SEM Scanning Electron Microscopy

SHaRE. Shared Research Equipment Collaborative Research Center

TEM Transmission Electron Microscopy

TMS The Minerals, Metals, \& Materials Society

UCB University of California, Berkeley

UCSB University of California, Santa Barbara

UM University of Michigan

UNLV University of Nevada, Las Vegas

USU Utah Sate University

UW. University of Wisconsin VHTR. Very-high Temperature Reactor 


\section{Dr. Todd Allen ATR NSUF Scientific Director and Professor of Engineering Physics, University of Wisconsin}

It is my great pleasure to introduce the Advanced Test Reactor National Scientific User Facility (ATR NSUF) 2010 Annual Report. This was a year of rapid growth for the NSUF, and we attribute this growth to the connections made between our users, our INL facilities, and our partner facilities, all facilitated through the efforts of the excellent NSUF staff. A first example of this growth is the introduction of rapid turnaround experiments, aimed at proposals with smaller scope than our initial NSUF focus on reactor experiments. The Rapid Turnaround Experiments are typically focused on samples from our library or use of our new analytical equipment and are reviewed immediately upon submittal. With the addition of rapid turnaround experiments we were able to utilize two of our partner facilities and awarded several experiments that will be described in the research projects section of this report. In 2010, some of our irradiation experiments were removed from ATR and post-irradiation examination (PIE) was initiated. This PIE work meant we had students spending part of a summer at the Idaho National Laboratory (INL) working with staff to analyze the irradiated materials. We also expanded the offerings of the Users Week courses to include a reactor instrumentation course. If this wasn't enough, we built world-class capabilities in the Center for Advanced Energy Studies (CAES), creating the Microscopy and Characterization Suite (MaCS) that will become available to ATR NSUF users in mid-2011.

For me, it was the year in which my vision for the user facility became reality. When I joined ATR NSUF as the Scientific Director in 2008, I had a vision of the user facility as a linked series of nuclear research facilities, allowing connections between people with a clever idea and the best nuclear facilities. These connections would lead to an increase in the overall state-of-knowledge in nuclear technology while exciting students and young researchers toward advanced research. I realized the model I envisioned

was a different kind of user facility concept-that ATR NSUF would be breaking new ground. However, I had the good fortune that the Department of Energy, Office of Nuclear Energy (DOE-NE) was willing to allow me to test this model. And test it we have, with great success.

This report showcases not only the research accomplishments of our principal investigators (PIs), but also how the connections between our partner facilities and the people who have used these facilities have resulted in relationships that would otherwise not have occurred. In line with this, we interviewed our primary points of contact at Illinois Institute of Technology, Massachusetts Institute of Technology, and the University of Michigan to ask them about how they became a partner of ATR NSUF, their experiences as a partner, and the kinds of research performed, capabilities built and relationships formed. We also spoke with several of the researchers who used these facilities. We asked them what they gained from this experience, and whether they would propose future experiments to be performed at partner facilities.

Since some of our growth included the use of PIE facilities at INL, we wanted to tell you about the ins and outs of performing the analysis at the Materials and Fuels Complex (MFC). We interviewed our PIE project manager who identified the experiments that have completed the irradiation process. He then explained how the capsules that hold the irradiated materials are disassembled and talked about the process for taking these materials and turning them 


\section{Welcome \& Introduction}

into samples for analysis. He also described the opportunities for students coming to INL to do PIE, along with the opportunities that will become available in FY 2011 for PIE in the MaCS laboratory in the CAES facility.

Finally, we talked with our industry program lead about opportunities for industry users of ATR NSUF facilities. He described the efforts of the industry advisory board, along with some of the challenges that still need to be addressed before a formal industry program can be launched.

One of our goals is to make this report useful to anyone interested in the opportunities offered through ATR NSUF. We therefore follow the highlights with an overview of ATR NSUF and its mission, capabilities offered by type, the various types of calls for proposals, and finally the 2010 Users Week and education program.

The second section of this Annual Report covers the various experiments (or in our terminology "projects") that were either continued or initiated in FY 2010. Since our full irradiation projects typically run for three or more years, it was very exciting to have rapid turnaround types of projects that were initiated and completed within the fiscal year. These experiments are a direct result of our partnership program; and the success of these projects and enthusiasm from our PIs for more of these kinds of research is very encouraging.

I hope you find the information contained in this report as exciting as I do. We are grateful to our partners for having confidence in this unique user facility model, and look forward to expanding on the concept in the coming years. As our experiments mature, our publication results will expand, providing scientists worldwide access to the latest research in nuclear fuels, materials and modeling.

\section{Enjoy!}

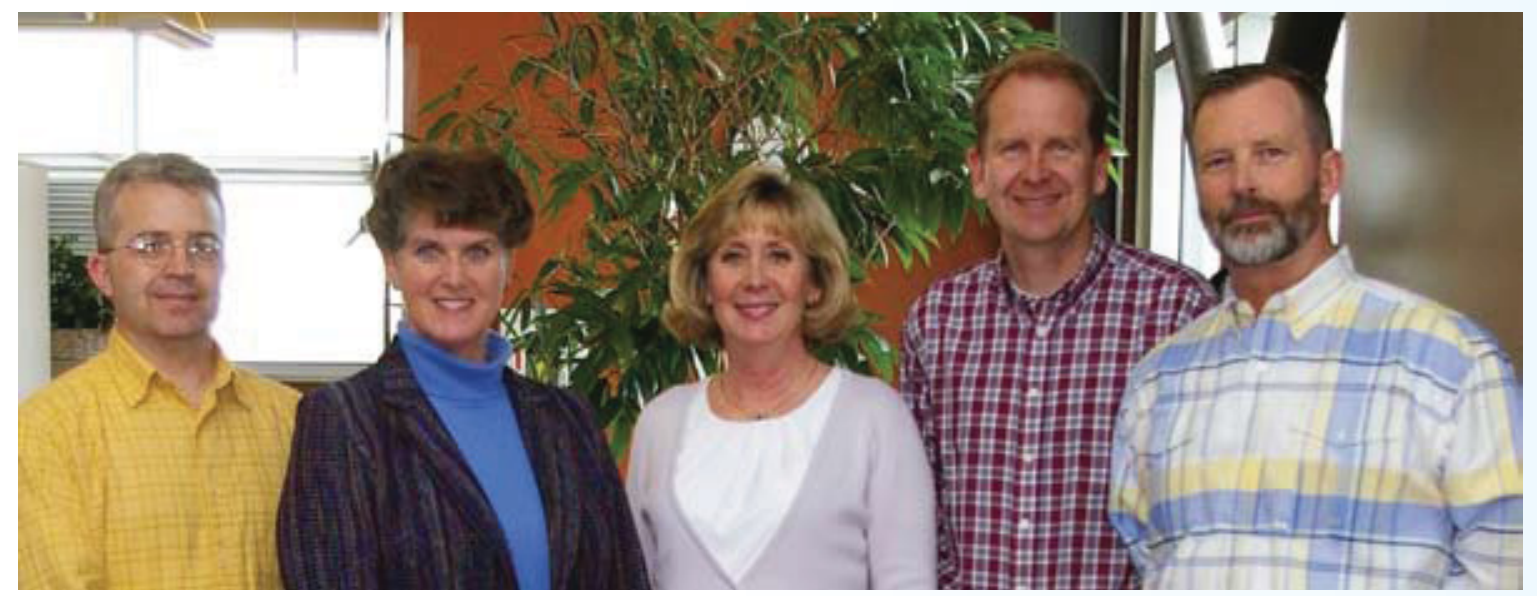

ATR NSUF staff from left: Collin Knight, Frances Marshall, Mary Catherine Thelen, Jeff Benson and Dan Ogden 
In 2008, as the ATR NSUF was just beginning to explore the vast opportunities of the nuclear research arena, two people met for reasons that, at the time, had nothing to do with the user facility. It would be hard to say whether they knew how important their acquaintance would become. But it was because of this acquaintance that a partnership was later formed that has proved successful on a number of fronts.

It was October of 2008 to be specific, when Professor Jeff Terry of Illinois Institute of Technology joined a group of scientists who wanted to convince DOE-NE of the importance of committing to the design and building of a dedicated beamline facility for synchrotron radiation projects. The group's idea centered on the belief that before new nuclear plants are built there should be a scientific understanding of degradation mechanisms in nuclear materials. According to Terry, "synchrontron radiation techniques revolutionized the semi-conducter industry in the late 1960s and early 1970s, and this group of like-minded researchers believed synchrotron radiation techniques could be used to perform a similar feat for nuclear materials research." After a number of meetings, the group took it upon themselves to write a proposal to DOE-NE for the design and building of a dedicated beamline facility for synchrotron radiation projects.

As you may have guessed, Todd Allen was also a part of this group. And while the group worked on the proposal, Allen approached Terry, knowing he was a professor at Illinois Institute of Technology (IIT), and knowing that IIT manages the Materials Collaborative Access Team (MRCAT) section of the Advanced Photon Source at Argonne National Laboratory (ANL). Allen wondered whether MRCAT could offer any help in proving to DOE that synchrotron radiation was important to the state-of-knowledge in reactor materials. The reason for Allen's interest was that MRCAT had been performing low-level radioactive materials research for more than 10 years. Allen suggested that by performing a proof-of-concept using MRCAT two things could be accomplished. First, to help prove to DOE the principle that "if you build it they will come." The second and more important thing it would accomplish is to demonstrate that useful information could be obtained by applying synchrotron radiation techniques to the study of nuclear engineering.

\section{Dr. Jeff Terry Professor \\ Illinois Institute of Technology}

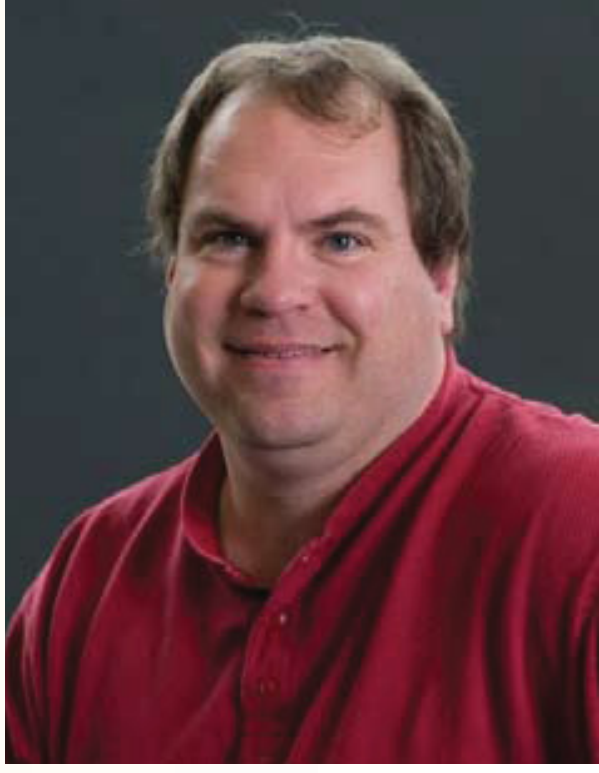

Making use of their extensive network of contacts, both Terry and Allen confirmed what they hoped would be true-there was interest within the community for this type of research. And so the partnership was formed and ATR NSUF opened a call for proposals. Terry explains, "What we found was very encouraging. I think it's important to highlight how much interest we got from the first call for synchrotron radiation proposals. For that first call, 15 days of beam time were made available to NSUF experimenters. Four proposals were awarded and the time needed far exceeded the days available. Many of the researchers submitted additional proposals to continue the research they had started!" Terry continues, "If this trend continues, we will have hard data proving that a dedicated facility is feasible and advisable."

Terry is happy that MRCAT is able to meet some of the research needs. "I can brag a bit here about MRCAT which was designed by the partnership with Argonne National Laboratory to handle radioactive materials. The MRCAT partners wanted to study the actinides plutonium and plutonium-oxide, and the MRCAT was designed with dedicated hepa-filtration that makes it easier to handle these actinides. In addition, the entire facility staff has DOE radiological worker training and MRCAT is probably the only synchrotron radiation facility in the U.S. that can claim this kind of expertise. That is part of why Todd was so interested in us, we had the facility, the expertise and the willingness to give this a try" explains Terry. 


\section{Illinois Institute of Technology}

Terry sees this partnership as very successful. When asked about working with ATR NSUF and its users Terry said, "Without ATR NSUF, the MRCAT would not have been used for these kinds of experiments. But it's not just the research that makes the partnership remarkable-it's the people doing the research that makes this so exciting. We simply would not have met these people if not for the partnership." Every ATR NSUF user, according to Terry, has been very good about paying attention to the safety requirements, and has worked well with the MRCAT staff. These interactions have helped MRCAT improve its facility.

Another aspect of the partnership Terry pointed out is that MRCAT is adding capability based on what ATR NSUF experimenters have asked for. Terry explains, "Because of this partnership, MRCAT has added a tomography capability (scale of 5 microns) they would not have considered adding in the past." Terry continues, "But it's not just the addition of capabilities, it's the way things happen when you connect people and facilities. For instance, one experiment involved MRCAT, ATR NSUF, INL and Los Alamos National Laboratory. And this was just one experiment. When you think about the whole partner facility concept being embraced by ATR NSUF, you realize the potential for immense benefit to the stateof-knowledge in nuclear research. As for MRCAT, we now have tomography capability that is available to anyone who wants to utilize our facility, including ATR NSUF users."

Terry recognizes that it will still take years for a dedicated synchrotron radiation facility to be designed and built, and in the interim he sees the partnership between MRCAT and ATR NSUF continuing to grow. He looks forward to new capabilities being added at MRCAT to address users' needs. He sees the user community continuing to expand and the connections among users and facilities as igniting the science. Now that the first round of experiments has been accomplished, would Jeff Terry describe all this? "Working with ATR NSUF users has been a blast!"

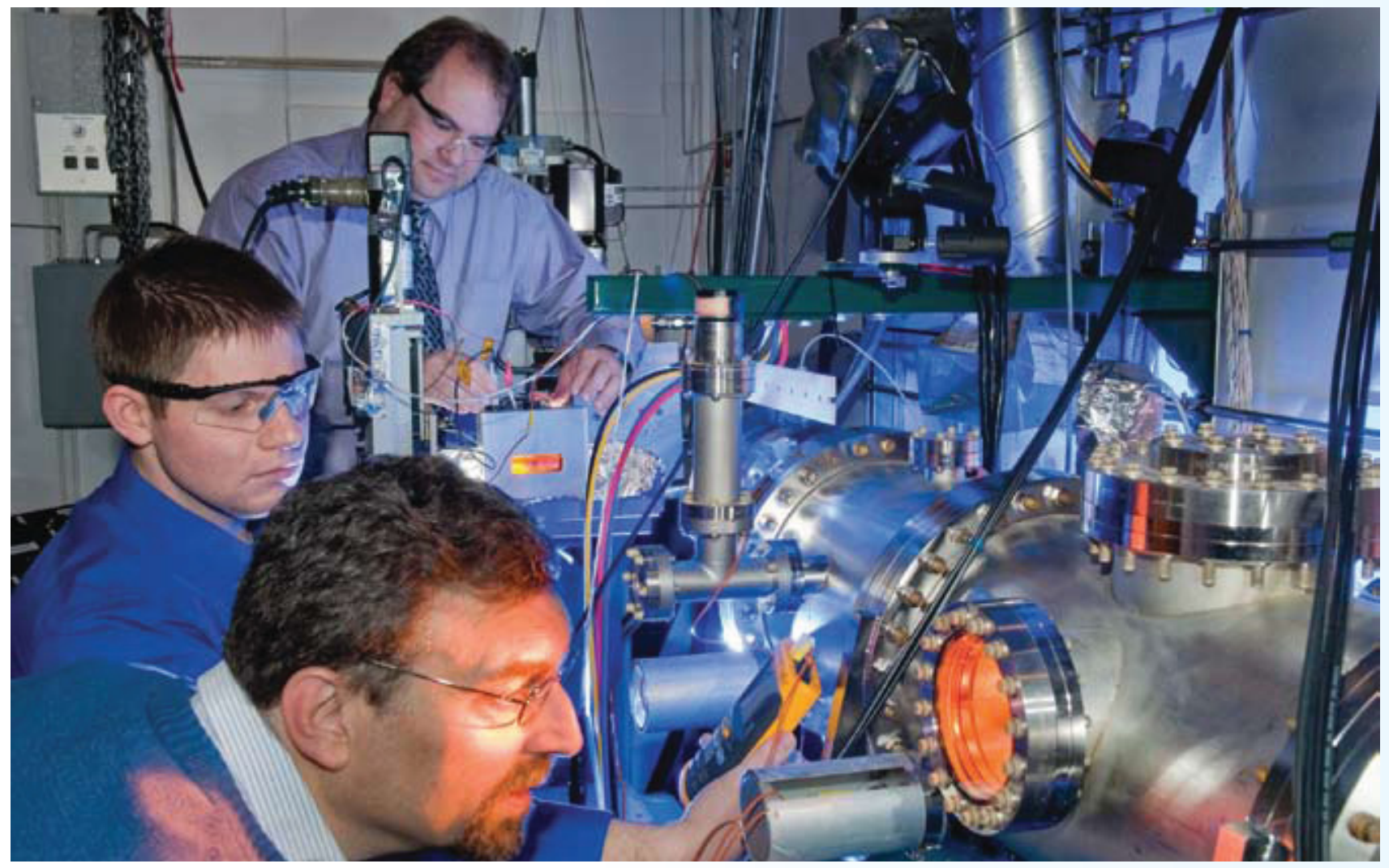

From top: Professor Jeff Terry, Dan Olive (graduate student) and Professor Carlo Segre of Illinois Institute of Technology. 


\section{Dr. Lin-wen $\mathrm{Hu}$ \\ Associate Director \\ Nuclear Reactor Laboratory}

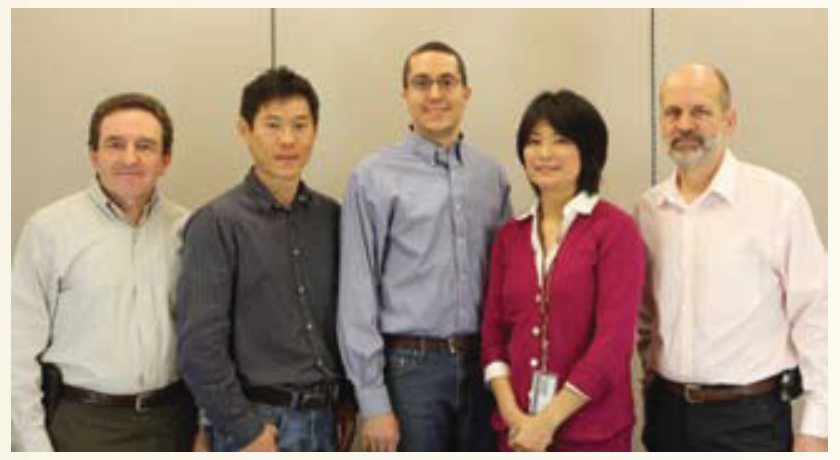

Massachusetts Institute of Technology
MIT Reactor Laboratory team from left: Yakov Ostrovosky, Sung joong Kim, David Carpenter, Lin-wen Hu, and Gordon Kohse.

When smart people get together, good things happen. And sometimes these good things exceed everyone's expectations. The relationship between ATR NSUF and Massachusetts Institute of Technology Reactor Laboratory (MITR) could be described in just this way. MIT and the INL have a long-standing relationship, with researchers from both organizations collaborating on research projects. But as ATR was being established as a national scientific user facility by the Department of Energy, officials from INL saw an opportunity that had not existed in the past. If the MITR could be added as a capability to the ATR NSUF, it might be possible to expand the kinds of research that could be performed.

This was a novel concept in the world of user facilities, and as with most novel concepts there was much to learn. A clear understanding was needed to seamlessly integrate the two facilities under one program. Bridges of communication had to be built. How would the infrastructures at two facilities be leveraged to benefit the research community, and who would make decisions about the research to be performed?

\section{Dr. Lin-wen Hu, Associate Director of the Nuclear} Reactor Laboratory at MIT, describes some of what happened next. "A faculty/staff exchange contract was established between MIT and INL so that scientists from both facilities could travel to and learn about the capabilities of the other facility."

Hu explained, "This contract provided the mechanism to bring people from the two facilities together. It was the bridge to communication, to learning about the unique capabilities of each facility. Through the faculty/staff exchange, specifics of how the research would be awarded, and what role MITR would play in this process were developed and formalized."

The faculty/staff exchange and the ensuing discussions occurred during 2007 and into 2008, very soon after the user facility was formally established by DOE. But the idea really took hold and became a reality after Todd Allen was hired as the Scientific Director of ATR NSUF in April of 2008. According to $\mathrm{Hu}$, "Todd was very excited by the capabilities of the MITR and the synergy gained from having two reactors available for ATR NSUF users." Hu continues, "Todd wanted to increase the kinds of capabilities ATR NSUF offered, and so MIT became the pilot facility for what would later become known as the ATR NSUF Partnership Program. It was an honor to take the lead in this program and to open MITR's irradiation facilities to outside users."

The ensuing relationship has proved fruitful to both organizations. Since becoming a partner, a number of experiments have been awarded to MITR and the working relationships between ATR NSUF users, INL and MITR staff have been extremely positive. MITR can perform work on novel materials that have not previously gone into test reactors. This provides an avenue for researchers to propose experiments that may not have been allowed in ATR - a plus for all parties.

However, the benefits don't just apply to the types of research offered. According to Hu, "MITR researchers gain a great deal from the relationships they form 


\section{Massachusetts Institute of Technology}

with both INL and university researchers." Hu explains, "For example, one INL researcher works with high-temperature, irradiation-resistant thermocouples and thermal conductivity sensors, and because of the partnership, MITR is now involved in new reactor instrumentation development research."

The partnership also provides an avenue for building new capabilities at MITR. According to $\mathrm{Hu}$, "The ATR NSUF research project awarded to University of California, Berkeley, provided an opportunity for MITR researchers to learn a new fuel rod design and fabrication process for which they previously had no experience." These relationships and added capabilities would not have happened without the partnership. Hu sees these relationships as multi-facetedbetween INL and MITR, and also between all the users whose research projects are awarded to MITR through ATR NSUF. Hu elaborates "my experience with these multi-faceted relationships has taught me that the strengths of each organization helps ensure the success of the project."
$\mathrm{Hu}$ radiates enthusiasm as she talks about the partnership and the almost unlimited opportunities offered. "My colleagues and I are privileged to work with distinguished researchers in proving the feasibility of a new concept. This partnership is all about the research that can be accomplished with ATR NSUF resources and expertise." She adds, "MITR is expanding its experimental capabilities and hiring new research staff to support more research. Through this relationship with ATR NSUF, MITR is developing new concepts for a high temperature irradiation facility-an essential test bed for advanced reactor materials."

When asked if she had anything else to say about this collaborative partnership, Hu says simply, "The ATR NSUF is one of the most successful initiatives of DOE-NE."

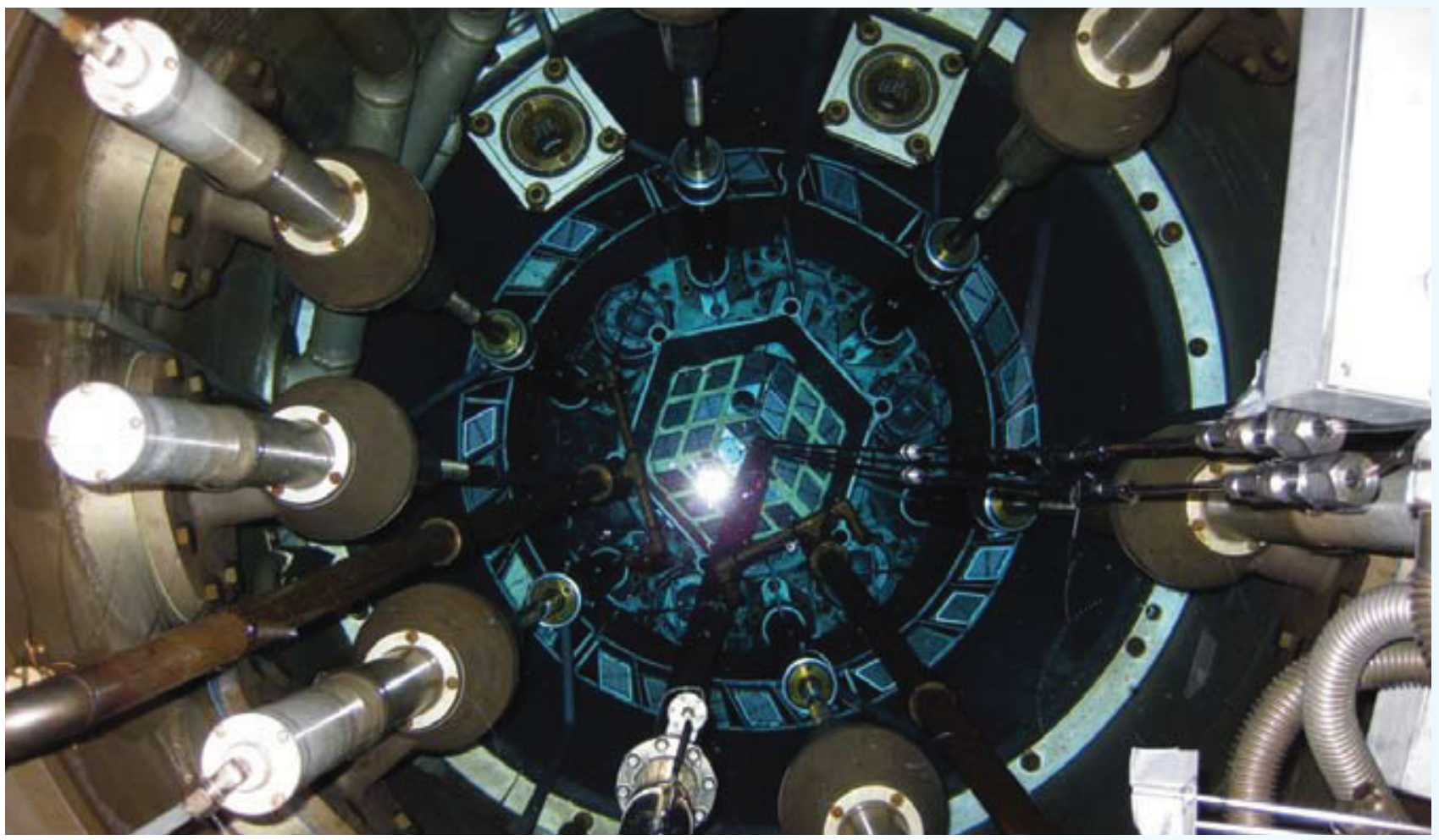

MIT Reactor core 


\section{University of Michigan}

get exposed to new research problems and form collaborations with researchers with whom continued joint research can be performed." He continues, "These opportunities would not have existed without ATR NSUF taking the lead in forming this network of partner facilities and offering these capabilities to scientists across the U.S."

When asked how he sees this partnership in the future, Was's enthusiasm was clear, "We are right now, writing a proposal to Nuclear Energy University Program (NEUP) infrastructure program to purchase a new accelerator to expand the capabilities in the MIBL. The plan is to create a triple beam facility to simulate effects of the multiple elements created in the nuclear reaction process - something called transmutation." He continues, "This kind of capability will be a huge boon to nuclear research in the U.S. The French and Japanese are ahead of us right now, but if this triple beam facility can be built here, the
U.S. will retain its position as a world leader in these kinds of research."

While Was's would be building these capabilities without ATR NSUF, he emphasizes the importance of ATR NSUF to nuclear research, "The ATR NSUF partner facility concept is a very unique cooperation that has the potential to set the standard for how facilities located around the country can cooperate to solve very complex problems." As Was sees it, "The trick was to find the facilities that could provide a broad range of capabilities, develop a model for access, and then make it all work administratively. ATR NSUF is making the model work for both the facilities and the researchers." He is happy to be part of this program, "It's a really key and important element in making irradiation effects research accessible to a wide range of researchers."
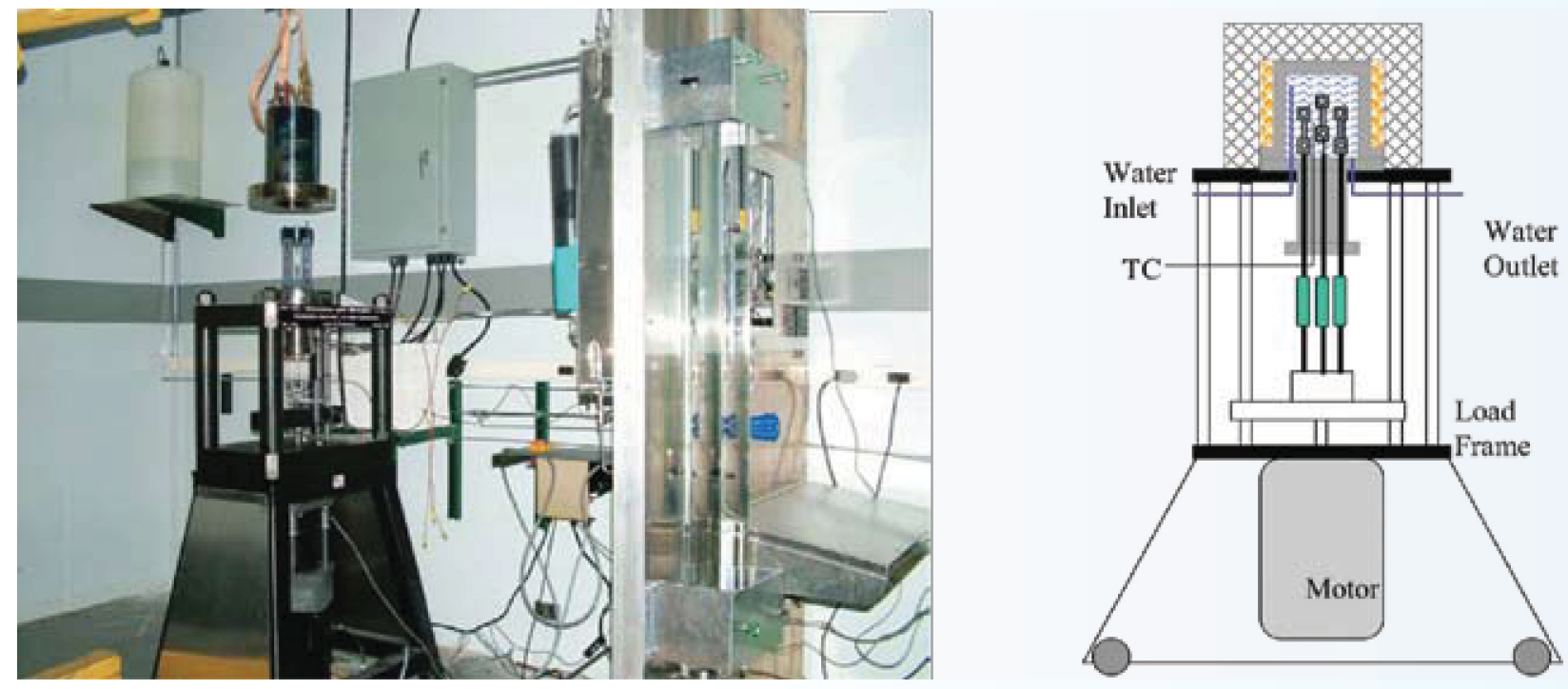

The supercritical water facility in the Irradiated Materials Laboratory, and the schematic of its mobile construction. 


\section{Users' Perspective on Partner Facilities}

The ATR NSUF partners interviewed for this report talked about the positive experiences they have had with the users we have sent them. They also spoke of the novel kinds of research performed and the unique opportunities these research experiments bring to their facilities. However, that is only one side of the story. In order to paint a balanced picture of whether the partner facility concept is a genuine success, we need to understand the experiences of the users of these facilities. We therefore interviewed a user from each of the three highlighted partners. Each of these users performed an experiment in 2010, so their perspective is still fresh.

We hope that by highlighting their experiences it encourages future proposers to try this very unique opportunity.

\section{Dr. Mehdi Balooch \\ University of California, Berkeley \\ Facility used - Massachusetts Institute of Technology Reactor}

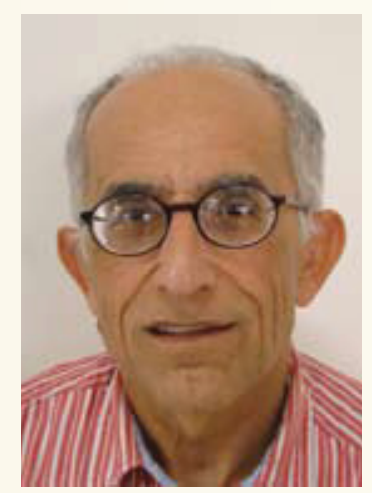

Dr. Mehdi Balooch, Senior Research Scientist at the University of California, Berkeley, had no idea his research project would be selected to be performed at the MITR. However, his surprise turned to enthusiasm as he began working with the MITR staff. "They have fantastic people who work hard and are very intelligent" Balooch said. This research project looks at hydride fuel elements, and is novel in its approach. According to Balooch, "The MIT group had some great ideas on how to design the experiment and they did a lot of calculations to make sure the experiment would run as planned." The goal of the research is to test the use of hydride fuels for use in light water reactors.

The project is a large collaborative effort with researchers involved from not only MIT and U. C. Berkeley, but also from Idaho and Oak Ridge National Laboratories. According to Balooch, "Idaho National Laboratory helped by cutting the experiment samples, and one of the co-PIs is from Oak Ridge National Laboratory has been instrumental in the design process and traveled to MIT to help load the samples into the capsule."
When asked about his experience with a partner facility and whether he would propose research that might go to a partner facility he said, "Yes! This is a good arrangement because it's hard for one laboratory have all the equipment that is needed. So if there are multiple partners, they can complete each other and by sharing equipment it lowers the cost of the experiment."

For more information on this research project, please turn to page 59 .

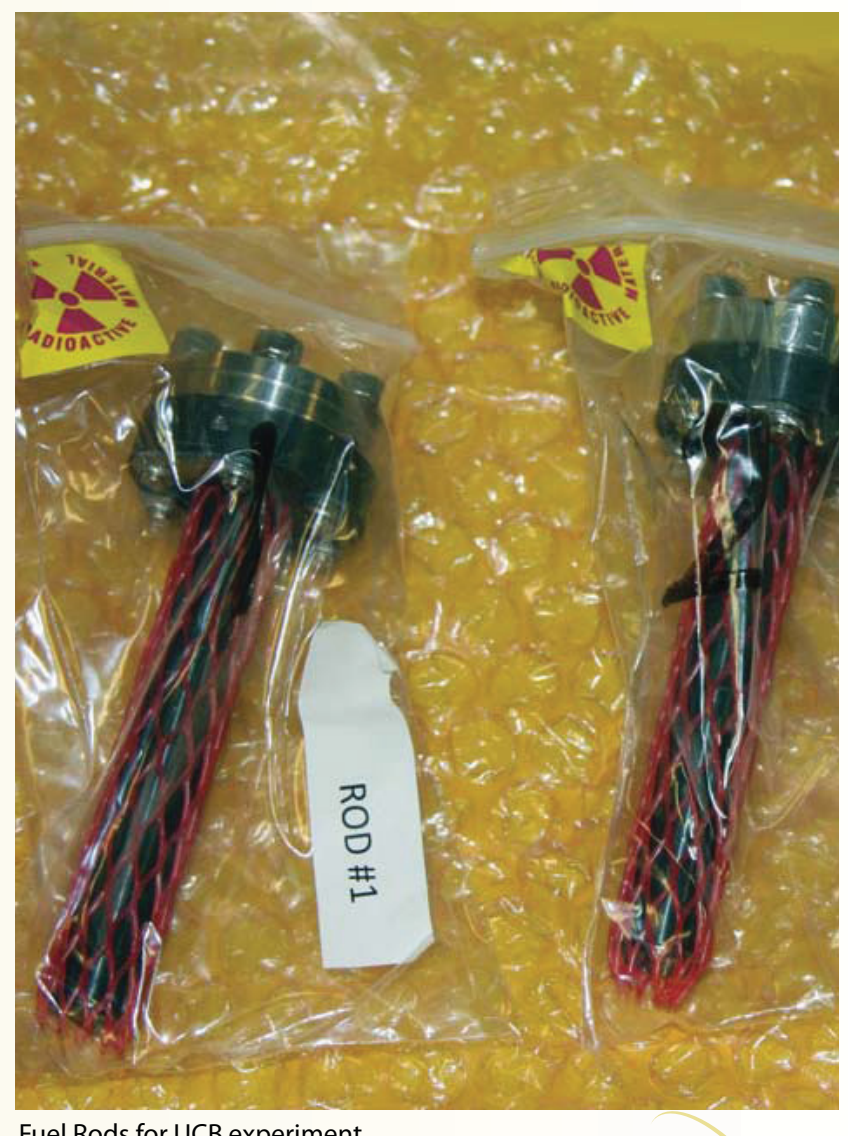




\section{Dr. Jian Gan}

Idaho National Laboratory Facility used -
University of Michigan
Ion Beam Laboratory

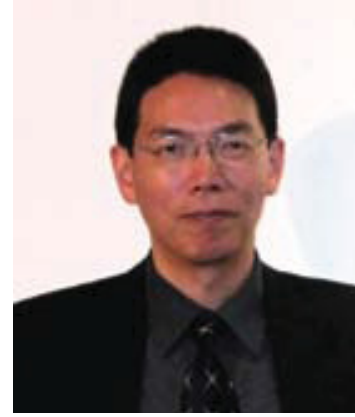

When Dr Jian Gan, Senior Staff Scientist at the Idaho National Laboratory, discovered that the MIBL was available to successful rapid turnaround experiment proposals, he jumped at the opportunity. Gan's research project studies coating applications, in this case TiN, on iron based fuel cladding in order to prevent chemical interactions with fuel, for fast reactor systems. Using the MIBL, they can get very high radiation doses in a very short time (days versus years in a reactor). So it's a tool for screening a large matrix of materials to find the best candidates for a particular application.

Gan's experience at MIBL was very positive, "It was a very effective and a truly "rapid turnaround" experiment. We were able to complete a heavy ion irradiation study within six months from design of the experiment to the analysis of the irradiation results. This is compared to several years for planning, execution and PIE for an ATR experiments. My collaborators and I were happy for the opportunity to take advantage of this unique program and access the MIBL to address our R\&D needs."

As an INL employee, Gan understands the benefits of the partner facility concept, "Having access to these post-irradiation examination facilities such as the MIBL means that more and broader research, to comprehensively study a phenomenon can be accomplished. It also opens avenues for collaborations that would not otherwise exist, and gives students a simple mechanism for involvement. Currently, students coming to INL have some challenges with respect to security requirements. The universities do not have these requirements and therefore students have easy access to unique capabilities."
Gan will take advantage of the rapid turnaround experiment process in the future. "Because of the ATR NSUF partnership program, researchers have connection to a broad range of complementary facilities, providing important insight into the complex irradiation behavior encountered in materials and fuels."

For more information on this research project, please turn to page 41 .

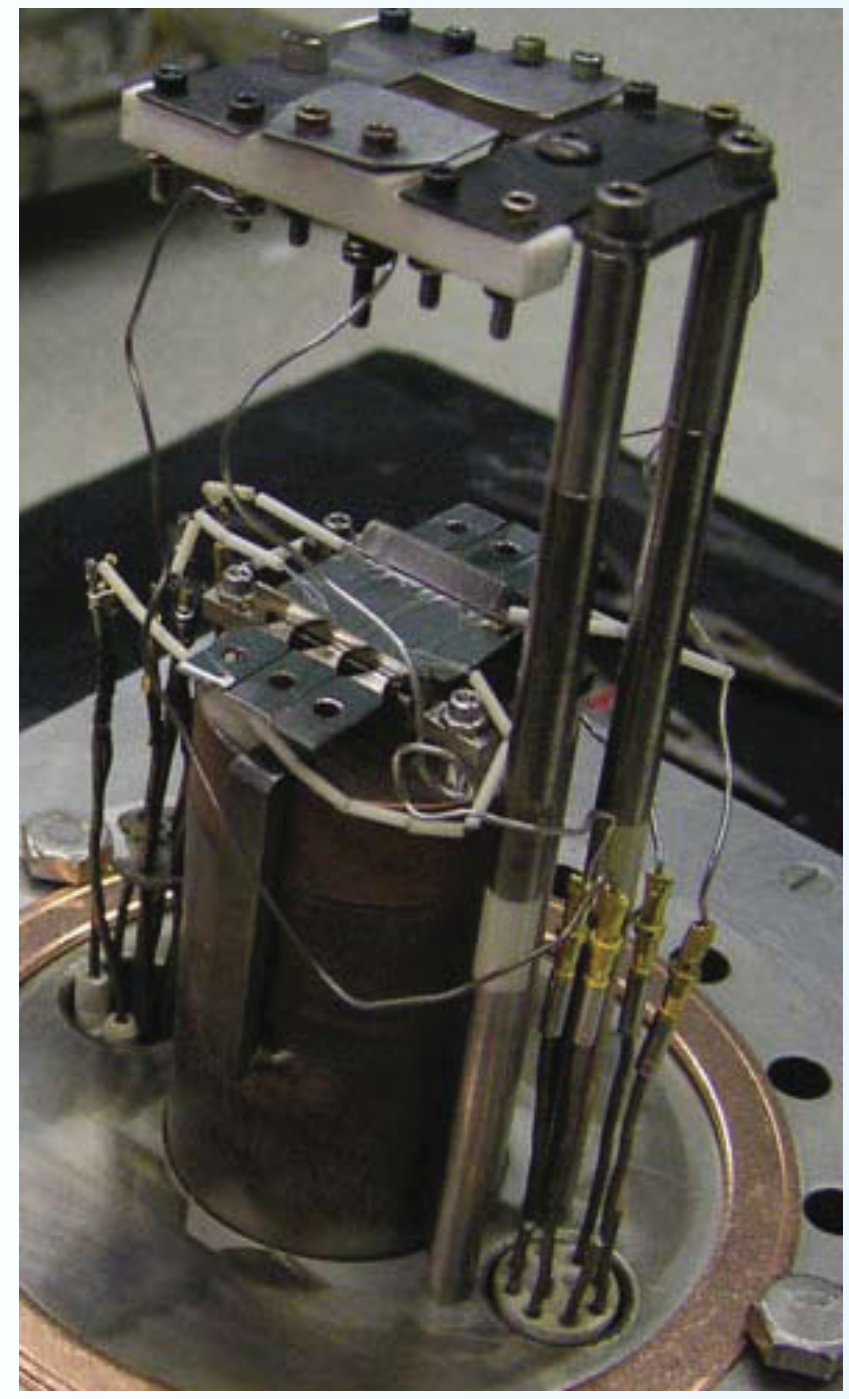

Photo of the samples, thermocouples and four electrodes used for centering the ion beam (top). 


\section{Users' Perspective on Partner Facilities (cont.)}

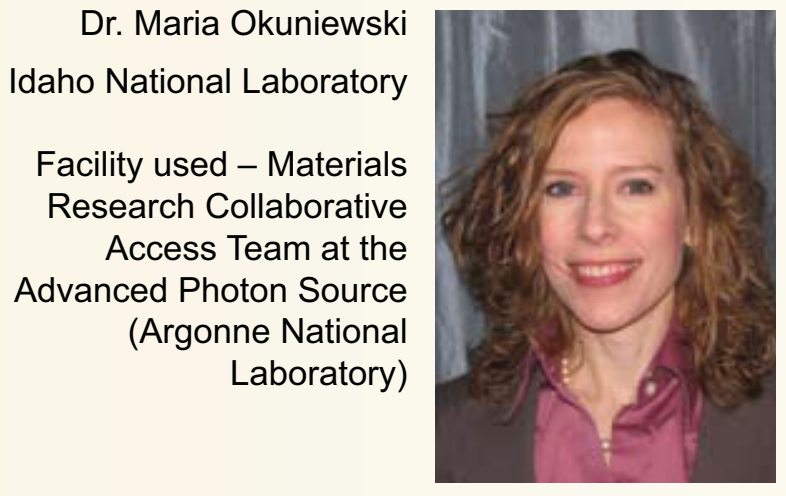

Dr. Maria Okuniewski, a nuclear engineer at INL not only knew her research would be performed at a partner facility, but was thrilled to have the opportunity. According to Okuniewski, "I was very excited to propose a synchrotron radiation experiment because I knew that through the partnership between ATR NSUF and Illinois Institute of Technology, if my proposal was selected I would have very quick access to the Materials Research Collaborative Access Team (MRCAT) beamline at the Advanced Photon Source (APS) at Argonne National Laboratory (ANL)." Okuniewski's research is examining how the fabrication and processing of fuels plates ultimately impacts the residual stress of the resultant specimens. Ultimately, this is important to help in the understanding of the correlation between fuel fabrication parameters and fuel performance in the reactor. According to Okuniewski, "Synchrotron X-ray diffraction is a nondestructive technique for analyzing residual stress $n$ specimens. Since it is a non-destructive technique, you can perform additional analyses such as electron microscopy and mechanical testing on the samples."

Partner facility experiments tend to be collaborative across a number of institutions, and Okuniewski's experiment was no exception. She also worked with a colleague from LANL who is an expert in diffraction. Through discussions with her LANL collaborator it was determined that the experiment would be better suited for synchrotron diffraction versus neutron diffraction due to the geometry of the specimens, as well as the capability of the synchrotrons to provide better spatial resolution.

Okuniewski's experience in working with the staff at MRCAT was excellent, "I had a great experi- ence. It was truly a team effort between INL, LANL, MRCAT, and ANL and everyone wanted the experiment to succeed." She continues, "I had the good fortune that MRCAT had recently conducted an ATR NSUF experiment and all the contributors got together and talked through the experience which made for a smooth transition for my experiment, particularly since we were going to be analyzing radioactive materials at the APS."

When asked if she would propose to a partner facility again she said, "Yes! I built some relationships that will result in future collaborations, and in fact I am collaborating on a proposal that is looking at developing a new type of detector for radiation damage in materials. This research, if awarded would also be performed at MRCAT."

The ATR NSUF partnerships enable the collaboration of technical experts from multiple institutions and the use of facilities to efficiently solve scientific problems.

For more information on this research project, please turn to page 57 .

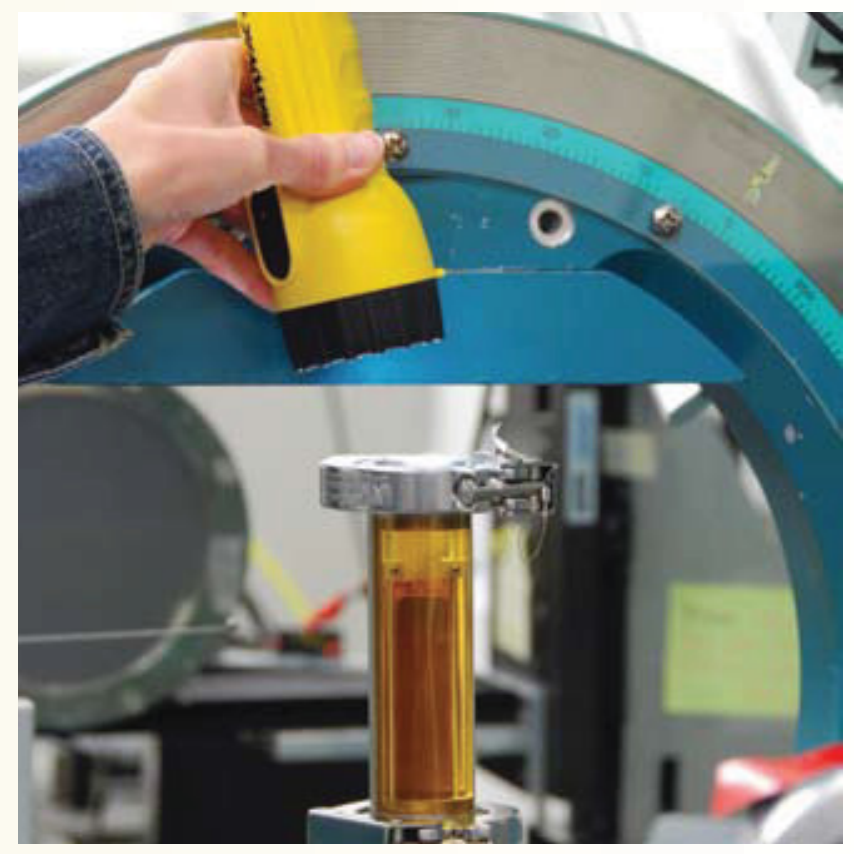

Alignment of the capsule containing bare DU-10Mo fuel foil. 


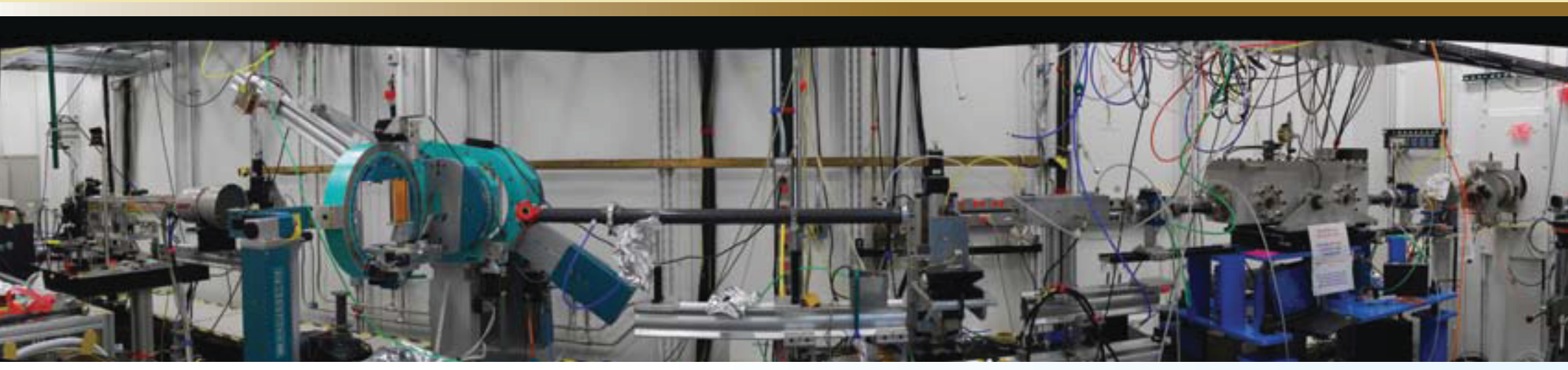

MRCAT at the Advanced Photon Source, Argonne National Laboratory.

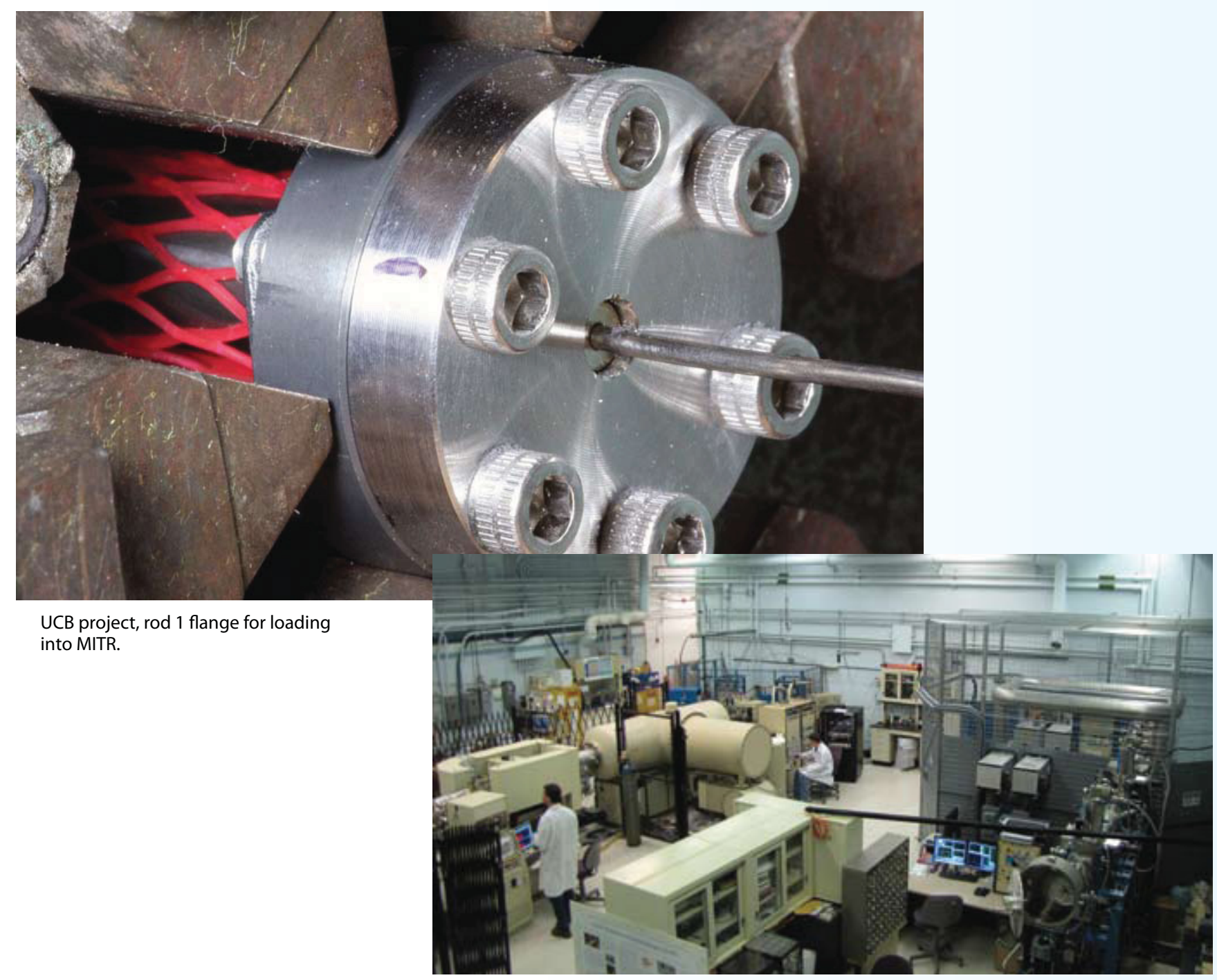

University of Michigan, lon Beam Laboratory. 
tion for the Department of National and Homeland Security gave him some knowledge on how to build bridges between national laboratories and industry. Therefore, when the position as Industry Program Lead opened recently, Jackson jumped at the chance.

Under development is an ATR NSUF industry program where industry users can pay for irradiation experiments and the use of post-irradiation examination facilities. "Currently the industry program primarily involves what are termed 'pilot projects' because they are intended to focus on establishing the way future projects will work between industry and ATR NSUF," says Jackson. An example of one of these pilot projects is the CRADA (cooperative research and development agreement) with the Electric Power Research Institute (EPRI) to test baseline and irradiated properties of alloys X-750 (a nickel-based super alloy) and XM-19 (a stainless steel alloy).

"We will mechanically characterize these materials in unirradiated and irradiated conditions; something that has not been done to a large extent in the past," Jackson explained.

Because both organizations are learning from this experience, ATR NSUF is sharing some of the cost with EPRI. In general, ATR NSUF is funding the

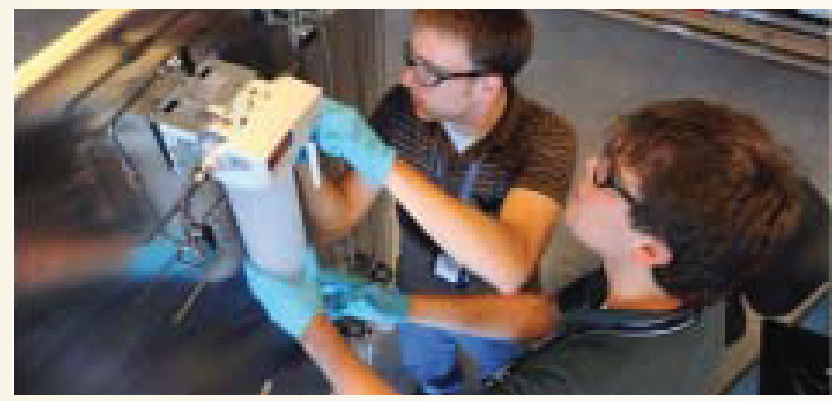

ATR NSUF student interns assemble equipment to be used for baseline characterization of reactor internal materials for EPRI project.

irradiation of the material and EPRI is funding the characterization. This program will utilize some of ATR NSUF's newest equipment and will pave the way forward for the industry user program. According to Jackson, "Pilot projects such as EPRI are helping the ATR NSUF to develop a complete industry experiment process starting from insertion into ATR and continuing to extraction, shipment, and movement between facilities located within the Materials and Fuels Complex (MFC) campus and ending with characterization of irradiated materials. A strong performance in this program with EPRI will also establish confidence in the way we do business here at the ATR NSUF for future industrial partners."

Jackson is very optimistic about the future of the ATR NSUF industry program, "The next five years should bring about some exciting changes with regard to industrial participation. In addition to our pilot programs," says Jackson "we have regular interaction with industry to ensure we are building capabilities that industry users will utilize."

To gauge industry needs and understand how best to collaborate, the ATR NSUF Industry Advisory Committee (ANIAC) holds annual meetings. Currently, the groups represented on the ANIAC committee are EPRI, General Electric, Westinghouse, AREVA, U.S. NRC, Exelon Corporation, Duke Energy, NEI, First Energy, Rolls Royce, the Materials Aging Institute (MAI), and other national labs. In the future, ATR NSUF also hopes to solicit participation from additional international companies such as Studsvik in Sweden. Initially, ANIAC members were asked to provide feedback on the types of resources they would like to have available and in the long term 


\section{Idaho National Laboratory}

these industry members will fulfill the very important role of bringing to light issues and research topics that should be explored.

This partnership is important in building a solid industry program. Jackson explained, "ANIAC representatives offer us insight on the way they'd like to do business and we do our best to work with them toward establishing an NSUF that meets these requirements. It is important to remember that the NSUF represents a huge shift in the way research will be done for these companies. It is exciting for them and exciting for us." Based on their input, ATR NSUF can facilitate finding a solution to research questions through its distributed network of partner institutions. These solutions can be as varied as providing specific equipment or expertise, to enabling the research to be performed at the University level by supplying funding through programs such as the Institute for Nuclear Energy Science, and Technology (INEST).

Because the ATR NSUF user facility concept is such a novel way for industrial companies to do research, there will be some challenges to confront. Jackson believes, "One of the big challenges that ATR NSUF will face with the addition of industry users will probably involve handling proprietary research." $\mathrm{He}$ continues, "There are times when a company would prefer to keep their trade secrets and we as a user facility need to understand how to accommodate this while still providing an easily accessible resource for all to utilize."

Other potential challenges are rigid scheduling and budget issues. "It is well known that in industry, time is money, so the expectation is that you will finish your research on time and within budget," Jackson says. Some issues, such as unexpected reactor outages, cannot be predicted, but ATR NSUF and its industry partners can work together to mitigate these issues. According to Jackson, "I certainly don't see any of these potential issues as showstoppers, but they will need to be dealt with in an intelligent way."

One of the ATR NSUF goals is to enable nuclear research that would otherwise not be done. According to Jackson, "collaborative research between universities and industry is absolutely invaluable to both sides. For instance, students who have the opportunity to work on an industrial program learn firsthand what is important in industry and how industrial partners work. They also have the unique benefit of working on a problem that addresses something real in the field. This is an experience that can never be recreated in a classroom." In addition to this, university researchers also have the added benefit of being able to stay abreast of the current issues in their field of research. This allows them to focus their research on topics that are relevant and likely to receive funding.

The collaborations ATR NSUF encourages among students, industry, and researchers greatly benefits industry as well. "From an industry perspective, I've always thought of working with students as the ultimate way to recruit and interview. What better way to find out about someone's capabilities than working on an actual project that is important to you," remarks Jackson.

The connections being made between industry, national laboratories, and universities through ATR NSUF are invaluable and the ATR NSUF serves as a kind of portal for collaborative research. According to Jackson, "It is an ideal facility for bringing industrial and university participants together in a research forum. The national laboratories are a natural bridge for this since they almost represent a hybrid between industry and universities. The ATR NSUF encourages collaboration among these three entities that otherwise would not exist. Overall, these relationships can only enhance the ATR NSUF's ability to solve technically challenging problems in a way that benefits everyone."

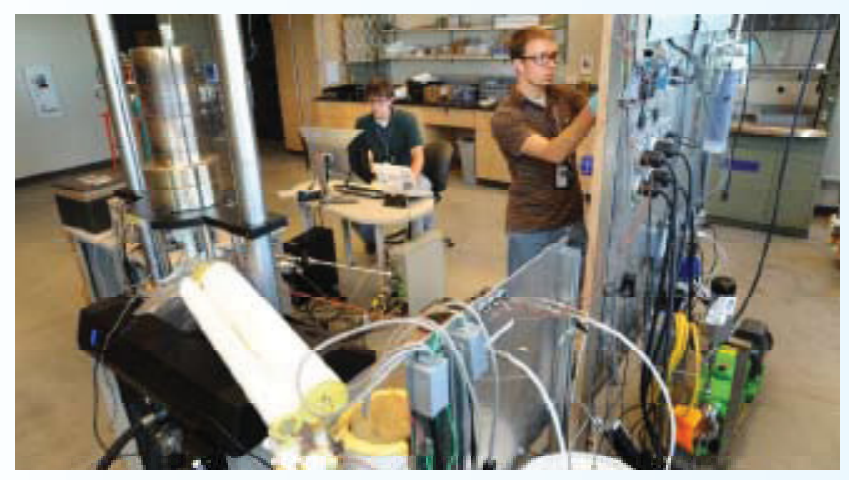

ATR NSUF student interns operate a system that simulates a Boiling Water Reactor (BWR) environment which will be useful to the EPRI project. 


\section{Collin Knight \\ ATR NSUF \\ Project Manager \\ Post-Irradiation \\ Examination \\ Idaho National \\ Laboratory}

Collin Knight is not afraid of a challenge. Prior to joining ATR NSUF as the post-irradiation examination (PIE) project manager, Knight worked as a project manager in the INL's National and Homeland Security directorate, Nuclear Nonproliferation Operations department, and as an engineer in the Nuclear Science and Technology Pyroprocessing department. The skills needed to excel in these very diverse fields are now serving him well in managing the PIE-side of the ATR NSUF experiments - a position that provides just the kinds of challenges he likes.

Knight joined ATR NSUF in May of 2010, and was immediately faced with developing a process for the smooth flow of the experiments from the irradiation capsule to preparation for analysis. He explains, "The process of getting the irradiated samples out of the cask, and ready for analysis is quite complex. When a capsule arrives in its transportation cask at MFC, it is unloaded into the Hot Fuel Examination Facility (HFEF) main cell and transferred into the containment box. There, skilled hot-cell operators use special vacuum holding tools, binoculars, spot lights, and a cell periscope to take the capsules apart, sort, and unload the specimens. It really is something to see." During this process, all of the samples are individually numbered or otherwise identified. Each one is cataloged into small storage containers. The storage receptacle (Figure 1) looks almost like a toolbox with pullout drawers to store the samples in.As of July 2010, a total of five university experiments involving twenty five test capsules have come out of the ATR and been delivered to the MFC. The test capsules included one from the University of
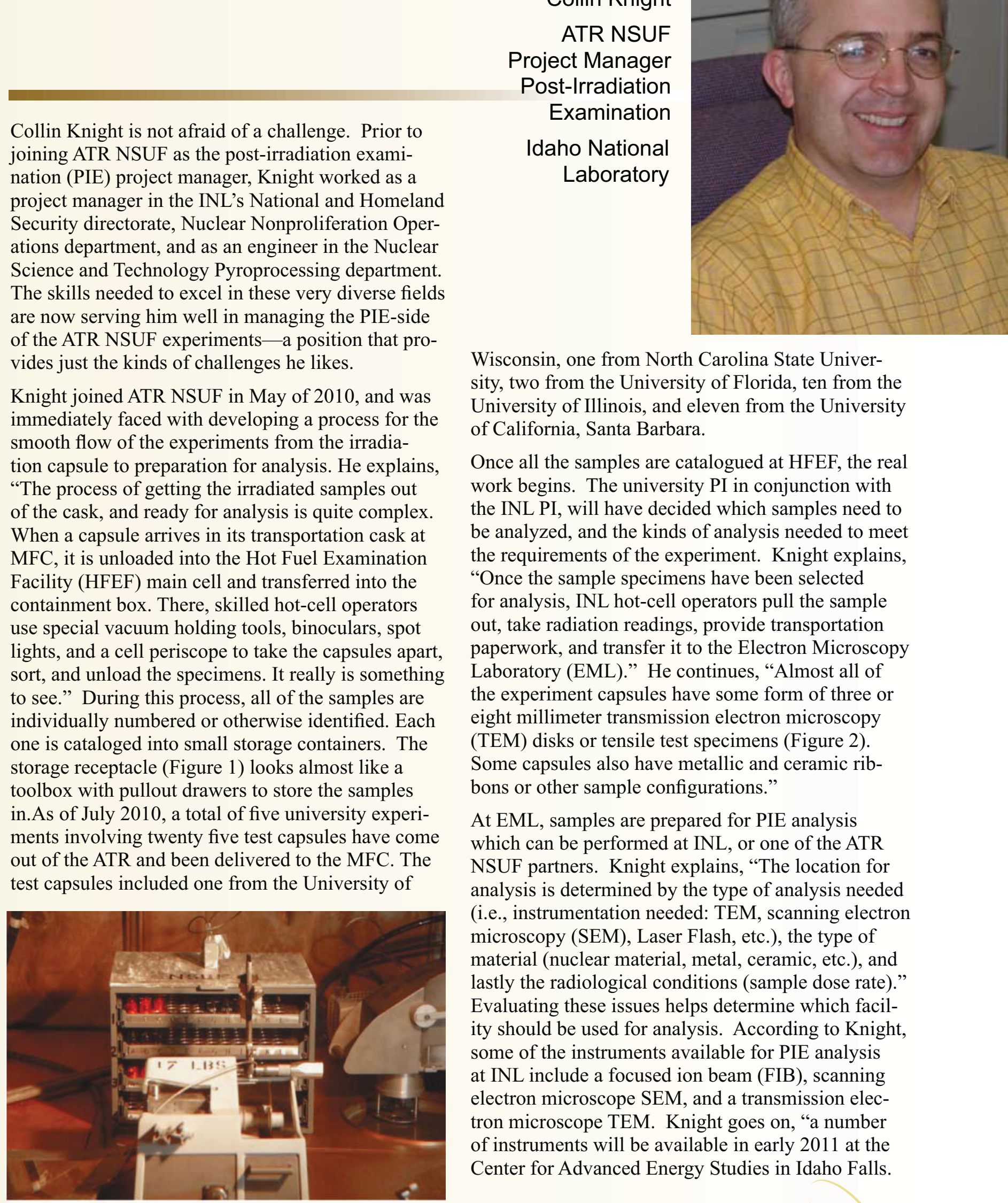

Wisconsin, one from North Carolina State University, two from the University of Florida, ten from the University of Illinois, and eleven from the University of California, Santa Barbara.

Once all the samples are catalogued at HFEF, the real work begins. The university PI in conjunction with the INL PI, will have decided which samples need to be analyzed, and the kinds of analysis needed to meet the requirements of the experiment. Knight explains, "Once the sample specimens have been selected for analysis, INL hot-cell operators pull the sample out, take radiation readings, provide transportation paperwork, and transfer it to the Electron Microscopy Laboratory (EML)." He continues, "Almost all of the experiment capsules have some form of three or eight millimeter transmission electron microscopy (TEM) disks or tensile test specimens (Figure 2). Some capsules also have metallic and ceramic ribbons or other sample configurations."

At EML, samples are prepared for PIE analysis which can be performed at INL, or one of the ATR NSUF partners. Knight explains, "The location for analysis is determined by the type of analysis needed (i.e., instrumentation needed: TEM, scanning electron microscopy (SEM), Laser Flash, etc.), the type of material (nuclear material, metal, ceramic, etc.), and lastly the radiological conditions (sample dose rate)." Evaluating these issues helps determine which facility should be used for analysis. According to Knight, some of the instruments available for PIE analysis at INL include a focused ion beam (FIB), scanning electron microscope SEM, and a transmission electron microscope TEM. Knight goes on, "a number of instruments will be available in early 2011 at the Center for Advanced Energy Studies in Idaho Falls.

Figure 1. Storage receptacle. 


\section{Idaho National Laboratory}

This facility, a collaborative effort between the INL, and the three Idaho universities (Boise State University, Idaho State University and University of Idaho) will house a FIB, SEM, TEM and a local electrode atom probe (LEAP)."

For the users whose analyses are performed at MFC, ATR NSUF provides a great deal of support helping them work through the logistics of coming to INL, and any potential obstacles they encounter during the experiment process. According to Knight, "The opportunities abound for the universities PIs or their counterpart students to interact with lab staff at MFC. Each irradiation experiment is assigned an INL experiment manager as well as an INL PI, both of whom interact with the university PI on the myriad details of an irradiation experiment."

One of the tools offered to PIs through the ATR NSUF is a sample library of irradiated materials. Knight explaines, "The sample library consists of material samples that are believed to be of value to researchers, including some of the samples from ATR NSUF experiments currently under way." He contin-

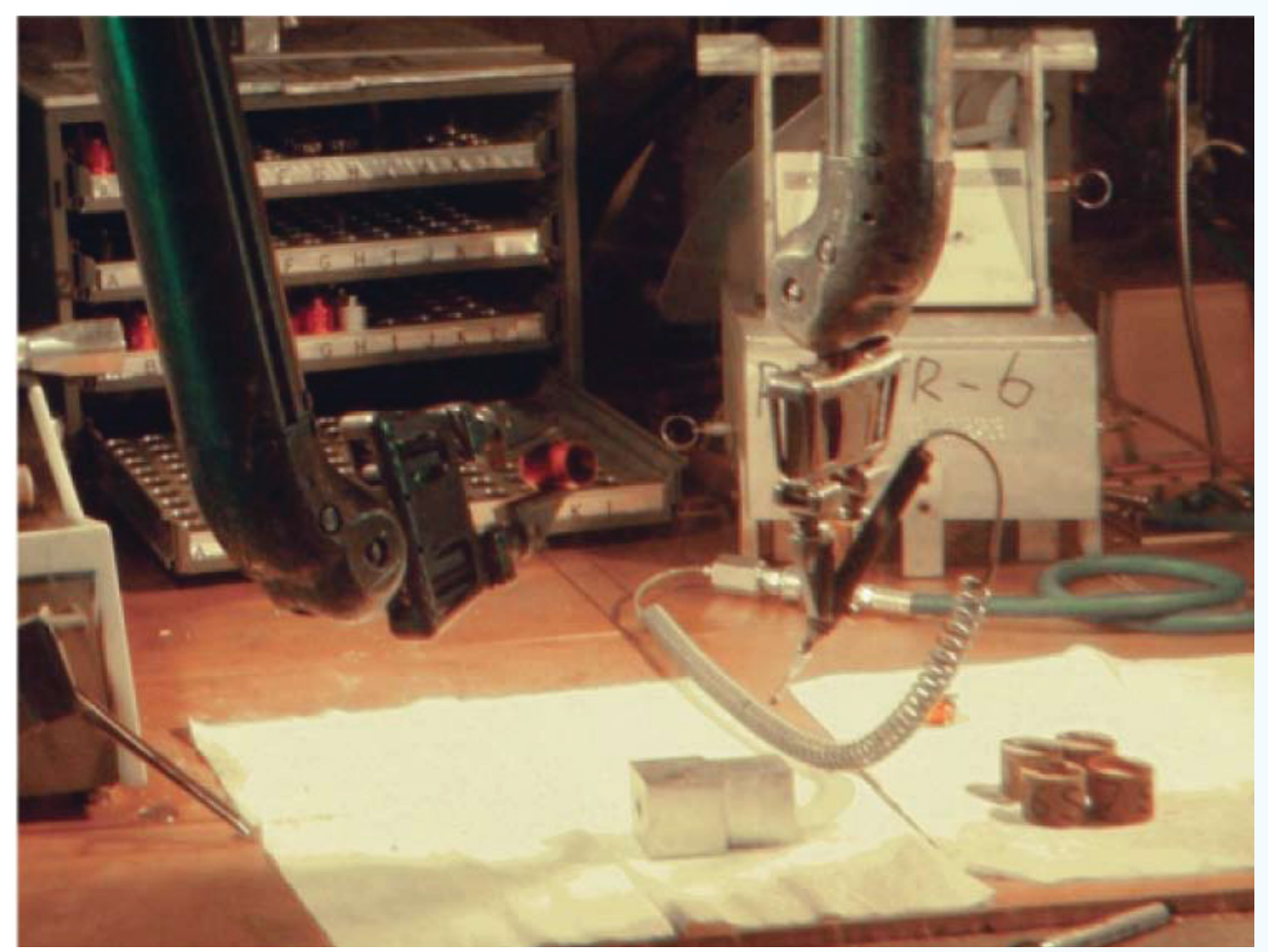

Figure 2. University of Wisconsin TEM disk being loaded into a sample storage container. ued, "If university PIs are willing, they can request to have any remaining samples from their projects put into the sample library so future researchers can have access to them. For instance, UC Santa Barbara has approximately 1300 samples, however they will probably only analyze on a fraction of them. The remaining samples will go into library."

Knight sees a bright future and continued growth for the PIE capabilities of the ATR NSUF. "I expect we will continue to grow more next year and we hope to add quite a few samples to the sample library," he says. But the ATR NSUF offers more than just great equipment, and a chance to perform irradiation experiments. According to Knight, "ATR NSUF is an avenue of collaboration among researchers who may otherwise not have met. He continues, "From an INL perspective, the benefits of interactions flow both ways-from the INL to users, as well as from users to the INL. INL principal investigators are seeing a lot more cross-connecting and collaboration since the creation of the ATR NSUF in 2007-much more than what they've had in the past." His conclusion, "This collaboration helps to advance research much better than if it were performed in isolation." 
ATR NSUF Program Information

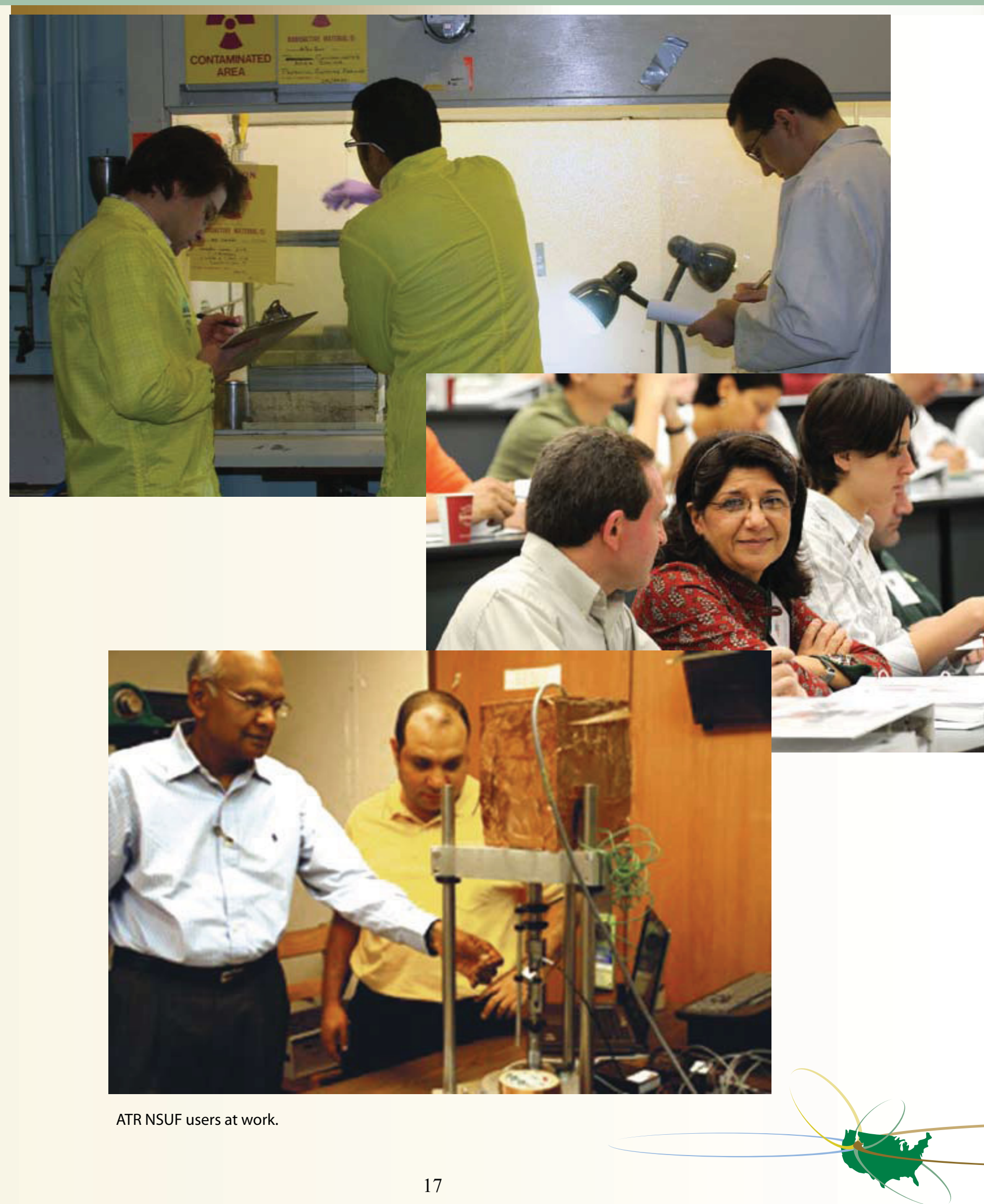




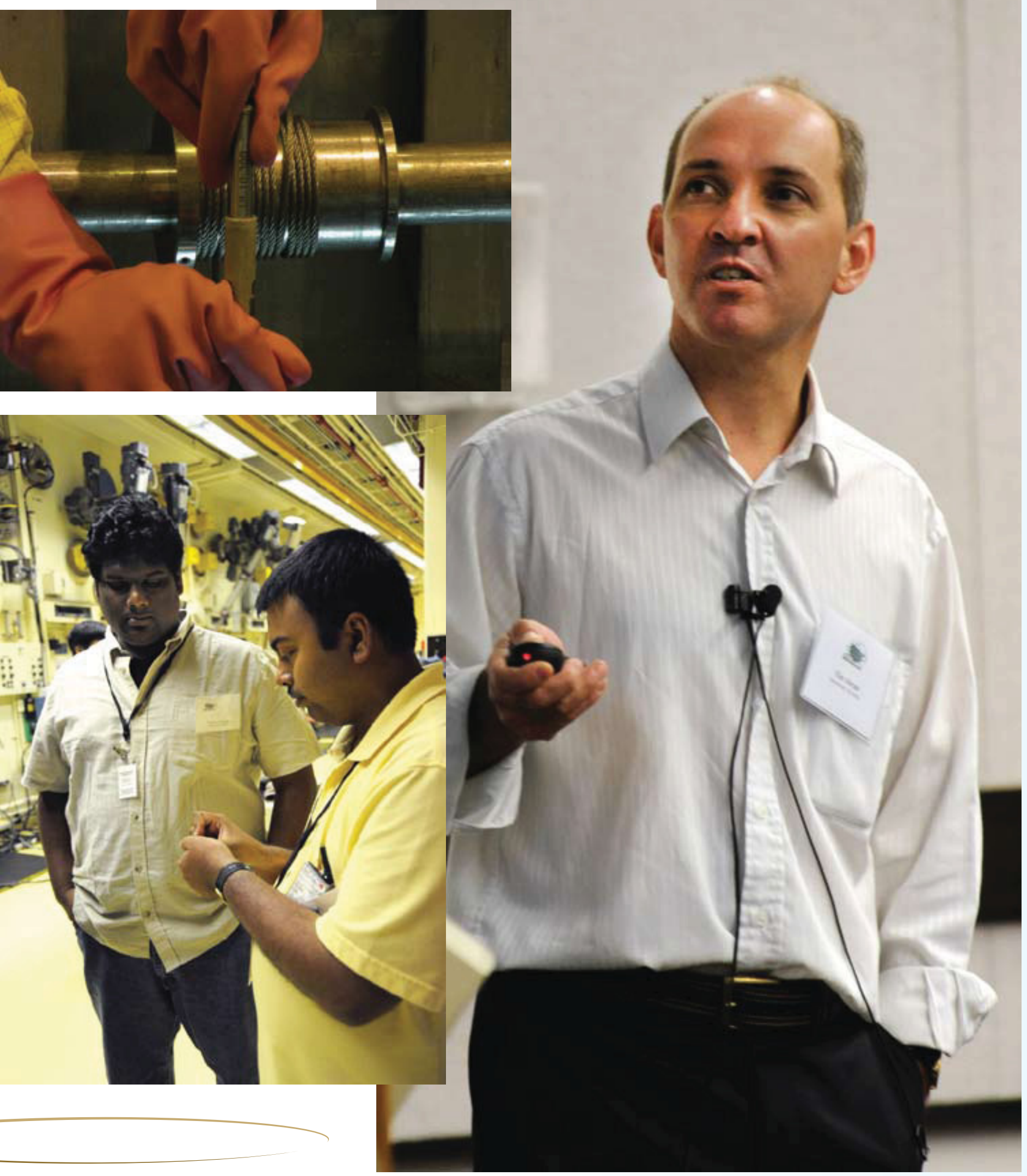




\section{Program Overview}

\section{ATR NSUF: A New Model for Collaboration}

ATR NSUF and its partner facilities represent a prototype laboratory for the future. This unique model is best described as a distributed partnership with each facility bringing exceptional capabilities to the relationship including reactors, beamlines, state-ofthe-art instruments, hot cells, and most importantly expert mentors. Together these capabilities and people create a nation-wide infrastructure that allows the best ideas to be proven using the most advanced capabilities. Through ATR NSUF, university researchers and their collaborators are building on current knowledge to better understand the complex behavior of materials and fuels in the radiation environment of a nuclear reactor.

Since ATR NSUF established the partnership program, six universities have offered their facility's capabilities, greatly expanding the kinds of research that can be offered. The avenues opened through these partnerships facilitate cooperative research across the country, matching people with capabilities, students with mentors. As new partners join
ATR NSUF, research opportunities will expand into new areas such as thermal hydraulics and advanced modeling.

In 2010, ATR NSUF included the INL and the following six universities:

- Illinois Institute of Technology (IIT)

- Massachusetts Institute of Technology (MIT)

- North Carolina State University (NCSU)

- University of Michigan (UM)

- University of Nevada -Las Vegas (UNLV)

- University of Wisconsin - Madison (UW).

In the pages that follow, you will read specific details on the capabilities of ATR NSUF and its partners.

You will also learn how to access these capabilities through the Calls for Proposals. We hope you take time to familiarize yourself with the many research opportunities offered, and consider submitting a proposal or two!

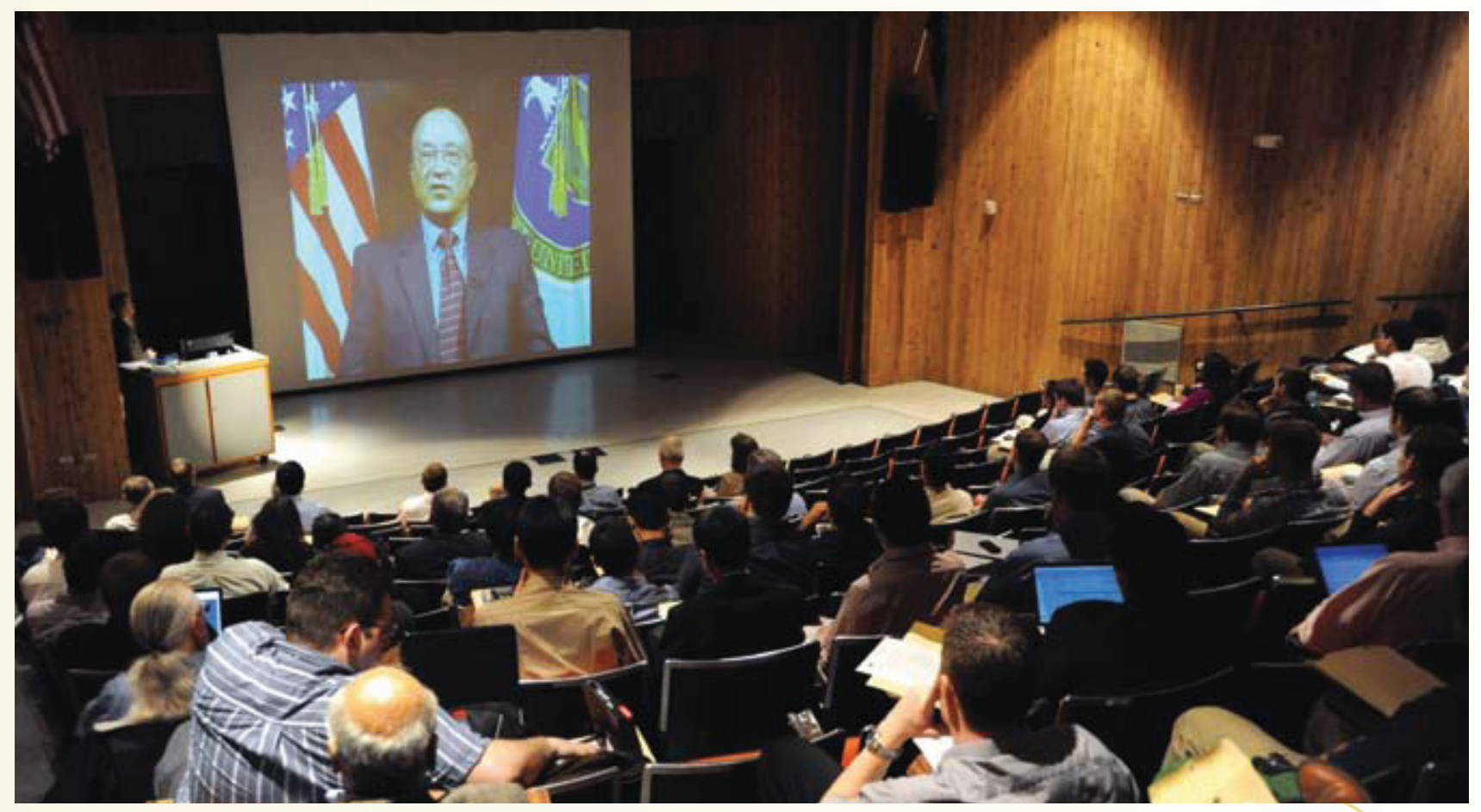

Dr. Pete Miller, former Assistant Secretary of Nuclear Energy giving the DOE welcome to participants of the 2010 ATR NSUF Users Week. 
Recent DOE-NE documents are useful guides for understanding the direction of nuclear energy research:

- Nuclear Energy Research and Development Roadmap Report to Congress - a plan for research, development and demonstration activities that will ensure nuclear energy remains a viable energy option for the U.S.

- Nuclear Energy Enabling Technologies (NEET) Workshop Report - a report of the recent meeting with stakeholders to obtain their input on the crosscutting technology needed to support NE roadmap objectives and to inform a possible solicitation for transformative, "out-ofthe-box" solutions across the full range of nuclear energy technology issues.

- 2010 Performance Plan - a review of FY 2009 performance and FY 2010 objectives in critical program areas with an overview of NE programs, funding profile and designated role within the DOE Strategic Plan.

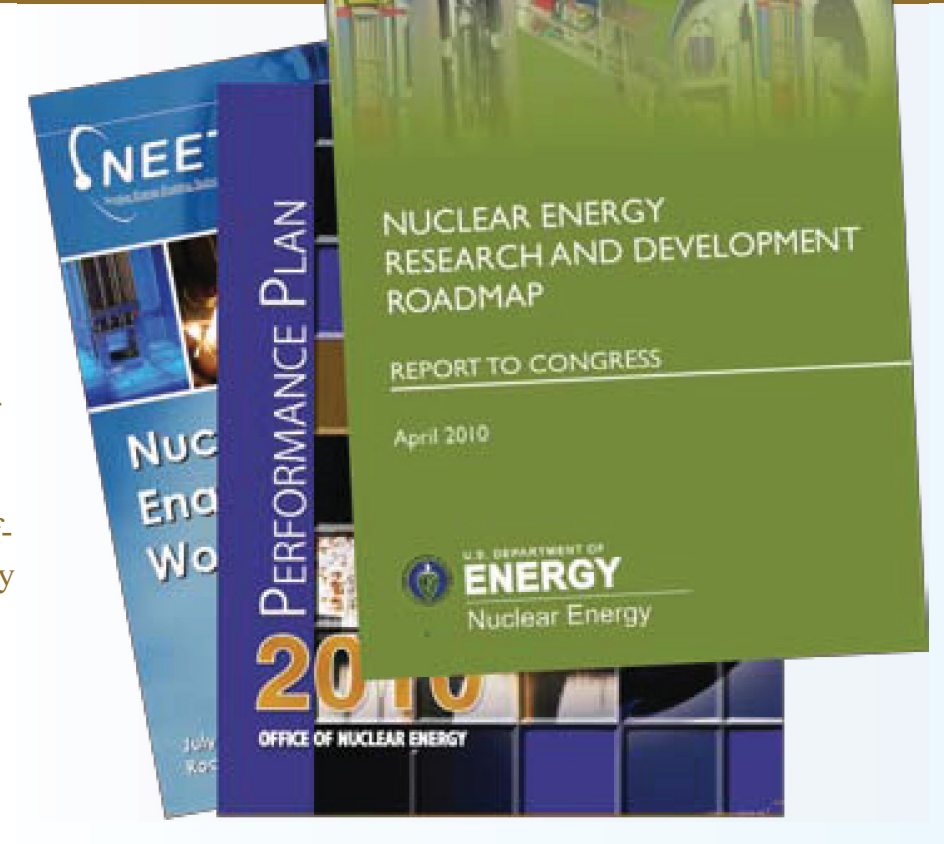

\section{ATR NSUF Research Supports DOE-NE Missions}

DOE-NE organizes its research and development activities based on four main objectives that address challenges to expanding the use of nuclear power:

- Develop technologies and other solutions that can improve the reliability, sustain the safety and extend the life of current reactors

- Develop improvements in the affordability of new reactors to enable nuclear energy to help meet the Administration's energy security and climate change goals

- Develop sustainable nuclear fuel cycles

- Understand and minimize the risks of nuclear proliferation and terrorism.
ATR NSUF research addresses a number of these mission needs. Most of the research contained in this report looks at either understanding the mechanisms of radiation on materials and fuels to address the challenges of the aging current fleet, or looks at materials and fuels for the next generation of reactors. To be eligible as an ATR NSUF research project, the research must support at least one of the DOE-NE missions. For specific information on DOE missions, please check out the following link: http://www.ne.doe.gov.

To learn more about proposing a research project, please visit the ATR NSUF website at: http://atrnsuf.inl.gov. 


\section{Reactor Capabilities}

The ATR NSUF offers researchers access to the ATR, which is located at the ATR Complex on the INL site.

The ATR has been operating continuously since 1967, when it primarily served the U.S. Navy in the development and refinement of nuclear propulsion systems. In recent years, the reactor has been used for a wider variety of government and privately sponsored research and now serves a range of research and isotope production customers. In FY 2010, the ATR NSUF also offered access to reactors at two university partner facilities: the MITR, which is the second largest research reactor at a U.S. university, and the PULSTAR reactor at North Carolina State University.

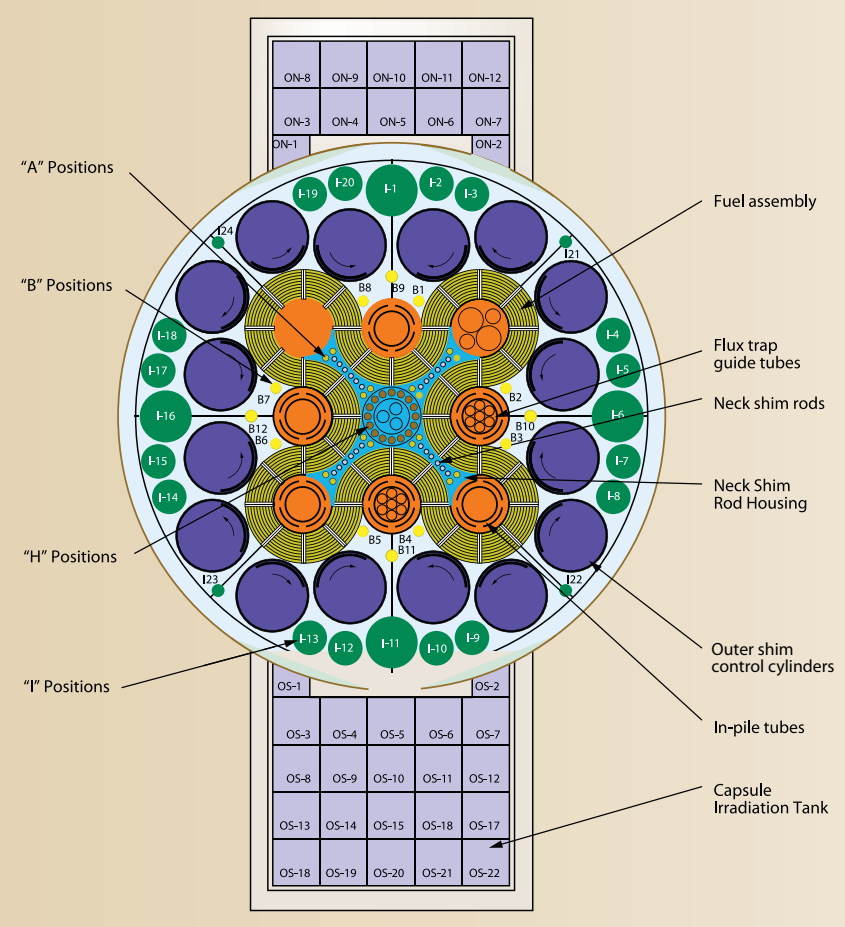

ATR unique serpentine design allows a variety of experiment configurations.

\section{Idaho National Laboratory: Advanced Test Reactor}

The ATR is a water-cooled, high-flux test reactor, with a unique serpentine design that provides large power variations among its flux traps. The beryllium outer shim control cylinders contain hafnium plates, which can be rotated toward and away from the core, and hafnium shim rods, which withdraw vertically and can be individually inserted or withdrawn for minor power adjustments. The reactor's curved fuel arrangement places fuel closer on all sides of the flux trap positions than is possible in a rectangular grid. The reactor has nine of these high-intensity neutron flux traps and 68 additional irradiation positions inside the reactor core reflector tank, each of which can contain multiple experiments. Experiment positions vary in size from 0.5 " to 5.0 " in diameter and all are 48 " long. The peak thermal flux is $1 \times 10^{15} \mathrm{n} / \mathrm{cm}^{2}$-sec and fast flux is $5 \times 10 \mathrm{n} / \mathrm{cm}^{2}-\mathrm{sec}$. When operating at full power of 250 MWth. There is a hydraulic shuttle irradiation system, which allows experiments to be inserted and removed during reactor operation, and pressurized water reactor (PWR) loops, which enable tests to be performed at prototypical PWR operating conditions.

More information: https://secure.inl.gov/atrproposal/documents/ATRUsersGuide.pdf. 


\section{Idaho National Laboratory: Advanced Test Reactor Critical Facility}

The Advanced Test Reactor Critical (ATRC) is a low-power version (same size and geometry) of the higher-powered ATR core. It is operated at power levels less than 5 KWth with typical operating power levels of $600 \mathrm{Wth}$ or less. The ATRC was designed and constructed in the early 1960's. It was originally used to support startup of the ATR. Currently, the primary use of the ATRC is to provide data for the design and safe operation of experiments for the ATR. The ATRC is also used to supply core performance data for the restart of the ATR after periodic core internals replacement. Occasionally the ATRC is used to perform low-power irradiation of experiments.

More information: https://secure.inl.gov/atrproposal/documents/ATRUsersGuide.pdf.

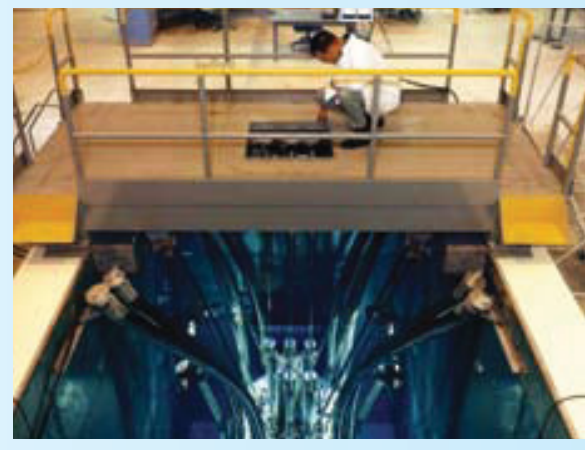

Aerial view of the ATRC reactor core and bridge.

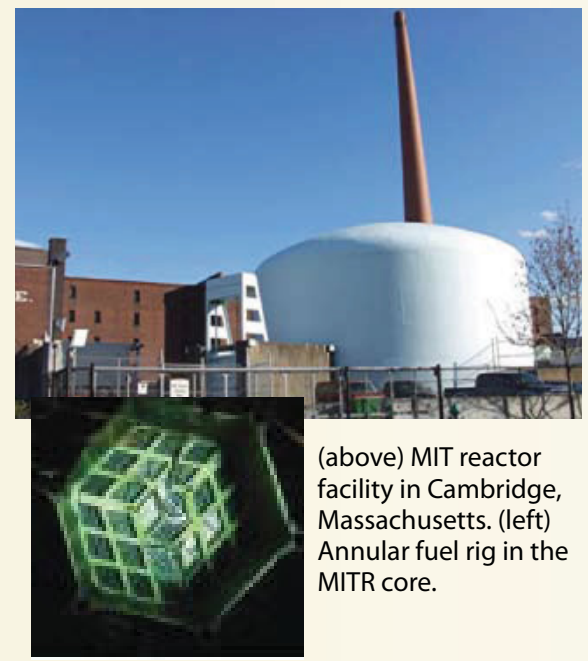

\section{University Partner: Massachusetts Institute of Technology Reactor (MITR)}

The MITR is a 5 MW tank-type research reactor. It has three positions available for in-core fuel and materials experiments over a wide range of conditions. Water loops at pressurized water reactor/boiling water reactor (PWR/BWR) conditions, high-temperature gas reactor environments at temperatures up to $1400^{\circ} \mathrm{C}$ and fuel tests at light water reactor (LWR) temperatures have been operated and custom conditions can also be provided. A variety of instrumentation and support facilities are available. Fast and thermal neutron fluxes are up to $10^{14}$ and $5 \times 10^{14} \mathrm{n} / \mathrm{cm}^{2}$-s. The MITR has received approval from the Nuclear Regulatory Commission for a power increase to $6 \mathrm{MW}$ which will enhance the neutron fluxes by $20 \%$.

More information: https://secure.inl.gov/atrproposal/documents/MITR_ UserGuide.pdf.

\section{University Partner: \\ North Carolina State University (NCSU) PULSTAR Reactor}

The PULSTAR reactor is a $1 \mathrm{MW}$ pool-type nuclear research reactor located in NCSU's Burlington Engineering Laboratories. The reactor, one of two PULSTAR reactors built and the only one still in operation, uses $4 \%$ enriched, pin-type fuel consisting of uranium dioxide pellets in zircaloy cladding. The fuel provides response characteristics that are very similar to commercial light water power reactors. These characteristics allow teaching experiments to measure moderator temperature and power reactivity coefficients including doppler feedback. In 2007, the PULSTAR reactor produced the most intense lowenergy positron beam with the highest positron rate of any comparable facility worldwide.

More information: https://secure.inl.gov/atrproposal/documents/PULSTARReactor.pdf.
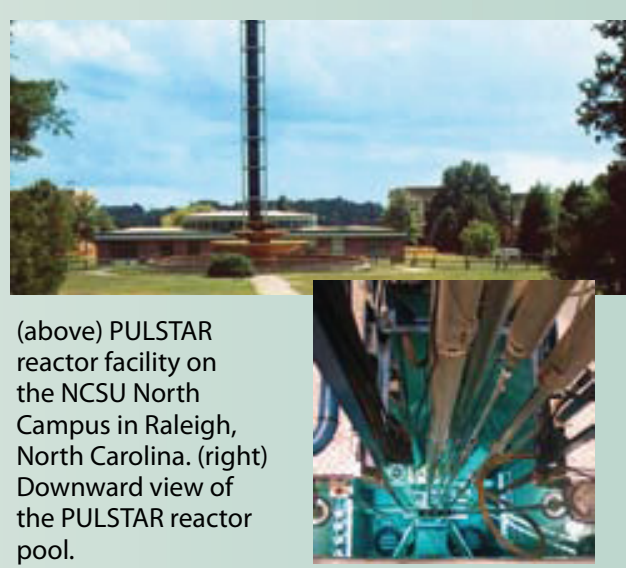


\section{Post-irradiation Examination Capabilities}

The ATR NSUF offers researchers access to a broad range of post-irradiation examination facilities.

In FY 2010, the ATR NSUF program offered researchers access to capabilities at INL's Materials and Fuels Complex as well as at four university partner facilities. These include the Nuclear Services Labora- tories at North Carolina State University; the Irradiated Materials Complex at University of Michigan; the Harry Reid Center Radiochemistry Laboratories at University of Nevada, Las Vegas; and the Characterization Laboratory for Irradiated Materials at University of Wisconsin.
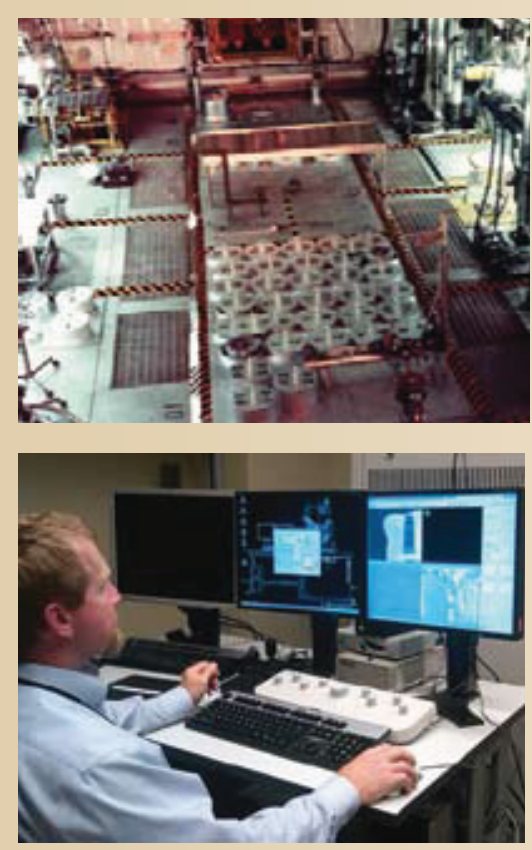

(above top) Hot Fuel Examination Facility, located at the Materials and Fuels Complex at DOE's INL site in Idaho. (above) A dual-beam focused ion beam (FIB) at the Center for Advanced Energy Studies (CAES).

\section{INL: Hot Fuel Examination Facility (HFEF), Analytical Laboratory, Electron Microscopy Laboratory}

The HFEF is a large alpha-gamma hot cell facility dedicated to remote examination of highly irradiated fuel and structural materials. Its capabilities include nondestructive examination, such as dimensional measurements and visual examination; and destructive examination, such as mechanical testing and metallographic/ceramographic characterization. The facility also offers a $250 \mathrm{kWth}$ Training Research Isotope General Atomics (TRIGA) reactor used for neutron radiography to examine internal features of fuel elements and assemblies.

The Analytical Laboratory is dedicated to analytical chemistry of irradiated and radioactive materials. It offers National Institute of Science and Technology (NIST)-traceable chemical and isotopic analysis of irradiated fuel and material via a wide range of spectrometric techniques, including inductively coupled plasma mass and optical emission spectrometry (ICP-MS and ICP$\mathrm{OES}$ ), a dynamic reaction cell for inductively coupled plasma-mass spectrometry (ICPMS-DRC) and thermal ionization mass spectrometry (TIMS).

The Electron Microscopy Laboratory (EML) is dedicated to materials characterization, primarily using transmission electron, scanning electron and optical microscopy. The EML also houses a dual-beam FIB that allows examination and small-sample preparation of radioactive materials for further atom probe, TEM and micro-mechanical testing. Part of the laboratory is dedicated to sample preparation, providing researchers with support, equipment, safety systems and procedures to prepare samples of diverse materials for analysis.

More information:

https://secure.inl.gov/atrproposal/documents/PIECapabilitiesGuide.pdf. 
University Partner:

North Carolina State University

Nuclear Services Laboratories

Post-irradiation examination capabilities at NCSU's Nuclear Services laboratories include neutron activation analysis, radiography and imaging capabilities and positron spectrometry.

More information:

https://secure.inl.gov/atrproposal/documents/PULSTARReactor.pdf.
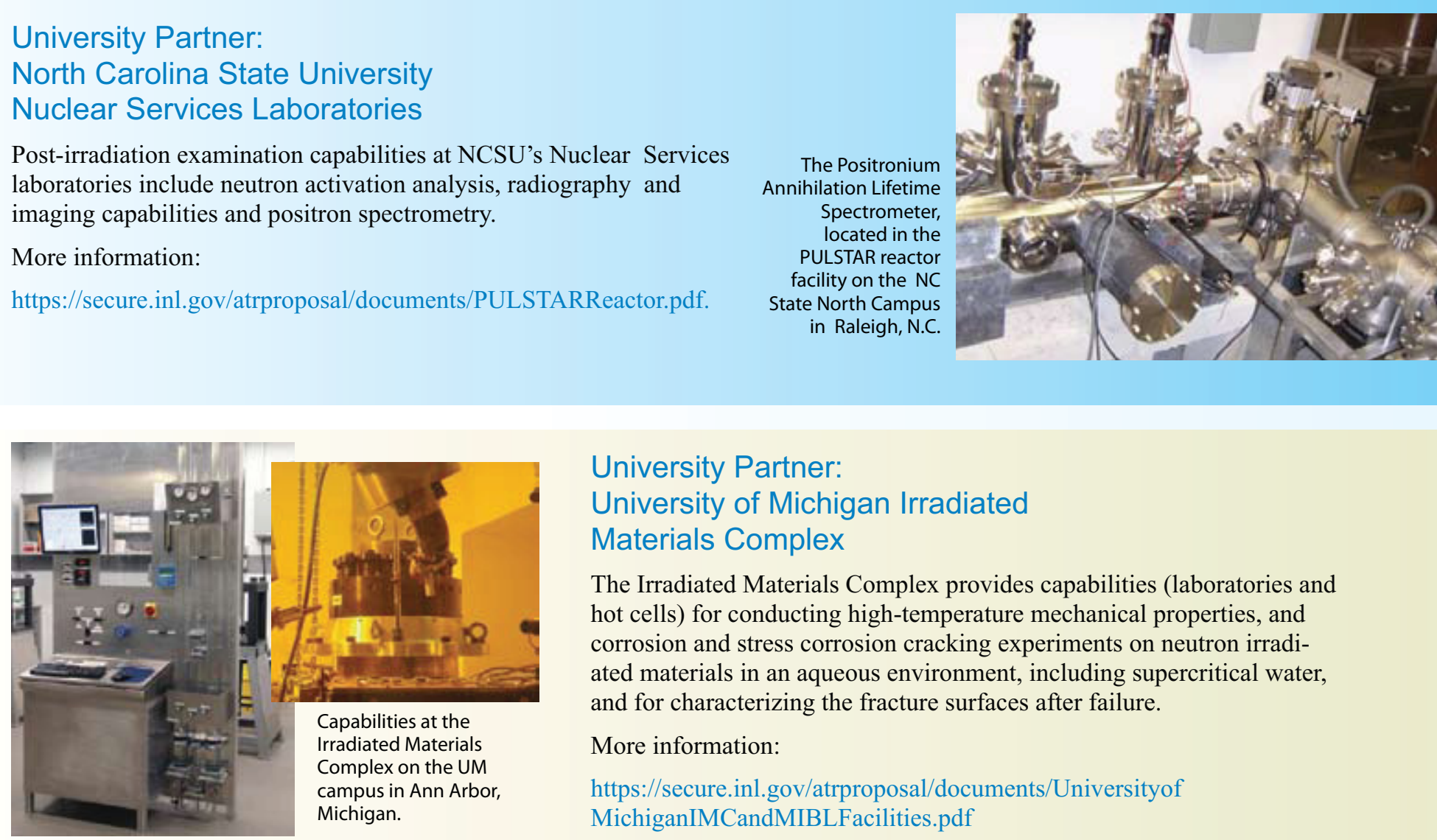

\section{University Partner: \\ University of Michigan Irradiated \\ Materials Complex}

The Irradiated Materials Complex provides capabilities (laboratories and hot cells) for conducting high-temperature mechanical properties, and corrosion and stress corrosion cracking experiments on neutron irradiated materials in an aqueous environment, including supercritical water, and for characterizing the fracture surfaces after failure.

More information:

https://secure.inl.gov/atrproposal/documents/Universityof MichiganIMCandMIBLFacilities.pdf

\section{University Partner: \\ University of Nevada, Las Vegas (UNLV) Harry Reid Center Radiochemistry Laboratories}

Post-irradiation examination capabilities at the Radiochemistry Laboratories include metallographic microscopy, X-ray powder diffraction, Rietveld analysis, scanning electron and transmission electron microscopy, electron probe microanalysis and X-ray fluorescence spectrometry.

More information: https://secure.inl.gov/atrproposal/documents/UNLVPartnerFacilityUserGuide.pdf.
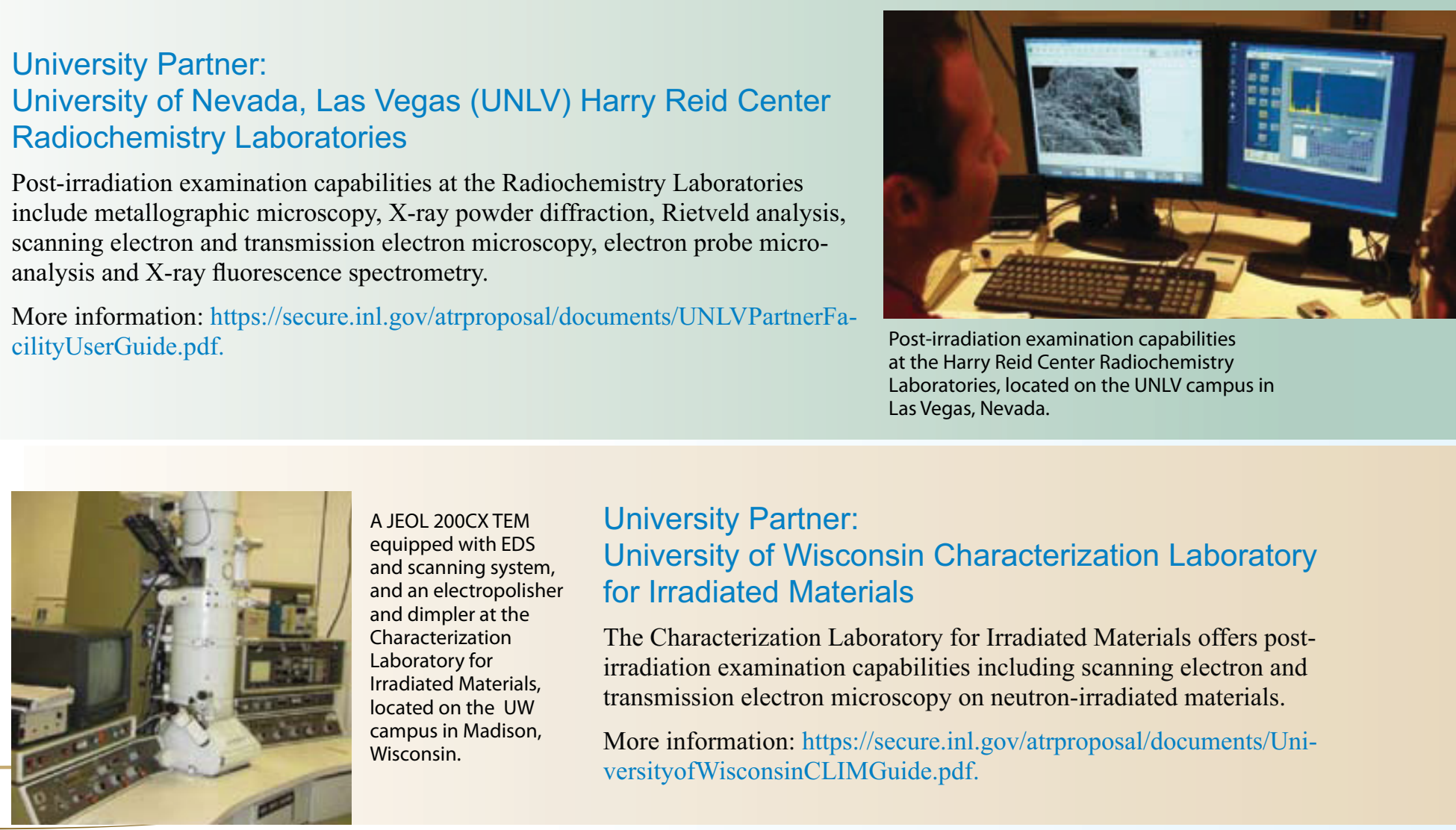

A JEOL 200CX TEM equipped with EDS and scanning system, and an electropolisher and dimpler at the Characterization Laboratory for Irradiated Materials, located on the UW campus in Madison, Wisconsin.

\section{University Partner:}

\section{University of Wisconsin Characterization Laboratory} for Irradiated Materials

The Characterization Laboratory for Irradiated Materials offers postirradiation examination capabilities including scanning electron and transmission electron microscopy on neutron-irradiated materials.

More information: https://secure.inl.gov/atrproposal/documents/UniversityofWisconsinCLIMGuide.pdf. 
University Partner:

North Carolina State University

PULSTAR Reactor Facility

The PULSTAR reactor facility offers a selection of dedicated irradiation beam port facilities - neutron powder diffraction, neutron imaging, intense positron source and ultra-cold neutron source. An intense positron source has been developed to supply a high rate positron beam to two different positron/positronium annihilation lifetime spectrometers.

More information: https://secure.inl.gov/atrproposal/documents/PULSTARReactor.pdf.

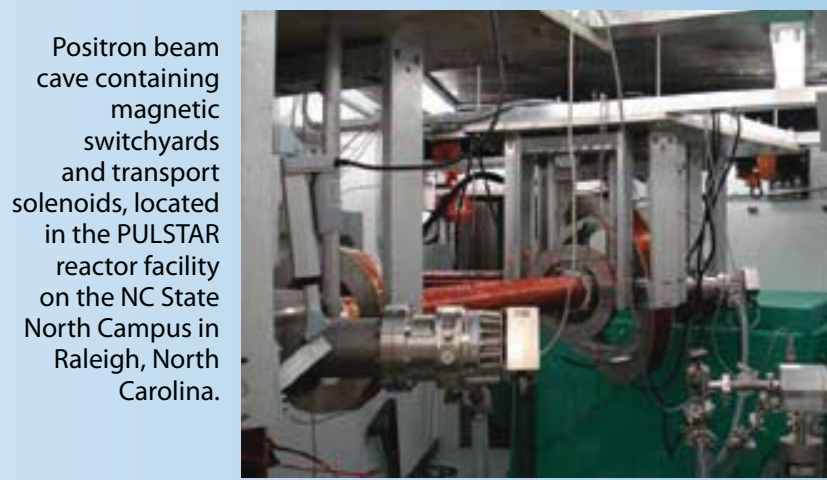

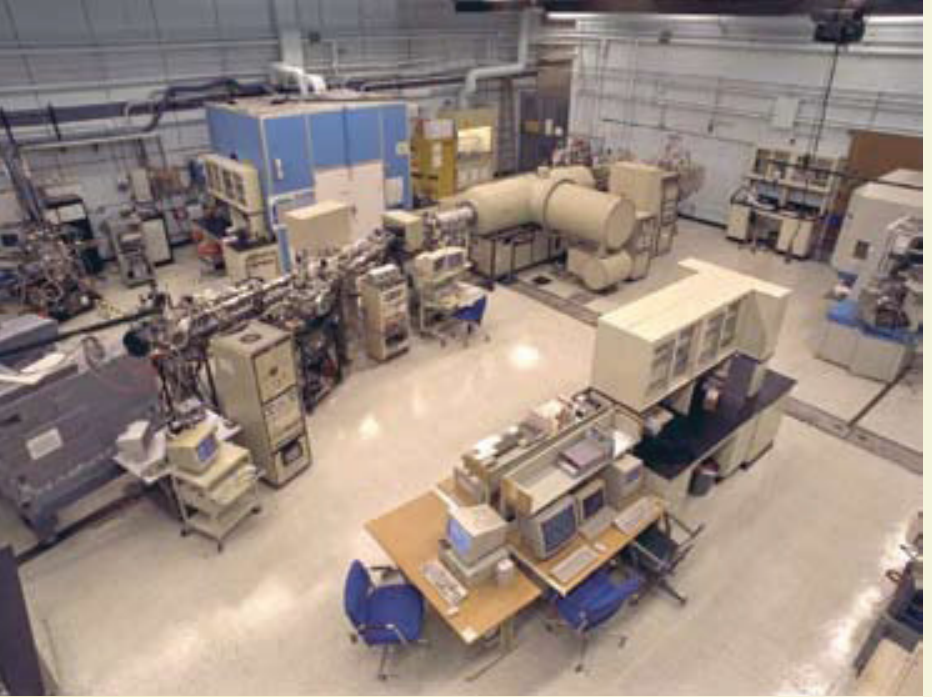

University Partner:

University of Michigan

Michigan Ion Beam Laboratory

The 1.7 MV Tandetron accelerator in the Michigan Ion Beam Laboratory offers controlled temperature proton irradiation capabilities with energies up to $3.4 \mathrm{MeV}$ as well as heavy ion irradiation.

More information: https://secure.inl.gov/atrproposal/documents/UniversityofMichigan IMCandMIBLFacilities.pdf.

Michigan Ion Beam Laboratory for Surface Modification and Analysis, located on the UM campus in Ann Arbor, Michigan.
University Partner:

\section{University of Wisconsin}

\section{Tandem Accelerator Ion Beam}

A 1.7 MV terminal voltage tandem ion accelerator (Model 5SDH-4, National Electrostatics Corporation Pelletron accelerator) installed at UW-M features dual ion sources for producing negative ions with a sputtering source or using a radio frequency (RF) plasma source. The analysis beamline is capable of elastic recoil detection and nuclear reaction analysis.

More information: https://secure.inl.gov/atrproposal/documents/UniversityofWisconsinCLIMGuide.pdf.

Tandem Ion Beam Accelerator, located on the UW campus in Madison, Wisconsin.

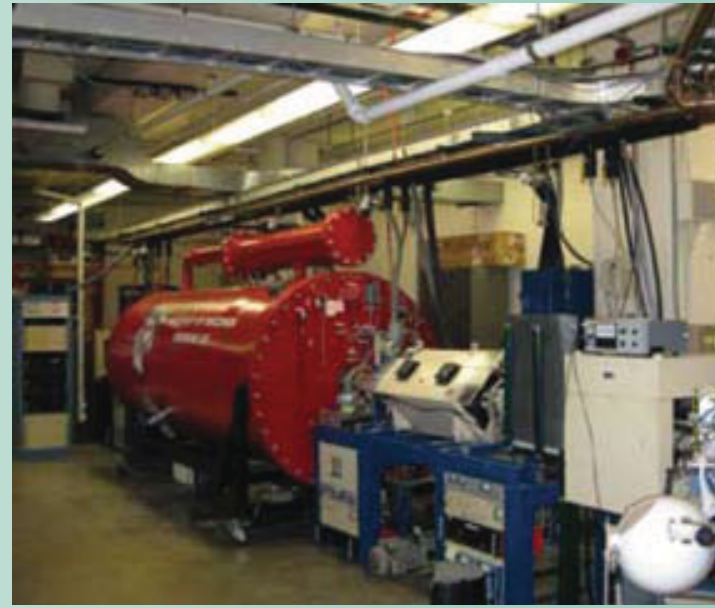




\section{Calls for Proposals}

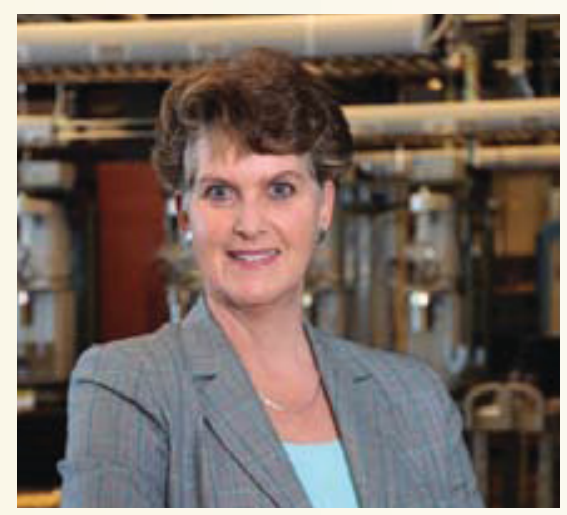

Frances Marshall

Manager, Program Operations (208) 526-8947

frances.marshall@inl.gov

Mary Catherine Thelen

Program Administrator

(208) 526-5209

mary.thelen@inl.gov

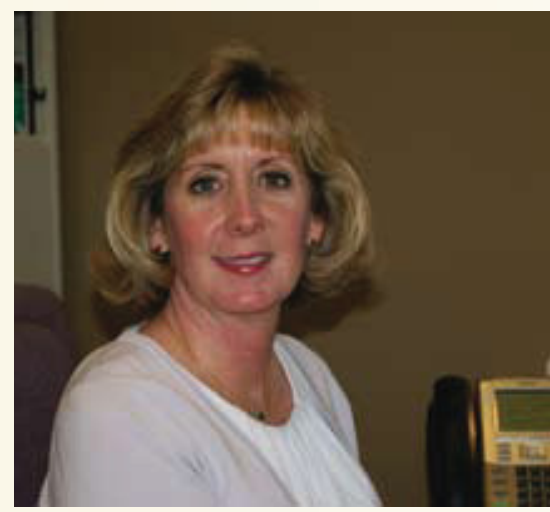

The ATR NSUF mission is to provide nuclear energy researchers access to world-class capabilities to facilitate the advancement of nuclear science and technology. This mission is supported by providing cost-free access to state-of-the-art experimental irradiation testing and post-irradiation examination facilities as well as technical assistance in design and analysis of reactor experiments. Access is granted through a competitive proposal process.

ATR NSUF offers three research proposal options (described in more detail below) through a userfriendly online submittal system that helps prospective researchers develop, edit, review and submit their proposals. ATR NSUF staff is available to help any researcher who desires to submit a proposal.

Submitted proposals should be consistent with the DOE-NE mission and its programmatic interests. These include the Light Water Reactor Sustainability, Fuel Cycle Research and Development, Advanced Modeling and Simulation, Next Generation Nuclear Plant and the Generation IV Nuclear Energy Systems Initiative programs.

All proposals are subject to a peer-review process before selection. An accredited U.S. university or college must lead research proposals for irradiation/ post-irradiation experiments. All ATR NSUF research must be non-proprietary and results are expected to be published. Collaborations with other national laboratories, federal agencies, non-U.S. universities and industries are encouraged. Any U.S.-based entities, including universities, national laboratories and industry can propose research that would utilize the Materials Research Collaborative Access Team (MRCAT) beamline at the Advanced Photon Source or would be conducted as a Rapid-Turnaround Experiment.

\section{Open Calls}

Irradiation, Post-Irradiation Examination, Critical Facility and Synchrotron Radiation Experiments

The ATR NSUF annually conducts two open calls for proposals: a fall call, which opens in late April and 
closes in October, and a spring call, which opens in late October and closes in late March or early April. Proposals are accepted for:

- Irradiation/post-irradiation examination of materials or fuels

- Post-irradiation examination of previously irradiated materials or fuels from the ATR NSUF sample library (described below)

- Research that requires the unique capabilities of the Advanced Photon Source through the MRCAT beamlime, operated by the Illinois Institute of Technology.

All proposals submitted to the open calls undergo thorough reviews for feasibility, technical merit, relevance to the DOE-NE missions and cost. The results are compiled and provided to a panel committee who performs a final review and ranks the proposals. The ranking is given to the ATR NSUF director. Awards are announced within two to three months of the call's closing date, generally in January and June. Awards allow users cost-free access to specific ATR NSUF and partner capabilities as determined by the program.

\section{Other Calls}

\section{Rapid-Turnaround Experiments}

Rapid-Turnaround Experiments are experiments that can be performed quickly - in two months or less - are relatively lost cost, and include, but are not limited to, post-irradiation examination, ion beam irradiation and neutron scattering experiments. Proposals for Rapid-Turnaround Experiments are reviewed within a month of submittal and awarded based on the following rankings:

- High Priority - Proposal is awarded immediately upon review if funding is available
- Recommended - Proposal is placed in a queue from which awards are made approximately every other month if funding is available

- Not Recommended - Proposal is not awarded, but the project investigators are offered an opportunity to read the review comments and then resubmit.

\section{New-User Experiments}

University or college researchers can gain experience in the intricacies of designing and conducting an inreactor test by submitting a letter of interest through the Call for Proposals web page. A New-User Experiment is initiated when three to five universities have expressed an interest. Each experimenter will have an opportunity to work with a variety of INL staff to design a capsule to meet an experiment's needs. The project ends with the samples inserted into the reactor.

For additional information about all call types, visit the ATR NSUF online webpage for proposals at: https://secure.inl.gov/atrproposal/Common/UserHome.aspx.

\section{ATR NSUF Sample Library}

IN 2009, the ATR NSUF established a sample library as an additional pathway for research. The library contains irradiated and non-irradiated samples in a wide range of material types, from steel samples irradiated in fast reactors to ceramic materials irradiated in the Advanced Test Reactor. Many samples are from previous DOE-funded material and fuel development programs. University researchers can propose to analyze these samples in a PIE-only experiment. Samples from the library may be used for proposals for open calls and Rapid-Turnaround Experiments.

As the ATR NSUF program continues to grow, so will the sample library. To review an online list of available specimens, visit: http://secure.inl.gov/ atrproposal/Common/UserHome.aspx. 


\section{Users Week}

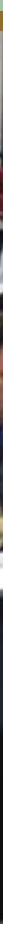

FY 2010 Users Week Fuels and Materials course participants.

The annual ATR NSUF Users Week offers researchers five full days of workshops, tours, discussions and classes. The focus is on providing an understanding of key nuclear technology gaps, capabilities required for addressing those gaps, recent or emerging advances, and techniques for conducting reactor experiments and post-irradiation examination.
Users Week is not just a way to learn more about ATR NSUF, its capabilities and ongoing research, it is also a great opportunity to meet other students, scientists and engineers who are interested in responding to the ATR NSUF's call for proposals. Users Week supports the ATR NSUF as a model for the laboratory of the future, where collaborative research and shared resources among universities and national laboratories will help prepare a new generation of nuclear energy professionals.

The week's events are free of charge for students, faculty and post-docs as well as researchers from industry and national laboratories who are interested in materials, fuels, post-irradiation examination and reactor-based technology development. In the three years since its inception, ATR NSUF Users Week has hosted 348 participants from 29 countries and 32 U.S. universities.

Student listening to a research forum presentation at 2010 Users Week. 
"We want to encourage people to become nuclear engineers and scientists and get back to the high numbers of graduates we had in the 1970s. Without a new generation of nuclear scientists, there will be no nuclear renaissance in the United States."

Scholarships to help defray travel, hotel and meal expenses are offered to university faculty and students on a competitive basis.

\section{What to Expect at Users Week}

Users Week kicks off with an introductory workshop to ATR NSUF, which includes a description of current and upcoming research capabilities offered by INL and university partners, a briefing on the solicitation process and opportunities within the education program, and a welcome from DOE, usually delivered by an official from DOE headquarters.

Each year, Users Week offers a number of workshops and courses for students to participate in. These may vary from year to year, but courses generally focus on a variety of topic-specific areas, such as in-reactor instrumentation, fuels and materials, or how to conduct radiation experiments.

Participants are always offered an opportunity to tour the ATR as well as INL's Materials and Fuels Complex where many post-irradiation examination
For more information about Users Week please visit the ATR NSUF website at: http://atrnsuf.inl.gov facilities are housed.

An annual research forum was initiated in 2009. The forum offers an opportunity for university, industry and national laboratory researchers to present their latest findings in a collaborative environment. The forum's primary focus will be on ATR NSUF-awarded research experiments as they progress.

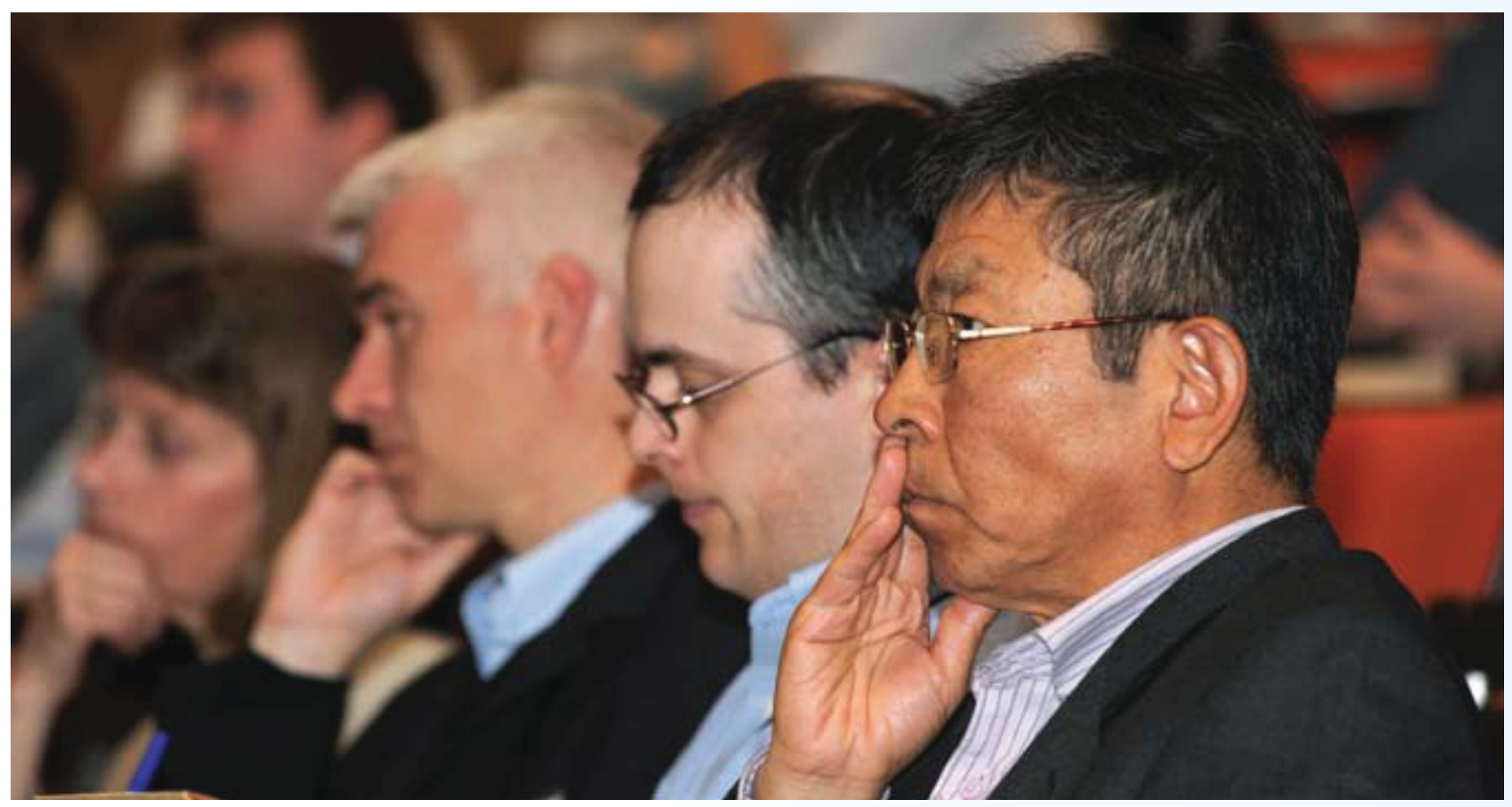

Participants at 2010 Users Week Introductory Workshop. 


\section{Educational Programs and Opportunities}

Jeff Benson

Education Coordinator

(208) 526-3841 jeff.benson@inl.gov

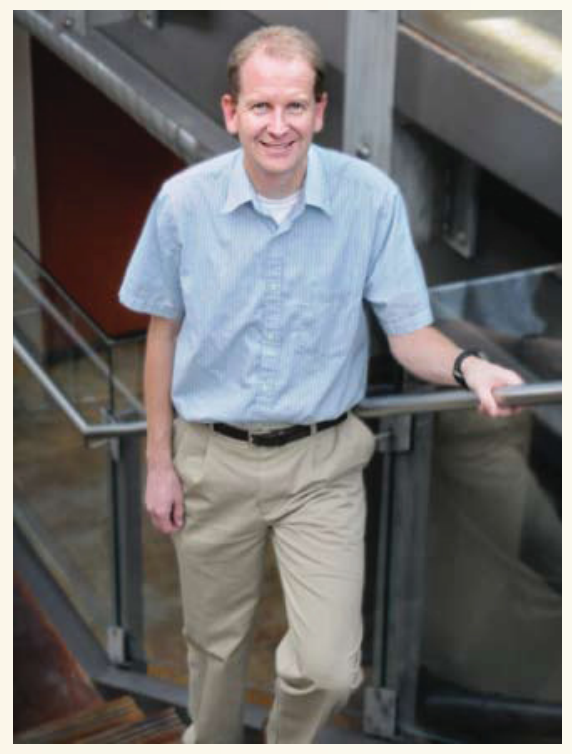

\section{Faculty/Student Research Teams (FSRT)}

This unique research opportunity provides faculty and students with a chance to spend part of a summer performing research in collaboration with an INL scientist or engineer. Projects are selected (depending on funding availability) through a special call for proposals, which is openly advertised and posted each fall on the ATR NSUF website.

Proposals are accepted for scientifically meritorious projects that result in increased research capability for the ATR NSUF. Specific areas of interest include:

- Ramp testing of fuel

- Instrumentation test capsule design

- In-canal measurements

- Integrated computational modeling for analysis of irradiation experiments

- In-reactor ultrasonic measurement

- Analysis of materials using advanced techniques.

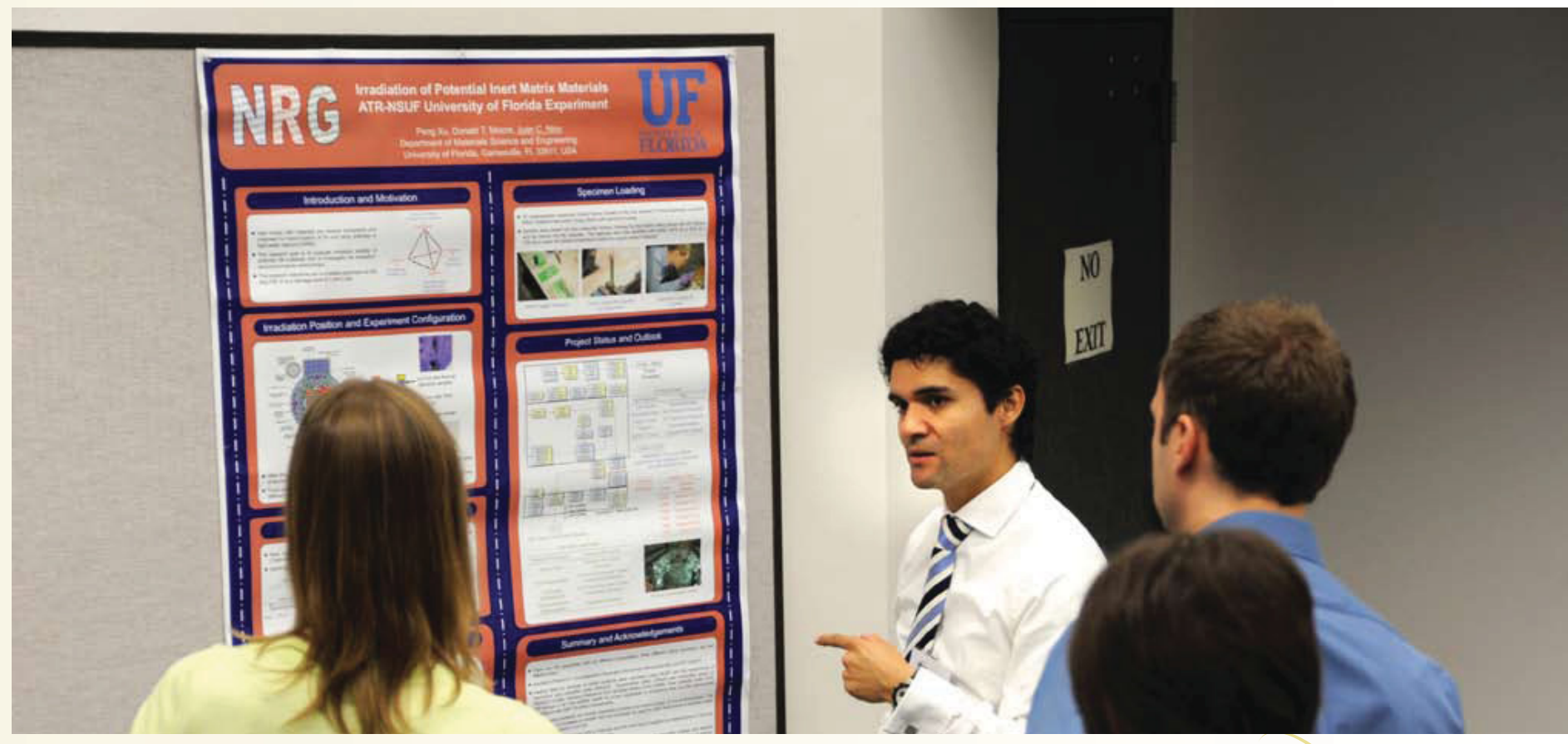

Photos of educational opportunities: (above) Poster Session during Users Week. (opposite top) students at Fuels and Materials workshop. (opposite bottom) students touring Hot Fuel Examination Facility.

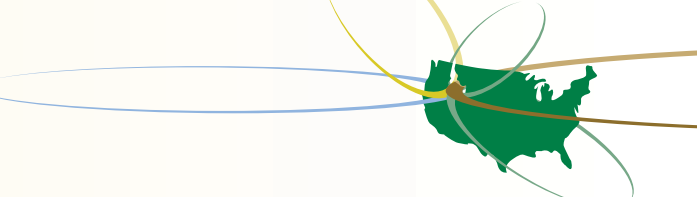




\section{Distributed Partnership at a Glance}

\section{d. Pls/Users is Collaborators}

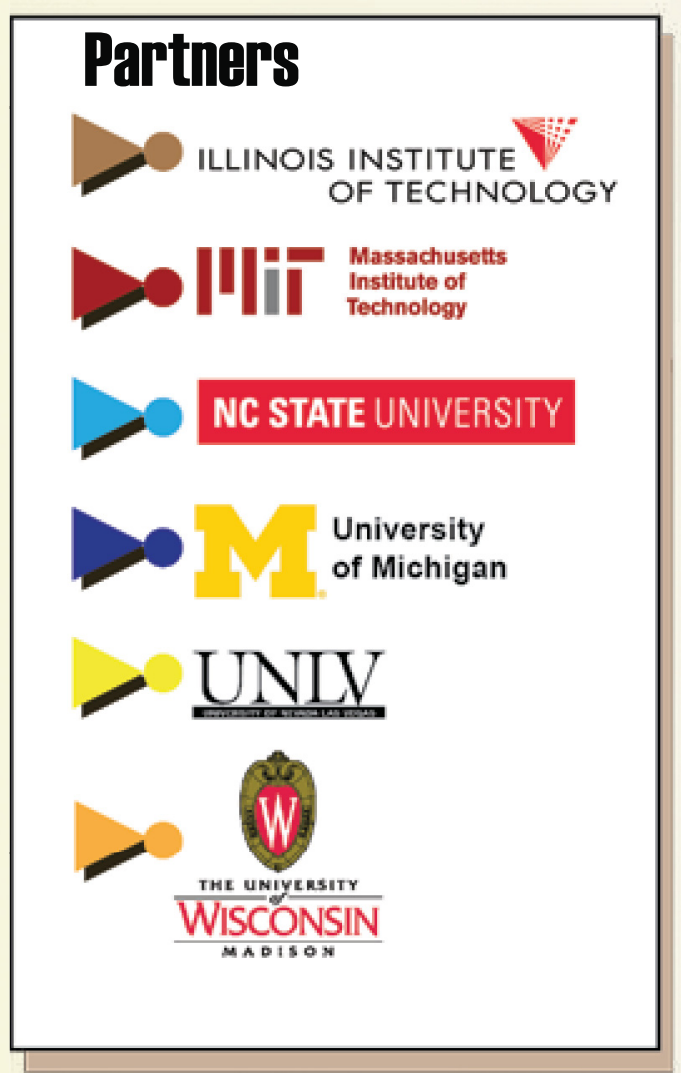

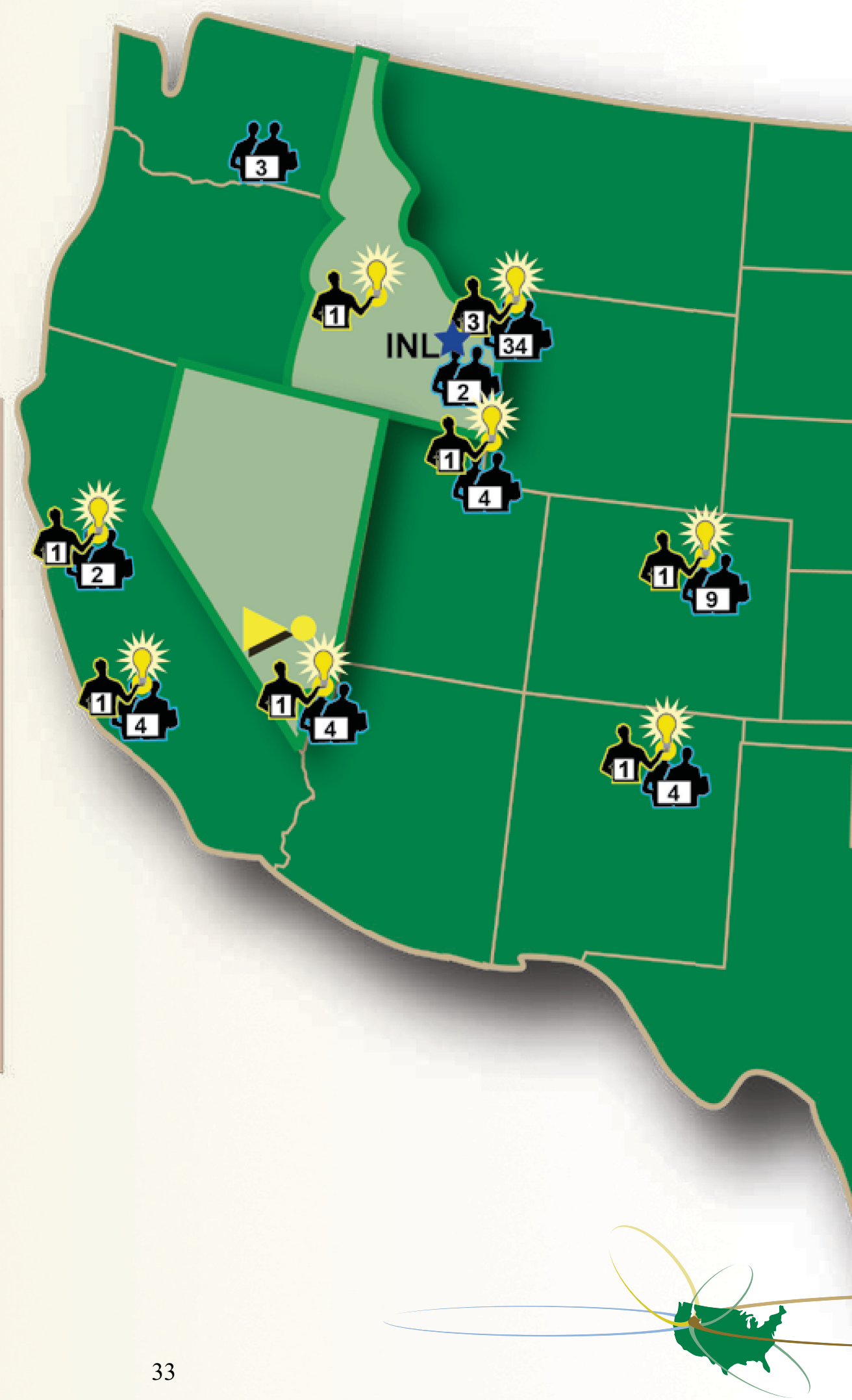


The Energy of Collaboration

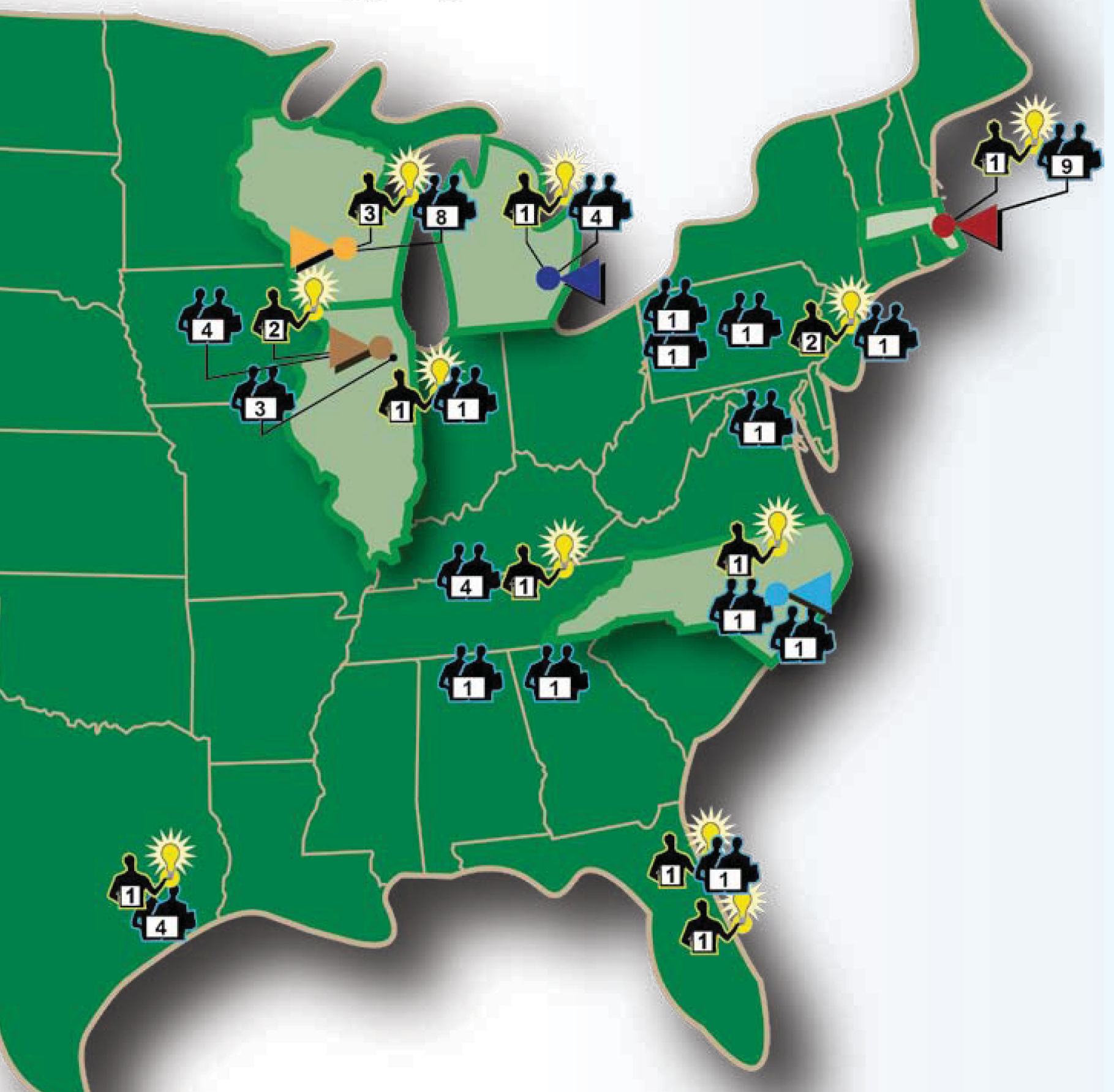




\section{Irradiation Effect on Thermophysical Properties of Hafnium Aluminide Composite: A Concept for Fast Neutron Testing at ATR}

\section{Introduction}

The development of advanced nuclear reactors is being hindered by the lack of domestic fast neutron testing capabilities. At this time, all advanced materials and fast reactor fuels are being tested in France or Japan. In order to meet the requirements for fuel cycle research and development and next generation nuclear plant programs, these capabilities need to be developed in the U.S. as well.

The thermophysical properties of $\mathrm{Al}_{3} \mathrm{Hf}$ and the effect of irradiation on it have never been measured.

\section{Project Description}

The concept behind this project is to incorporate booster fuel and a thermal neutron filter into one of the corner lobes in the INL's ATR to augment the neutron flux and filter the thermal neutrons to enable the testing of advanced materials and fuels in a fast neutron flux environment. The material used, hafnium aluminide $\left(\mathrm{Al}_{3} \mathrm{Hf}\right)$ particles in an aluminum matrix $\left(\mathrm{Al}_{3} \mathrm{Hf}-\mathrm{Al}\right)$, can also transfer heat from the experiment to pressurized water cooling channels. Thermal analyses indicate that this material is capable of keeping the system components below their maximum allowable temperature limits.

The thermophysical properties of $\mathrm{Al}_{3} \mathrm{Hf}$ and the effect of irradiation on this material have never been measured. These data are essential in order to proceed with the design and optimization of the neutron filter. Specific objectives of this ATR NSUF experiment are to determine:

- The thermophysical and mechanical properties of intermetallic $\left(\mathrm{Al}_{3} \mathrm{Hf}\right)$ and composite $\left(\mathrm{Al}_{3} \mathrm{Hf}-\mathrm{Al}\right)$ samples at different temperatures

- The effects of irradiation on the thermophysical and material properties of both samples

\section{Distributed Partnership at a Glance}

\begin{tabular}{|c|c|}
\hline ATR NSUF and Partners & Facilities \& Capabilities \\
\hline INL & Advanced Test Reactor \\
\hline \multicolumn{2}{|c|}{ Team Members/Collaborators } \\
\hline \multicolumn{2}{|c|}{$\begin{array}{l}\text { - USU - Heng Ban (principal investigator); Heather Wampler, Adam } \\
\text { Gerth, Kurt Harris (undergraduate students); Adam Zabriskie } \\
\text { (graduate student) } \\
\text { - INL - Donna Post Guillen (principal investigator) } \\
\text { - UNLV - Thomas Hartmann (collaborator) }\end{array}$} \\
\hline
\end{tabular}

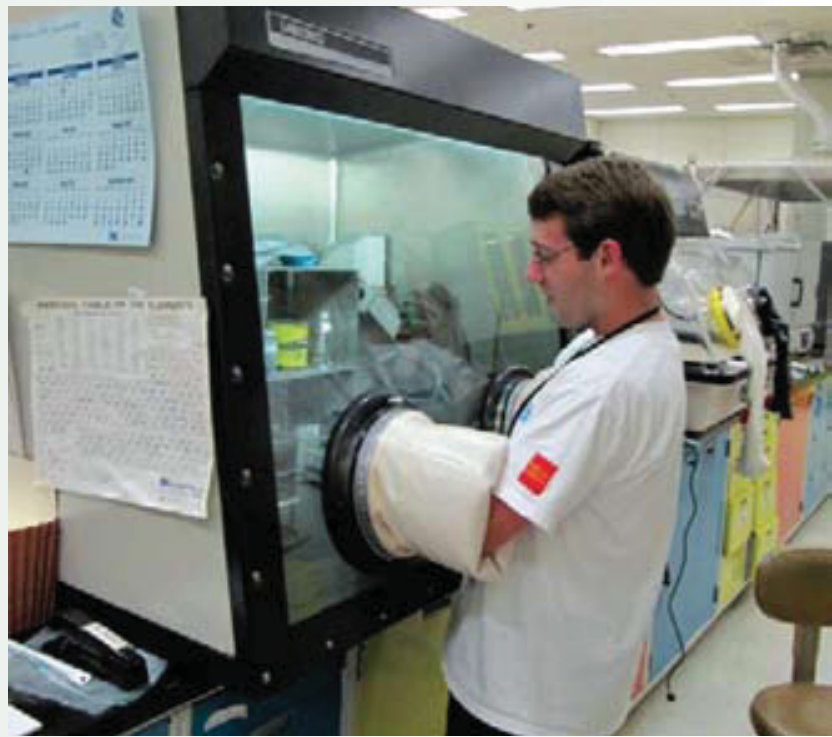

USU student working in a glovebox with newly developed materials to be irradiated.

- Physical/morphological, metallurgical and microstructural changes in the composite sample after different cycles of irradiation

- The corrosion behavior and radioactive decay byproducts of both samples.

In addition to filling a knowledge gap on the basic properties of these materials, and advancing the scientific understanding of irradiation effects on them, this experiment will provide necessary data for the development of a fast neutron test capability at the ATR. The end result will directly support the DOE's mission and benefit the science community in general.

\section{Accomplishments}

A quality-approved process for fabricating material specimens was established. Specimen materials were fabricated at INL and sent to an outside laboratory for independent elemental analysis. Flow testing of the irradiation capsule design was performed and compared to computational fluid dynamics predictions.

\section{Future Activities}

During the late fall of 2010, the specimen materials will be machined into various size disks, rods and tensile test specimens. Over the winter, characterization of material specimens will be performed to document thermophysical properties of the pre-irradiated materials. Corrosion testing of selected specimens will performed in the autoclave at 
INL's Materials and Fuels Complex. Insertion of the experiment into the reactor is anticipated to occur in April 2011.

\section{Publications and Workshop Reports}

(1) D. P. Guillen, B. P. Durtschi, A. X. Zabriskie and H. Ban, "Integrated Static and Flow-Through Capsule Assembly for Irradiation Testing," 2011 American Nuclear Society Meeting, June 26-30, 2011.

(2) "Manufacturing Process Specification for Utah State University ATR NSUF Experiment Specimens," Idaho National Laboratory PLN-3559, August 3, 2010.

(3) D. P. Guillen, D. L. Porter, J. R. Parry, H. Ban, "In-Pile Experiment of a New Hafnium Aluminide Composite Material to Enable Fast Neutron Testing in the Advanced Test Reactor," 2010 American Nuclear Society International Congress on Advances in Nuclear Power Plants ICAPP '10, Paper 10115, San Diego, CA, June $13-17,2010$
(4) H. Wampler, A. Gerth, H. Ban, D. P. Guillen, D. L. Porter, C. Papesch, and T. Hartmann, "Fabrication and Characterization of a Conduction Cooled Thermal Neutron Filter," 2010 American Nuclear Society International Congress on Advances in Nuclear Power Plants ICAPP '10, Paper 10118, San Diego, CA, June 13-17, 2010.

\section{Patents}

(1) A request to proceed with patent application BA-537, Manufacturing Process for HfAl Composite Material, was approved by the Business Exploitation Strategy Team (BEST) committee. Inventors: Donna Guillen, Doug Porter, Dave Swank and Arnie Erickson.

\section{This experiment will provide neces- sary data for the development of a fast neutron test capability at the ATR.}

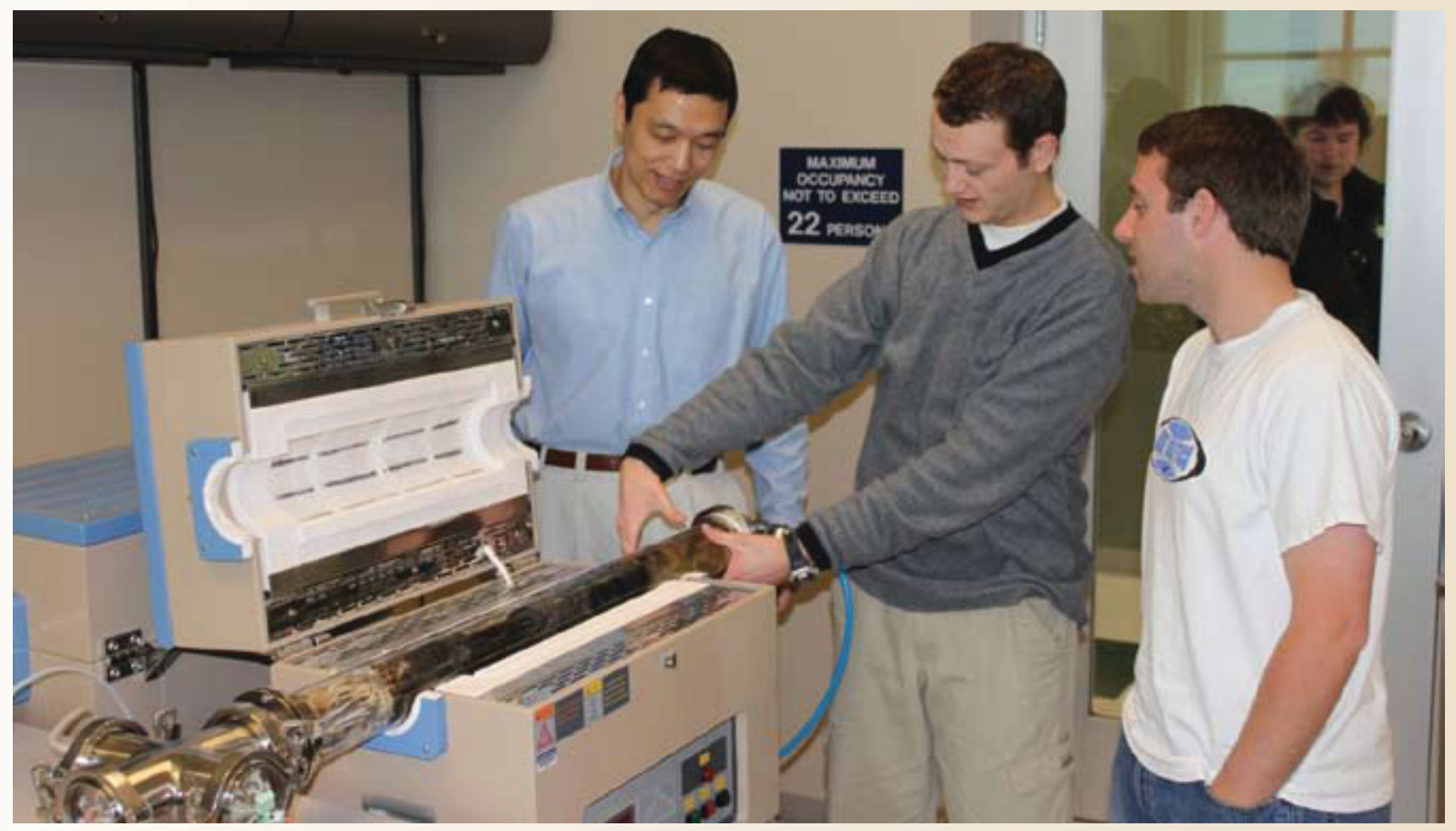

USU students and the principal investigator discuss the details of the thermal insulation arrangement in a thermal conductivity measurement system. 


\section{Advanced Damage-Tolerant Ceramics: Candidates for Nuclear Structural Applications}

\section{Introduction}

A new class of ternary carbides and nitrides, known as MAX phases, has numerous potential applications for use in next-generation nuclear reactors. All MAX phases are fully machinable even though some of them, such as $\mathrm{Ti}_{3} \mathrm{SiC}_{2}$ and $\mathrm{Ti}_{2} \mathrm{AlC}_{2}$, are similar to titanium metal in density but are three times as stiff.

\section{Project Description}

Now in its second year, this project continues to investigate the damage response of titanium silicon carbide $\left(\mathrm{Ti}_{3} \mathrm{SiC}_{2}\right)$ and titanium aluminum carbides $\left(\mathrm{Ti}_{3} \mathrm{AlC}_{2}\right.$ and $\mathrm{Ti}_{2} \mathrm{AlC}$ ) after they are exposed to a spectrum of irradiation consistent with conditions found in light water nuclear reactors.

The ternary carbide samples are exposed to a series of neutron fluence levels at moderate to high irradiation temperatures (Table 1) in the ATR at the INL. The progress of the damage to the microstructures and the effects of the radiation on the mechanical and electrical properties of the materials will be characterized during post-irradiation examinations.

The results will provide an initial database that can be used to assess the microstructural responses and mechanical performances of layered, machinable ternary carbides.

\section{Accomplishments}

The project team completed the following tasks during the program's first year:

- Design of specimens and irradiation capsules was completed using facilities at Drexel University

(Drexel), Savannah River National Laboratory (SRNL) and INL

- The irradiation plan was completed

- MAX materials were synthesized

- MAX specimens were machined/fabricated and characterized at Drexel
- External starting chemical purity certifications of the MAX specimens were completed at Drexel

- Unirradiated microstructural analysis, including grain size, texture and impurity phases, was completed at Drexel

- Baseline microstructure evaluation (Figure 1) and mechanical (Figure 2) and resistivity testing were completed at Drexel and SRNL.
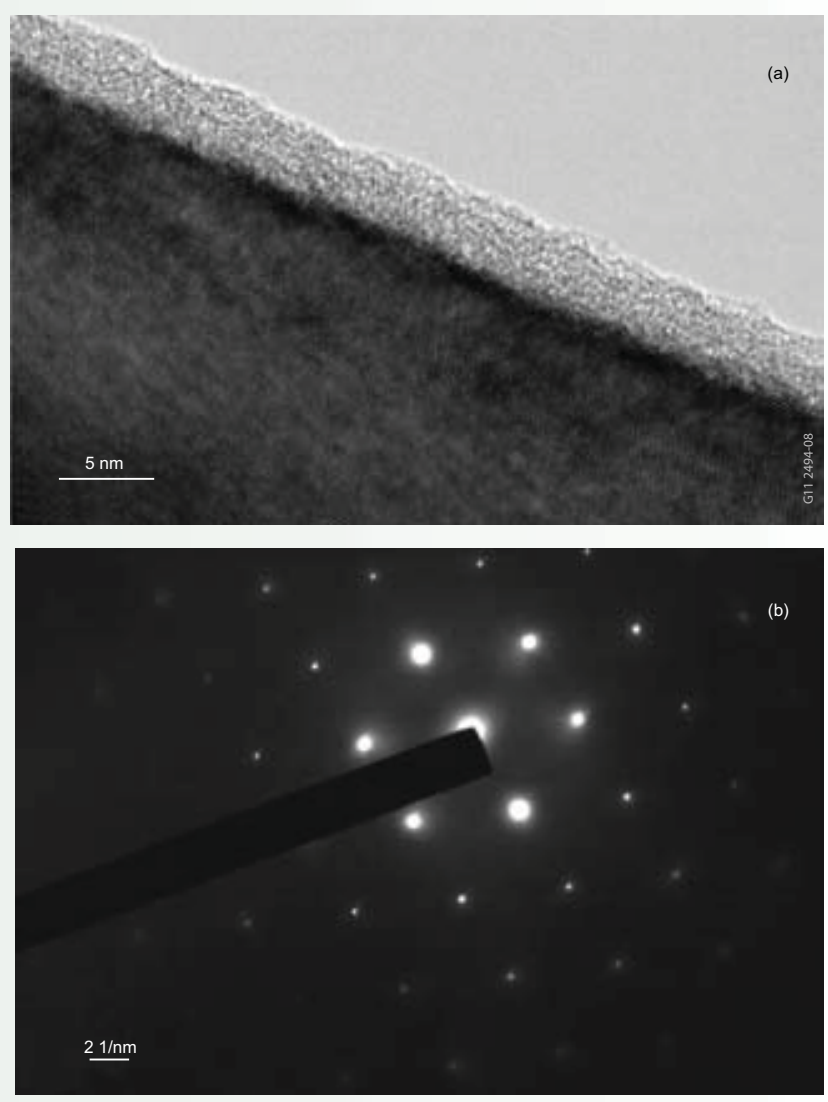

Figure 1. (a) TEM micrograph of a $\mathrm{Ti}_{2} \mathrm{AIN}$ sample (b) Selected area.

Table 1: Test matrix for sample irradiation

\begin{tabular}{|l|l|l|l|}
\hline Material & Temperature $\left({ }^{\circ} \mathbf{C}\right)$ & Target Dose $\left(\mathbf{d p a}^{*}\right)$ & Specimen Types \\
\hline $\mathrm{Ti}_{3} \mathrm{SiC}_{2}$ & $100,650,1000$ & $0.1,1.0,10.0$ & TEM, Resistivity, Tensile \\
\hline $\mathrm{Ti}_{3} \mathrm{AlC}_{2}$ & $100,650,1000$ & $0.1,1.0,10.0$ & TEM, Resistivity, Tensile \\
\hline $\mathrm{SiC}$ & $100,650,1000$ & $0.1,1.0,10.0$ & TEM, Resistivity, No Tensile \\
\hline
\end{tabular}

${ }^{*}$ For simplicity use a conversion of $7.0 \times 10^{20} \mathrm{n} / \mathrm{cm}^{2}=1.0 \mathrm{dpa}(\mathrm{E}>1.0 \mathrm{MeV})$ 

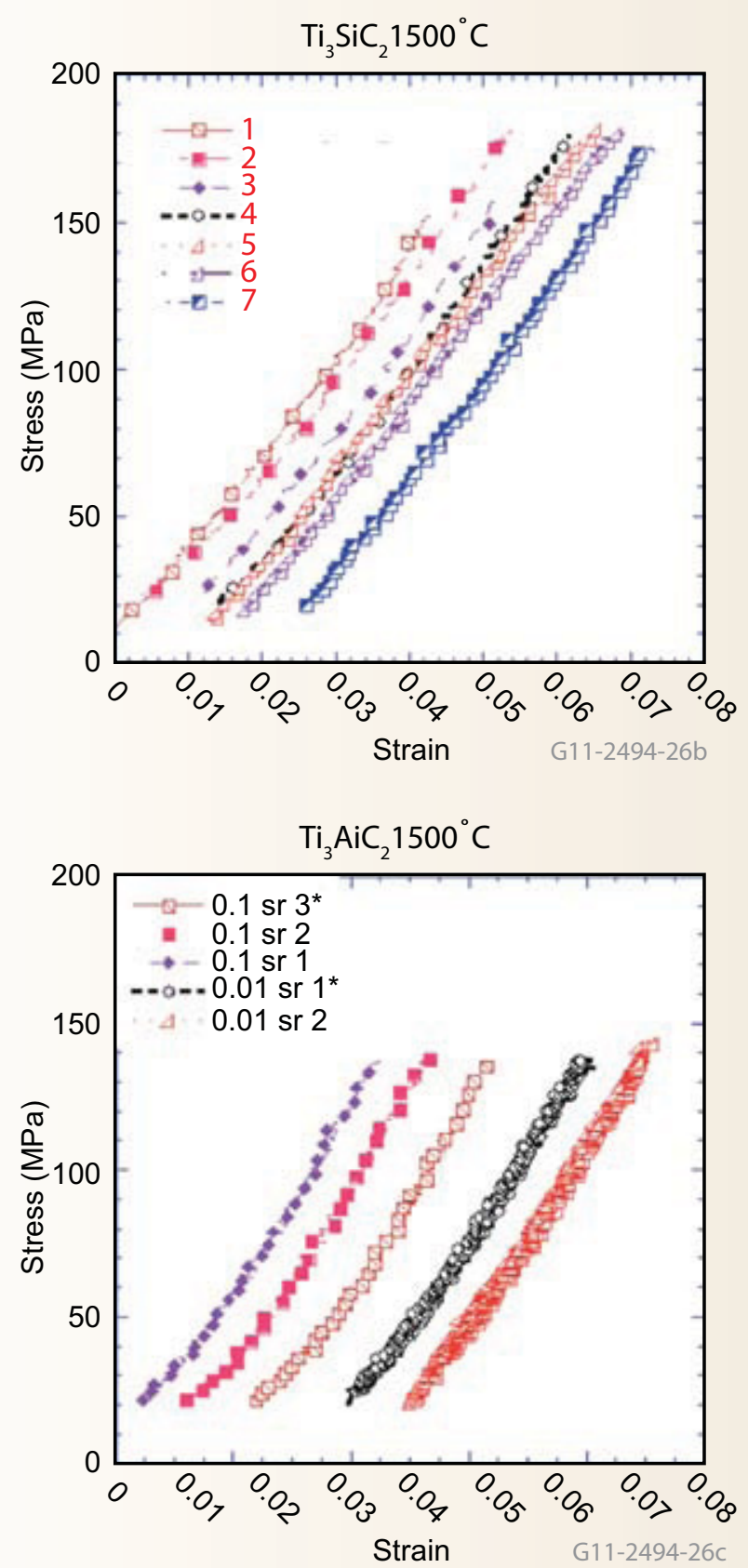

Figure 2. Engineering stress-strain curves for (a) $\mathrm{Ti}_{3} \mathrm{SiC}_{2}$ and (b) $\mathrm{Ti}_{3} \mathrm{AlC}_{2}$. Each plot shows multiple test samples for each material.

\section{MAX phases, a new class of ternary carbides and nitrides, have promise for use in next-generation nuclear reactors.}

\section{Future Activities}

Once the samples are removed from the reactor, they will be characterized to quantify the effects of the radiation on their properties and microstructures. The next set of samples will be placed into the reactor in spring 2011 at a fluence of approximately $1 \mathrm{dpa}$. The first batch of specimens being exposed to a fluence of $\approx 9$ dpa has been placed in the ATR and will be removed in summer of 2011.

\section{Publications}

(1) E. N. Hoffman, M. W. Barsoum, R. L. Sindelar, D. Tallman. 2010, "MAX Phases and Their Potential for Nuclear Reactor Applications," American Nuclear Society: 2010 Annual Meeting. San Diego, CA June $13-17,2010$

(2) E. N. Hoffman, D. W. Vinson, R. L. Sindelar, D. J. Tallman, G. Kohse and M. W. Barsoum, "MAX Phase Carbides and Nitrides: Properties for Future Nuclear Power Plant Applications," submitted for publication in Journal of Nuclear Materials.

\section{Distributed Partnership at a Glance}

\begin{tabular}{|c|c|}
\hline ATR NSUF and Partners & Facilities \& Capabilities \\
\hline Idaho National Laboratory & Advanced Test Reactor, PIE facilities \\
\hline \multicolumn{2}{|c|}{ Team Members/Collaboration } \\
\hline \multicolumn{2}{|c|}{$\begin{array}{ll} & \text { Drexel University - Michel W. Barsoum (principal investigator), } \\
\text { Darin Tallman (graduate student) } \\
\text { - } \\
\text { INL - Jian Gan (co-principal investigator) } \\
\text { - Savannah River National Laboratory - E.N. Hoffman } \\
\text { (collaborator), R.L. Sindelar (collaborator) }\end{array}$} \\
\hline
\end{tabular}




\section{Introduction}

In January 2010, the ATR NSUF awarded the University of Nevada, Las Vegas (UNLV) a three-year research project to advance the development and qualification of the ATRC as a general purpose thermal spectrum facility. This would enable ATRC to complement the LANL Criticality Experiments Facility at the National Nuclear Security Site in Nevada.

Due to budget constraints, the project could not be started in FY 2010. In the interim, Dr. Beller and two UNLV students were awarded a FSRT project at the Center for Advanced Energy Studies CAES where they completed research to support the project.

A previous investigation had found the use of the ATRC to conduct experiments such as integral cross-section measurements and criticality benchmarking to be feasible. ${ }^{1}$ However, the neutron transport model used in that study was only an approximation of the ATRC core configuration, and would not be sufficient for use in actual experiments to determine the computation of biases and uncertainties necessary for international benchmark evaluations.

\section{Project Description}

In the first phase of the FSRT project, a UNLV doctoral candidate and MS graduate student in Materials and $\mathrm{Nu}-$ clear Engineering, developed a physically accurate radiation transport model of the ATRC in collaboration with INL technical staff members. Experience with Monte Carlo particle codes (MCNP) allowed the student to reference drawings and reports from a criticality study conducted in 1994 to correct the previous model, and then begin the criticality benchmark evaluation of the experiment.

\section{This research will complement the Los Alamos National Labora- tory Criticality Experiments Facility.}

The second member of the team was asked to design, acquire components, construct and program a device that measures the elongation of small Zirconium metal samples during high-dose irradiation damage experiments in support of the Electric Power Research Institute (Figure 1).

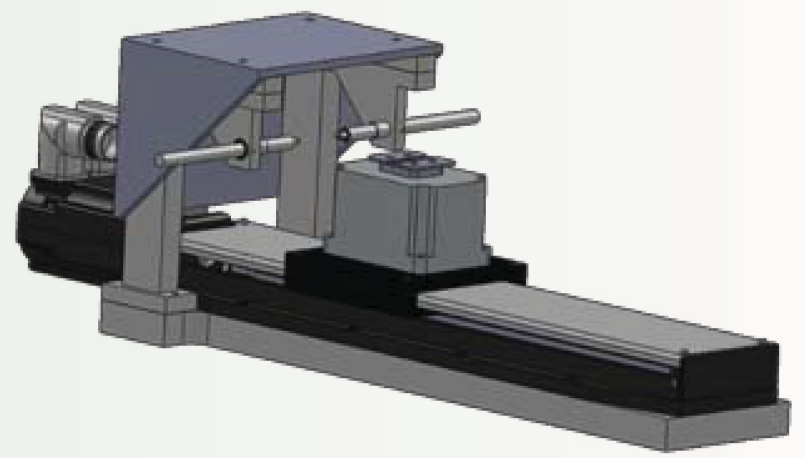

Figure 1. CAD drawing of the device for measuring the radiation-induced elongation of zirconium samples.

Also during the course of the summer, the PI developed a design concept for an aluminum cassette to be inserted into the ATRC for criticality benchmark validation experiments (Figure 2). This design and the results of the criticality sensitivity studies were incorporated into a draft experimental plan which was submitted to INL.

\section{Accomplishments}

All projects were successfully completed. At the end of the summer, both students presented seminars and submitted abstracts to an international conference for presentations on the work accomplished. This project was an invaluable experience for both students as evidenced by the following:

"My summer internship was filled with first-hand experiences, networking and great challenges. It exposed me to professionals and students alike who were willing to help me succeed. It was an amazing experience that provided me with skills and insight you can't learn in a classroom."

Anthony Santo Domingo, UNLV B.S. Mechanical Engineering student at undergraduate research assistant. 
"The time spent at INL under the FSRT program was invaluable. I benefited from being able to interact face-toface with the scientists and engineers and having access to the lab's state-of-the-art facilities."

Kimberly Clark, UNLV doctoral candidate and MS M\&NE graduate.

\section{Future Activities}

The MCNP model of the ATRC was submitted to INL and will continue to be upgraded during the ongoing evaluation of the 1994 experiment. The abstracts submitted by both students were accepted for presentation at the February 2011 meeting of The Materials Society. ${ }^{2}$

\section{Footnotes}

(1) John D. Bess, "Preliminary Assessment of ATRC Capabilities to Provide Integral Benchmark Data for Key Structural/Matrix Materials that May be Used for Nuclear Data Testing and Analytical Methods Validation," Report INL/EXT-09-15591, Idaho National Laboratory, March 2009.

(2) Kimberly Clark, John D. Bess and Denis Beller, "Criticality Validation and Reactor Physics Experiment for the Advanced Test Reactor National Scientific User Facility," accepted for presentation at the annual meeting of The Materials Society, San Diego, CA, February 27 - March 3, 2011.

\section{Planned Publications}

(1) Anthony Santo Domingo, Mitchell Meyer and Denis Beller, "Micron-Displacement Measurement for Small Samples in the Advanced Test Reactor National Scientific User Facility," accepted for presentation at the annual meeting of The Materials Society, San Diego, CA, February 27 - March 3, 2011.

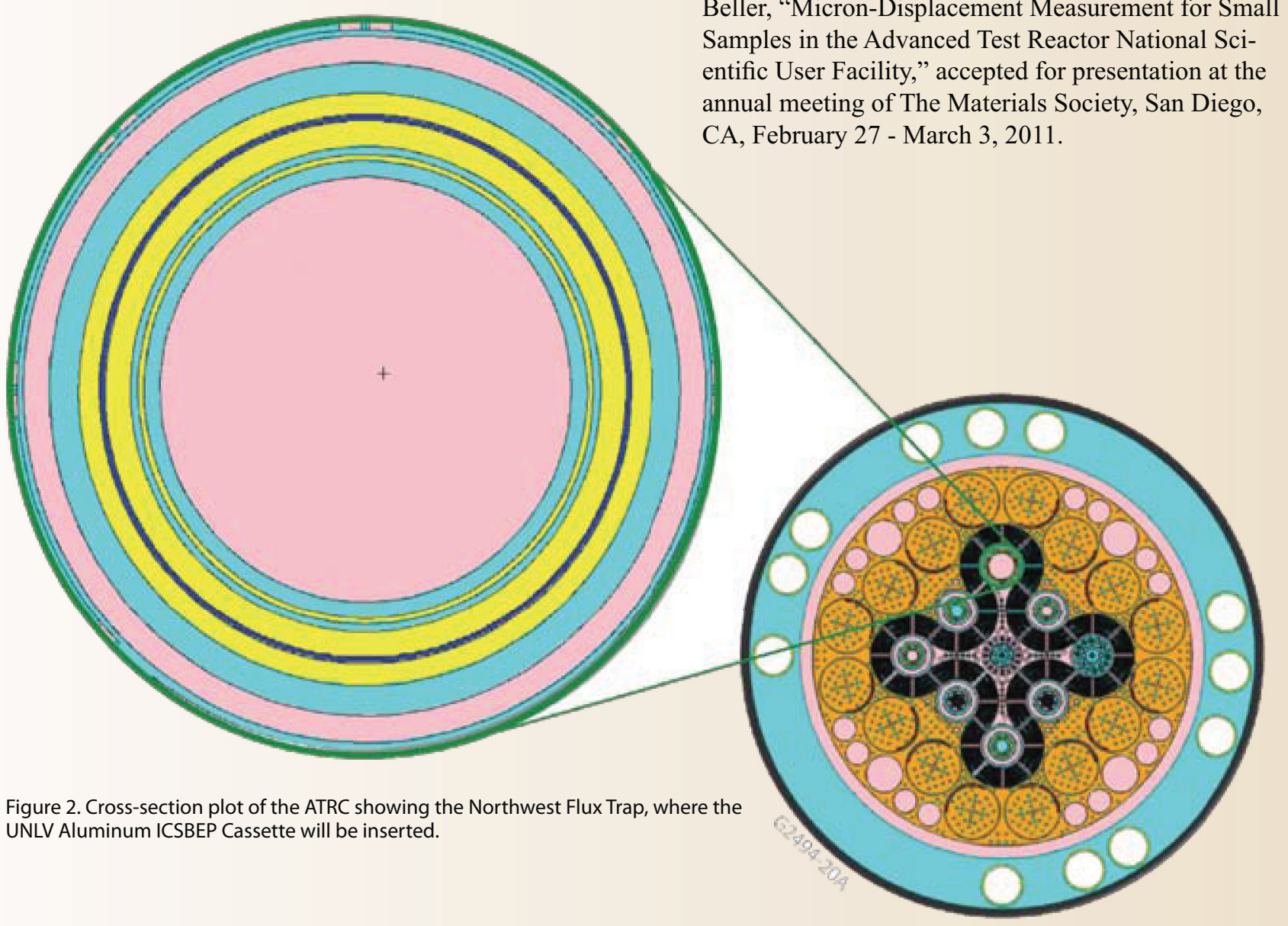




\section{Introduction}

The fuel cycle and waste management capabilities of fast reactors play an important role in a sustainable program of nuclear energy development. One of the major concerns for the next generation of fast reactor fuels is fuel cladding chemical interaction (FCCI). In a typical HT-9 cladding, FCCI is driven by the transport of iron $(\mathrm{Fe})$, fission product and fuel constituents between the cladding and the fuel. This typically results in degradation causing the formation of brittle phases in the cladding. The current option is to develop cladding alloys with good resistance to FCCI, but these are very limited. However, a strong and robust ceramic coating is considered a viable remedy to the problem.

One of the major concerns for the next generation of fast reactor fuels is fuel cladding chemical interaction.

\section{Project Description}

This RTE project is investigating a $1-\mu \mathrm{m}$ thick, single-layer coating of titanium nitride (TiN), and a multilayer coating of titanium nitride/aluminum nitride (TiN/AIN) with a sub-layer thickness of 50 nanometers. Both have been demonstrated to be effective as diffusion barriers. The microstructural stability of these coatings on HT-9 and an MA-957 alloys was tested under heavy ion irradiation to 10, 50 and 200 displacements per atom (dpa). Using transmission electron microscopy (TEM), the microstructural evolution as a function of irradiation dose will be characterized in the coating as well as at the interface. The effect of irradiation on the bonding strength of the coating/cladding interface will also be evaluated.

The use of heavy Fe ions will introduce high displacement damage over a short time that is equivalent to the cladding's target lifetime doses. It will also minimize the undesired chemical effect by using the same Fe ions for the Fe-based alloy. Another advantage of using heavy ion irradiation is that the samples are not activated from irradiation. This work will provide valuable insight into the role of cladding coating in mitigating FCCI.

\section{Accomplishments}

All samples were coated under the same conditions, with three different zones on the cladding varying in composition and physical parameters (Figure 1). Three identical pairs of coupon samples were used, each pair consisting of HT-9 and MA-957 alloys (Figure 2). The coating was applied by the thin film group at Texas A\&M University using pulsed laser deposition (PLD).

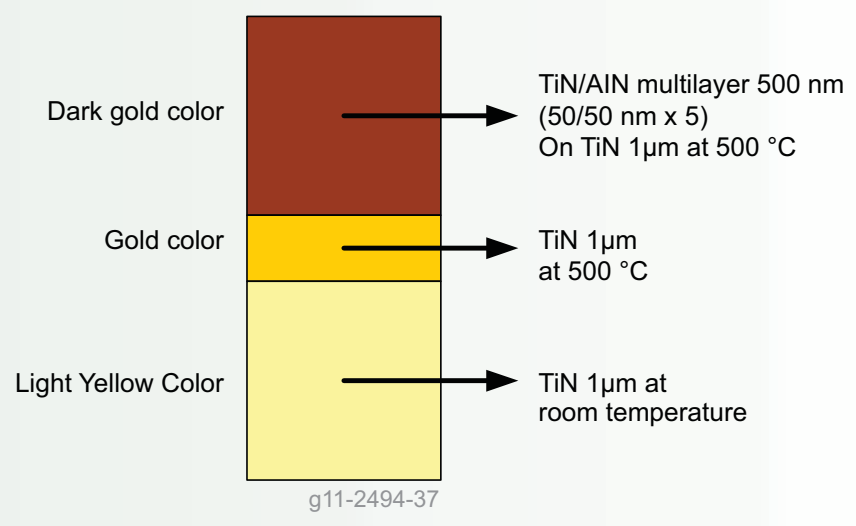

Figure 1. Schematic of TiN/AIN and TiN-coated large bars (HT-9 and MA957) for heavy ion irradiation test.

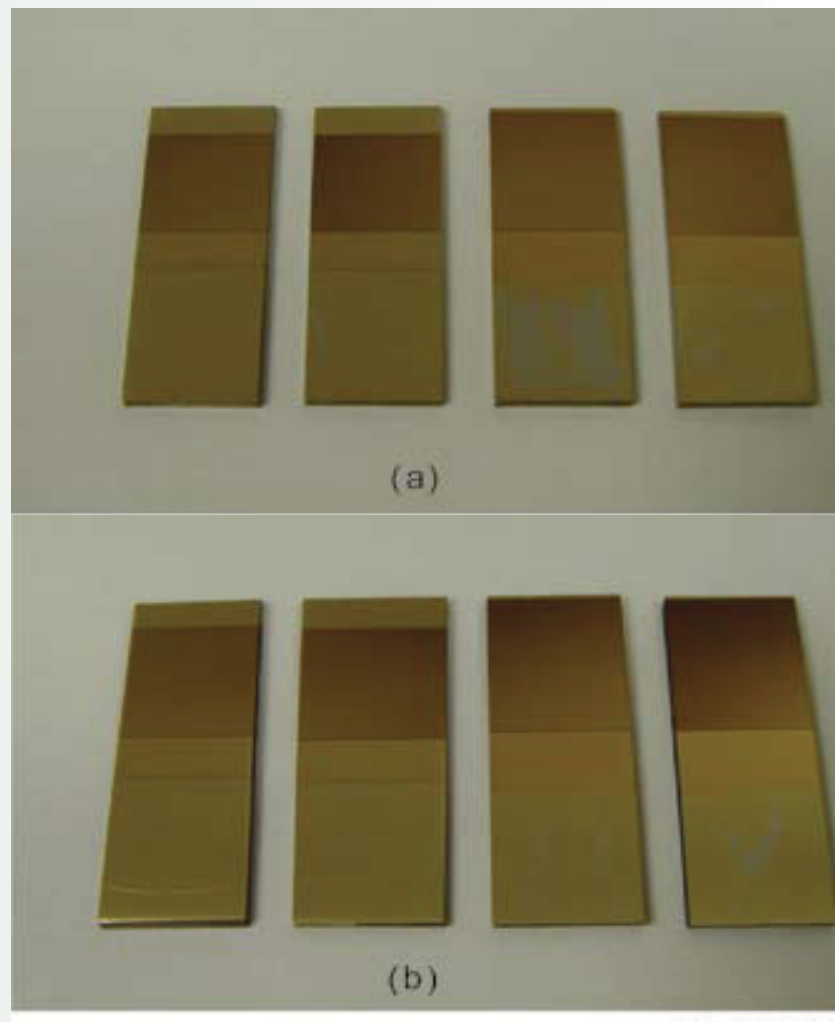

g11-2494-39

Figure 2. TiN/AIN $\left(500^{\circ} \mathrm{C}\right)$ and $\operatorname{TiN}\left(500^{\circ} \mathrm{C}\right.$ and room temperature) on selected area: (a) HT-9 bars and (b) MA957 bars 
$\mathrm{MeV} \mathrm{Fe}$ ions at $500^{\circ} \mathrm{C}$ ) at the Michigan Ion Beam Laboratory (MIBL), a partner of the ATR NSUF. The samples are currently under investigation at the INL. Preliminary microstructural characterization results from scanning electron microscopy (SEM) suggest that the ceramic coating on the HT-9 alloy performed better than that on the MA-957 alloy.

The strong collaboration of two universities on this project greatly enhances the ATR NSUF role by expanding the research capabilities, promoting education and advancing nuclear energy research and development.

The strong collaboration of two universities on this project greatly enhances the ATR NSUF role.
Distributed Partnership at a Glance

ATR NSUF and Partners Facilities and Capabilities

\begin{tabular}{|l|l}
\hline University of Michigan & Ion Beam Laboratory \\
\hline
\end{tabular}

Team Members/Collaborators

- INL - Jian Gan and Jim Cole (principal investigators)

- UM - Gary Was, Ovidiu Toader (collaborators)

- Texas A\&M - Haiyan Wang, Ickchan Kim, Fauzie

- Khatkhatay, and Liang Jiao (collaborators)

\section{Future Activities}

More detailed investigation will be carried out on the irradiated samples using TEM. The cross-section TEM sample preparation will be done using the focused ion beam (FIB) left-out technique. Characterization results from both SEM and TEM will be fed back to the thin film group at Texas A\&M for improvement of the ceramic coating on the diffusion barrier.

\section{Publications}

Preliminary results will be presented at Materials Science \& Technology conference in October 2011. More complete results and analysis will be published as a journal article. 


\section{Introduction}

A joint project was instituted in 2010 between the INL and Idaho State University (ISU), in collaboration with the French Atomic Energy Commission (CEA), to evaluate real-time, in-pile, flux detection sensors using the ATRC facility at INL. Results will be used to gain insights into which type of detector can provide the best online regional ATRC power measurement. This may offer the potential to increase the ATRC's ability to perform low-level irradiation experiments using specialized fixturing and software being developed for this project.

\section{Research results will provide insights into the best detectors for online regional ATRC power measurement.}

In addition, the data should provide insights about the viability of using these detectors in the ATR. Hence, this effort complements current activities to improve ATR software, tools, computational protocols and in-core instrumentation under the ATR Modeling, Simulation and V\&V Upgrade initiative. It will likewise complement the work to replace nuclear instrumentation under the ATR Life Extension Project.

\section{Project Description}

The project is comparing the accuracy, response times and long-duration performances of several real-time sensors, including:

- Miniature fission chambers developed by the CEA

- Specialized, self-powered neutron detectors (SPNDs) developed by the Argentinean National Energy Commission (CNEA)

- Specially developed commercial SPNDs and back-toback fission chambers developed by ANL.

INL is developing specialized instrument positioning hardware, and associated software, to facilitate the evaluations. Calculations will be made by ISU to assess the performance of the new flux detection sensors and compare data with existing flux wire measurements employed in ATRC fuel elements. The uncertainty associated with real-time flux detector data is currently up to 30 percent. The tasks performed in this project offer significant promise toward lowering that figure, increasing INL's ability to obtain more precise flux measurements.
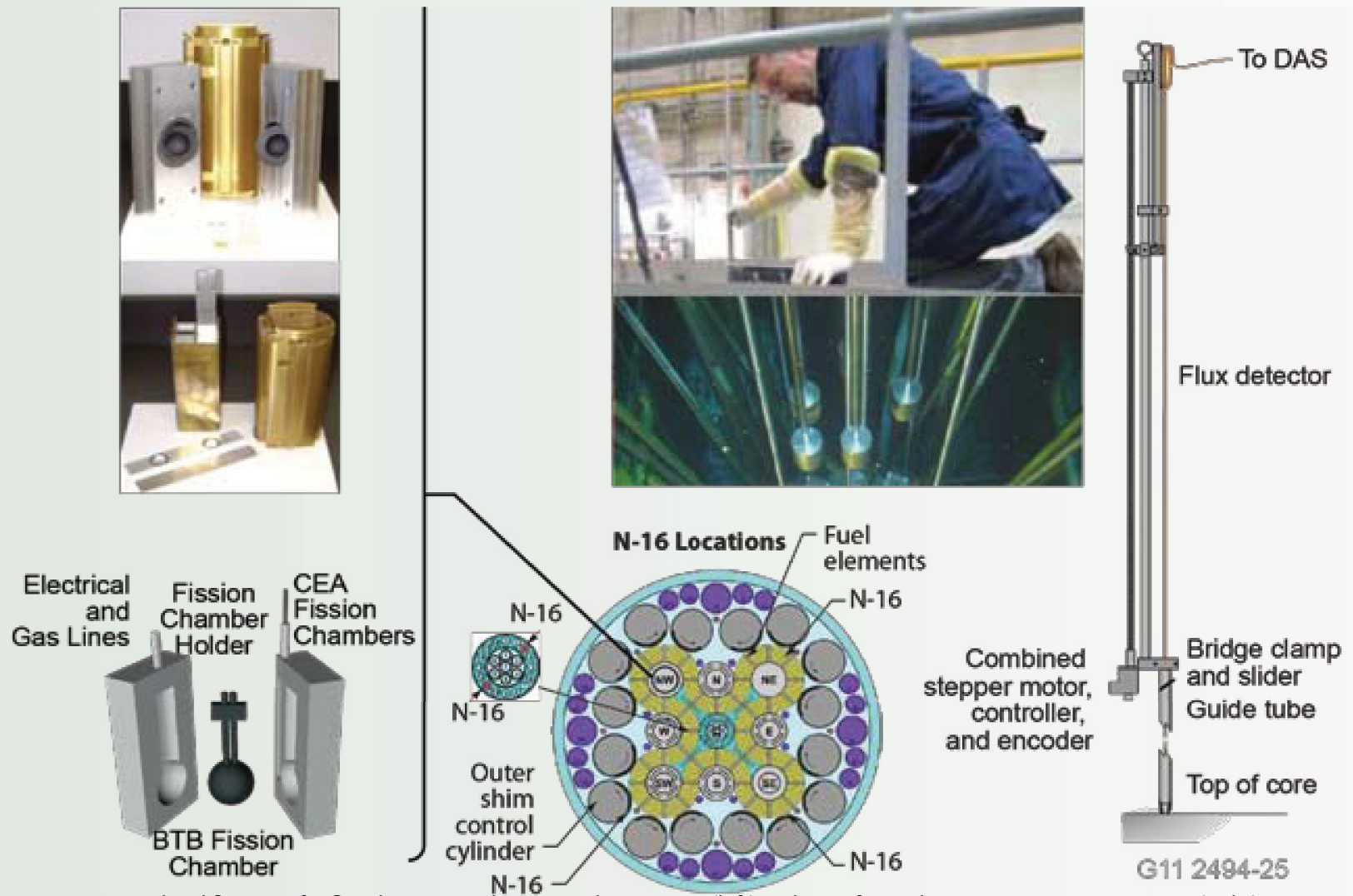

Figure 1. Specialized fixturing for flux detector evaluation in the NW-LIPT (left) and EGTs for evaluations in six N-16 positions (right) 
"The ATRC capability developed in this project provides researchers from ISU, INL, CEA (Commissariat de Energie Atomique in France) and other organizations a unique opportunity for evaluating real-time flux detectors. "'

George Imel, Ph.D., Professor, Founding Dean, College of Science and Engineering, Idaho State University

\section{Accomplishments}

During FY 2010, specialized fixturing for installing real-time flux detectors in six of the $\mathrm{N}-16$ positions in the ATRC, and integral fluence detectors in the ATR's Northwest Large In-Pile Tube (NW-LIPT), was designed, fabricated and installed. Experiment Guide Tubes (EGTs) allow real-time flux detectors to be axially positioned in the ATRC at up to six N-16 positions, while foils were placed in the NW-LIPT (Figure 1). Ultimately, such fixturing will be used to calibrate and improve the accuracy of real-time flux detectors.

Prior to testing, ISU inspected, tested and evaluated the SPND's and BTB chambers in their AGN-201 research reactor. Given the age of the original chambers, new drawings were developed and four new identical BTB chambers were constructed. LabView ${ }^{\circledR}$ software was written by ISU to facilitate the flux detector evaluations at ISU and testing at the ATRC.

\section{Future Activities}

Flux detector (e.g. SPND and fission chamber) testing will be initiated at ISU in October 2010, and foils will be irradiated in the NW-LIPT with a number of national and international partners present to assist with the initial evaluations (Figure 2). The following tasks are also anticipated to be performed in FY 2011:

- Continued evaluations of SPNDs and CEA fission chambers using specialized fixturing developed to axially position the detectors in the $\mathrm{N}-16$ positions of the ATRC

- Calibration of the newly constructed BTB chambers. Testing will take place at ISU in a multitude of different neutron irradiation environments using the AGN-201 reactor, the Idaho Accelerator Center's $25 \mathrm{MeV}$ linac, and the AmBE sealed neutron source.

- Fixturing for installing BTB fission chambers in the NW-LIPT will be developed

\begin{tabular}{|l|l|}
\hline \multicolumn{2}{|l|}{ Distributed Partnership at a Glance } \\
\hline ATR NSUF and Partners $\quad$ Facilities \& Capabilities \\
\hline INL & $\begin{array}{c}\text { Advanced Test Reactor - Critical } \\
\text { Facility, PIE facilities }\end{array}$ \\
\hline \multicolumn{2}{|l|}{ Team Members/Collaborators } \\
\hline - ISU - George Imel, Jason Harris (principal investigators); \\
Eric Bonebrake (M.S. candidate, Nuclear Engineering) \\
INL - Joy Rempe (co-principal investigator); Ben Chase \\
(ISU Ph.D. candidate); David Nigg, Troy Unruh (collaborators) \\
CEA - Jean Francois Villard, Benoit Geslot, Christophe \\
Domergue (collaborators)
\end{tabular}

\section{Publications}

G11-2494-32a

(1) T. Unruh, B. Chase, D. Nigg, J. Rempe, P. Hart, E. Bonebrake, J. Harris, G. Imel, C. Domergue, and B. Geslot, "Real-time in-core neutron detector evaluations at the Advanced Test Reactor Critical Facility," 14th International Symposium on Reactor Dosimetry, Bretton Woods, NH, May 22-27, 2011.

(2) T. Unruh, J. Rempe, D. Nigg, P. Hart, G. Imel, J. Harris, and E. Bonebrake, "Flux Sensor Evaluations at the ATR Critical Facility," 7th International Topical Meeting on Nuclear Plant Instrumentation, Control, and Human Machine Interface Technologies (NPIC\&HMIT 2010), Las Vegas, NV, November 7-11, 2010.

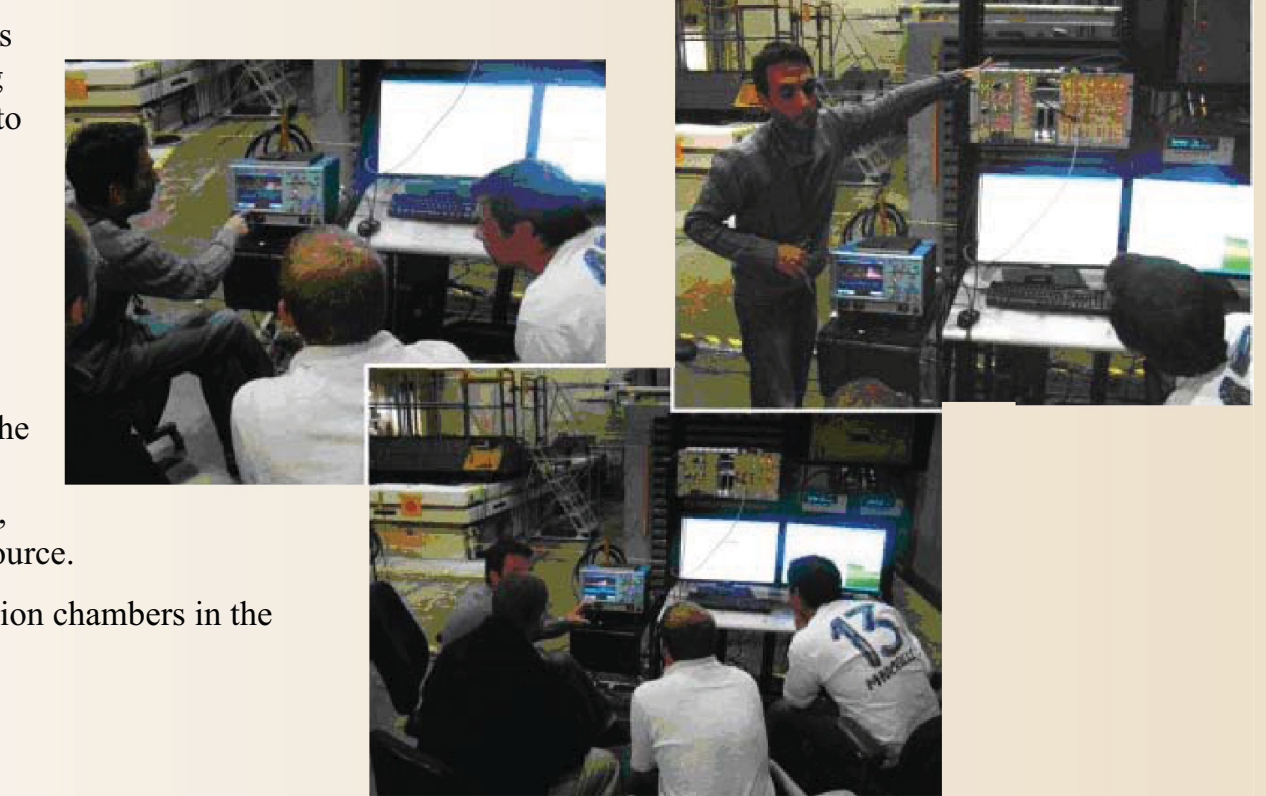

Figure 2. Benoit Geslot and Christophe Domergue, CEA, assist INL and ISU researchers in evaluating signal from CEA fission chambers. 


\section{Introduction}

Recent studies devoted to the development of Generation IV nuclear reactor systems have pointed out the need for more accurate data. Very high mass actinides can play a significant role in the feasibility assessment of innovative fuel cycles. For example, the potential build-up of ${ }^{252} \mathrm{Cf}$ when recycling transuranic waste in light water reactors leads to increased neutron emissions that could impact the fuel fabrication process. As a consequence, nuclear data on higher mass transuranics should be significantly improved.

\section{Very high mass actinides can play a} role in the feasibility assessment of innovative fuel cycles.

\section{Project Description}

Partially funded by the Department of Energy's Office of Science, MANTRA became an official ATR NSUF project in January 2010. The principle behind this experiment is to irradiate very pure actinide samples in the ATR and measure the transmutation produced after a given time. Determining the nuclide densities before and after irradiation will allow inference of energy-integrated neutron cross-sections, an approach which has been used in the past.

Some of the atom densities of the transmutation product will be determined using the accelerator mass spectrometry (AMS) technique at the ATLAS Analysis Support Center (ASC) located at ANL. AMS is sensitive enough to measure quantities of long-lived, rare isotopes with high discrimination in the presence of more abundant ones using very small amounts of material. While AMS facilities have traditionally been limited to the assay of low-tomedium atomic mass materials, recent progress has been seen in extending AMS to heavier isotopes.

The detection limit of AMS is several orders of magnitude lower than that of normal mass spectrometry techniques. Abundances as low as $10^{-12}$ can be detected. This allows more transmutation products to be measured and, consequently, more neutron cross-sections to be inferred from a single sample.

In order to achieve independent sets of measurements, more conventional analytical and radiochemical techniques were used as well, including:

- Inductively-coupled plasma quadrupole mass spectrometry

- Thermal ionization mass spectrometry.

\section{Accomplishments}

FY 2010 has been devoted mostly to defining three objectives:

(1) It was decided to irradiate the following isotopes: ${ }^{232} \mathrm{Th},{ }^{235} \mathrm{U},{ }^{236} \mathrm{U},{ }^{238} \mathrm{U},{ }^{237} \mathrm{~Np},{ }^{238} \mathrm{Pu},{ }^{239} \mathrm{Pu},{ }^{240} \mathrm{Pu},{ }^{241} \mathrm{Pu}$, ${ }^{242} \mathrm{Pu},{ }^{241} \mathrm{Am},{ }^{243} \mathrm{Am},{ }^{244} \mathrm{Cm}$ and ${ }^{248} \mathrm{Cm}$. These enriched isotopes are available at INL and were chosen because they are important for reactor physics and fuel cycle studies. Only a few mg of each material will be needed in order to prepare the experimental samples.

(2) Based on an analysis of neutron flux levels with regard to advanced reactor designs, it was decided to use cadmium and enriched boron neutron filters around the actinide samples in order to minimize the number of thermal neutrons (Figure 1). The neutron capture reactions on ${ }^{10} \mathrm{~B}$ and ${ }^{113} \mathrm{Cd}$ have large cross-sections and strongly impact the neutron spectrum.
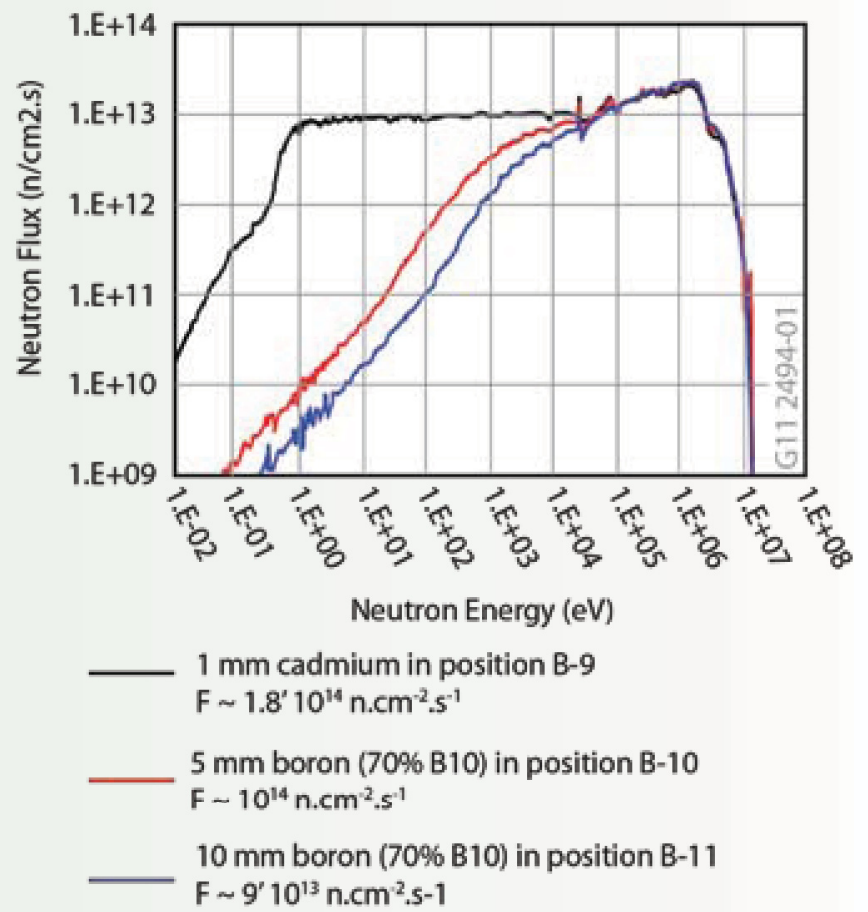

Figure. 1. Analytical results of the neutron flux in the samples with boron and cadmium filters. 
(3) The analyses highlighted the importance of precise characterization of the nuclide densities, as well as the neutron fluence, in order to minimize the uncertainty on the inferred actinide capture cross-sections. These relative uncertainties are based on a number of factors:

- The uncertainties on the nuclide densities

- The uncertainties on the neutron fluence

- The level of impurities

- The absolute value of the cross-section

- The absolute value of the neutron fluence.

Based on these analyses, it was decided to irradiate the cadmium samples for one 55-day cycle in the ATR, and the boron-filtered samples for two 55-day cycles, in order to accumulate a sufficient amount of transmutation products. This process led to the conclusion that the isotopes ${ }^{232} \mathrm{Th}$, ${ }^{238} \mathrm{U},{ }^{237} \mathrm{~Np},{ }^{242} \mathrm{Pu},{ }^{243} \mathrm{Am}$ and ${ }^{248} \mathrm{Cm}$ should be given the highest priority for AMS measurements.

Finally, the dosimeter materials used to help characterize the neutron irradiation environment have been chosen and ordered. The energy responses of three different materials are shown in Figure 2.

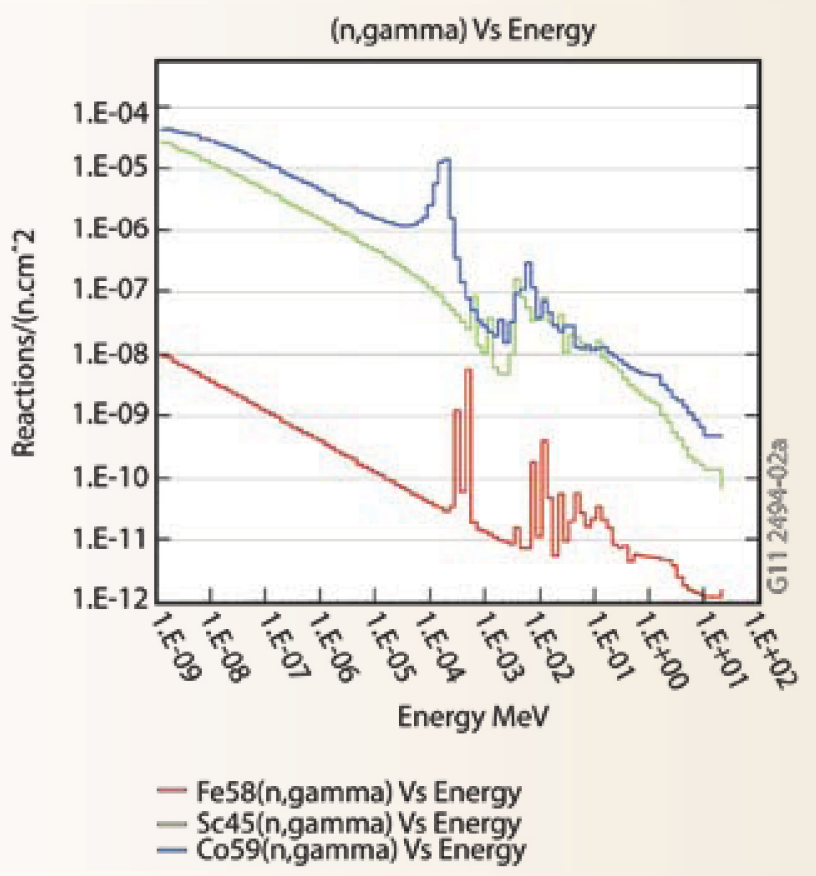

Figure 2 Examples of Different Energy Responses of Candidate Foils
Distributed Partnership at a Glance

ATR NSUF and Partners Facilities \& Capabilities

\begin{tabular}{|l|l|}
\hline INL & Advanced Test Reactor, PIE facilities \\
\hline
\end{tabular}

Team Members/Collaborators

- ISU - George Imel (principal investigator); Eric Burgett, (collaborator); Jyothir Kumar (M.S. candidate)

- INL - Gilles Youinou (co-principal investigator); Chris Matthews, Jacqueline Fonnesbeck (collaborators)

- ANL - Richard Pardo, Filip Kondev (collaborators)

G11-2494-01a

\section{Future Activities}

Due to insufficient funding, sample preparation and experiment design are behind the initial schedule. The samples are expected to be inserted into ATR in 2012.

\section{Publications}

(1) G. Youinou, G. Palmiotti, M. Salvatores, G. Imel, R. Pardo, F. Kondev, M. Paul, "Principle and Uncertainty Quantification of an Experiment Designed to Infer Sactinide Neutron Capture Cross-Sections," INL/EXT10-17622 (2010).

(2) G. Youinou, M. Salvatores, M. Paul, R. Pardo, G. Palmiotti, C. McGrath, F. Kondev, G. Imel, "MANTRA: An Integral Reactor Physics Experiment to Infer Actinide Capture Cross-Sections from Thorium to Californium with Accelerator Mass Spectrometry." Eleventh International Conference on Nuclear Data for Science and Technology, Jeju Island, Korea (2010).

(3) G. Youinou was invited to present the MANTRA experiment at the FCR\&D Nuclear Physics Working Group meeting, June 24-25, 2010, in Port Jefferson, New York.

(4) G. Palmiotti, an INL Fellow, was invited to present the MANTRA experiment at the Third Meeting of the Expert Group on Integral Experiments for Minor Actinide Management, September 13-14, 2010 at NEA Headquarters, Issy-les-Moulineaux, France. 


\section{Introduction}

This project is part of a larger effort to develop and qualify silicon-carbide ( $\mathrm{SiC}$ ) composite materials for use as fuel cladding in pressurized water reactors (PWR). The potential benefits of developing the $\mathrm{SiC} / \mathrm{SiC}$ composite "triplex ceramic cladding" to replace the zirconium alloy fuel cladding presently used in PWRs include:

- Better fuel behavior in loss-of-coolant accidents (LOCA) and departure-from-nucleate-boiling transients

- Increased fuel burn-up.

These benefits arise from SiC's inherent high-temperature strength and radiation resistance as well as the following engineered features of the cladding:

- An inner monolithic $\mathrm{SiC}$ layer that prevents the release of fission product gases

- An SiC fiber-based composite middle layer that provides mechanical strength and a "graceful failure mode" that retains solid fission products and maintains a coolable geometry even under LOCA conditions

- An outer layer of chemical-vapor-deposited SiC that provides corrosion resistance as well as protection against fretting and debris damage.

If these performance advantages can be demonstrated, improved fuels can be designed to enhance the safety, reliability and economy of commercial reactors.

\section{Project Description}

The primary focus of the research is to expose a variety of candidate tubing materials and bonding methodologies to

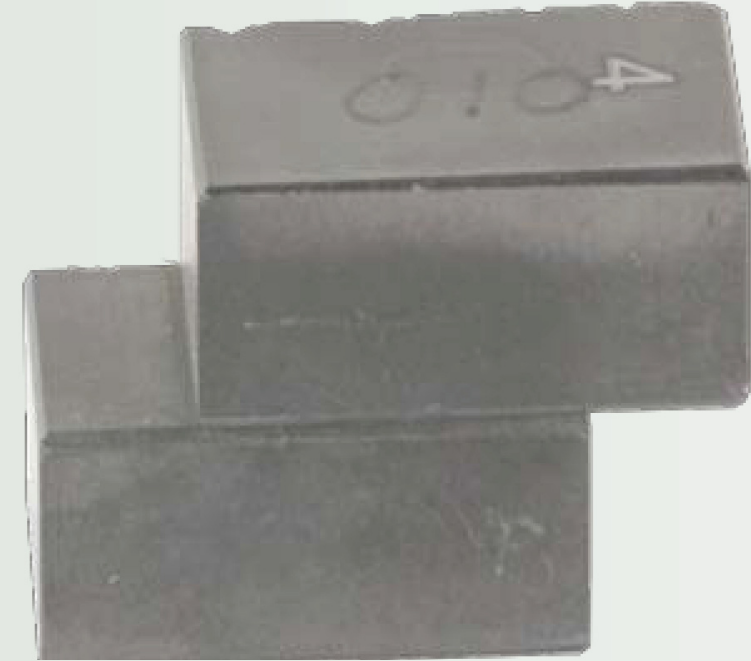

Improved fuel cladding for better fuel behavior in loss-of-coolant accidents and increased fuel burn-up.

PWR conditions. This is being done in an in-core loop at the MITR.

During the first irradiation period, three sets of material samples were placed in the MITR:

- A set of eight previously irradiated "Round 7" triplex $\mathrm{SiC} / \mathrm{SiC}$ composite tubes

- A set of four previously unirradiated $\mathrm{SiC}$ monolith tubes of the type used in the "Round 7" triplex tubes

- A set of six bond specimens (two each of three different bond technologies).

The samples were irradiated for 45 days under PWR coolant conditions of $300^{\circ} \mathrm{C}$ at approximately 3,250 megawatthours $(\mathrm{MWh})$ of reactor operation, which is the equivalent of 28 days of full-power neutron exposure.

At the end of the first exposure, the MITR was shut down for an extended period to replace the primary heat exchangers. After the reactor was restarted and tested, the second irradiation period was undertaken with the following materials:

- The same set of 12 "Round 7" tubes and monoliths described above

- One surviving bond sample from the first irradiation period together with a new, unirradiated bond sample of the same type

- A set of nine previously irradiated "Round 6" triplex tubes.
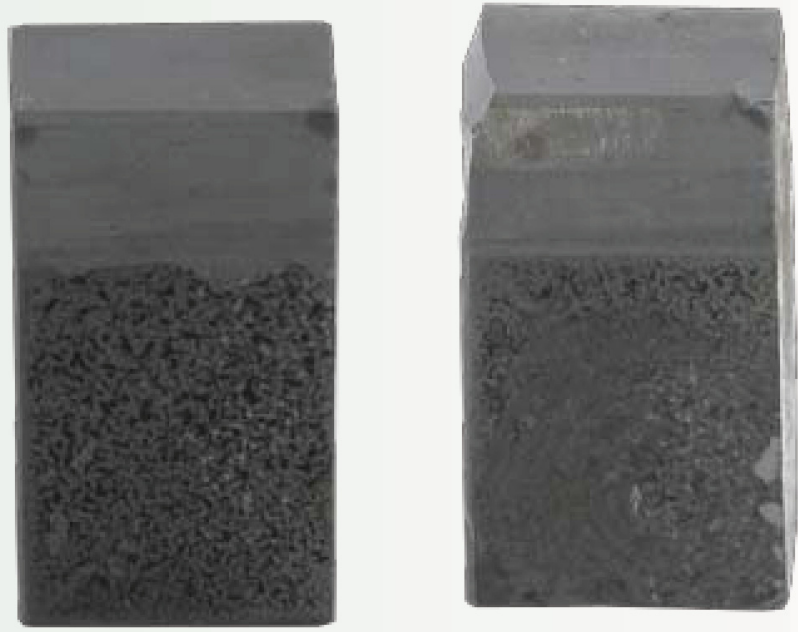

Figure 1. Example of debonded sample block following irradiation in the MITR. 
Mujid S. Kazimi, TEPCO Professor of Nuclear Engineering and Director of MIT Center for Advanced Nuclear Energy Systems

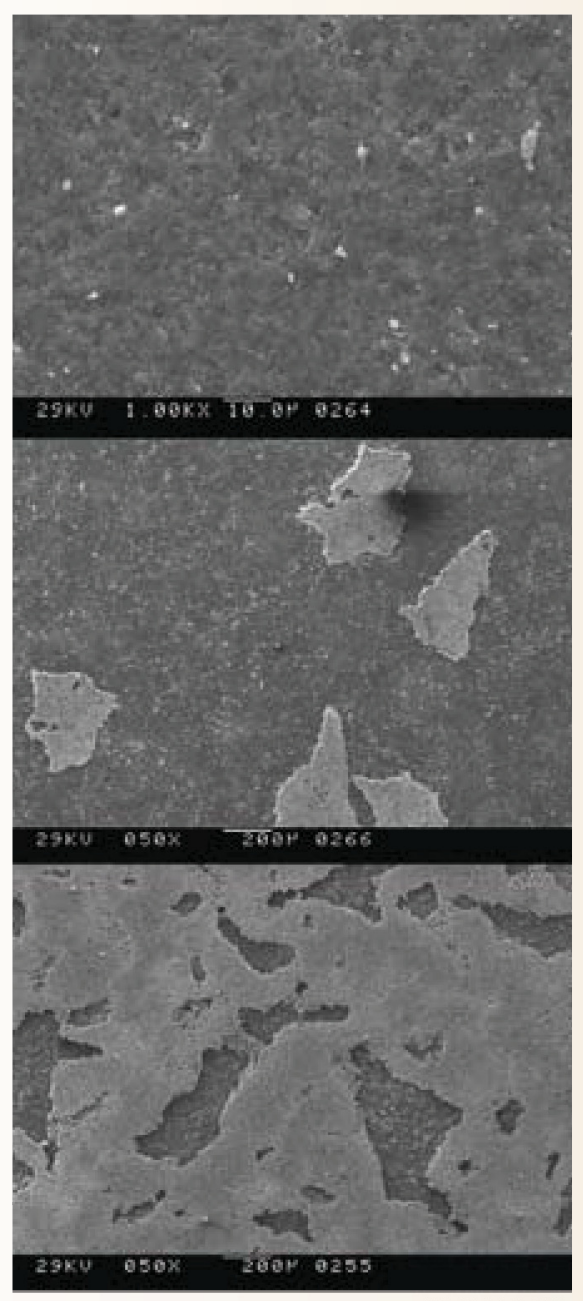

G112404-13h

Figure 2. SEM micrographs showing the unbonded surface (top) and areas from the two debonded half samples (bottom). The light areas in the lower micrographs show elemental composition signatures consistent with the bond material used.

This sample set was irradiated for 43 days at $300^{\circ} \mathrm{C}$, accumulating approximately 3,950 MWh of MITR operation or the equivalent of 34 days of full-power reactor operation. PIE includes characterizing the resulting corrosion behavior of the samples as well as the evolution of their mechanical properties.

\section{Accomplishments}

In FY 2010, the project team performed sample irradiation in the MITR, PIE of capsule disassembly and basic examinations of bond and tube samples. Additional PIE as well as neutronic and fuel performance calculations were also performed.
Following the first irradiation period, the bond samples were extracted and examined. All but one of the six samples had debonded under irradiation (Figures 1 and 2). Evaluation of the debonding is ongoing. The project team is giving special attention to the effect of sample geometry and differential irradiation swelling between the $\mathrm{SiC}$ and the bond materials. Other PIE activities being undertaken at MIT include:

- Burst testing of previously irradiated samples

- Development of methods for measuring thermal conductivity changes using segments cut from triplex tube samples.

\section{Future activities}

Irradiation of the three sample sets will continue through June 2011. Bond samples will be extracted and examined at that time, and a new set of bond samples will be inserted into the reactor. This last step will depend on when the project team receives the new bond samples and the condition of the two samples currently in the reactor. The new samples will be provided by Westinghouse Electric Company (WEC). Other potential vendors include EWI, Saint Gobain, Toshiba and Teledyne.

Depending on the total exposures achieved and subject to discussions with WEC and Gamma Engineering, Inc., one or both sets of tube samples may also be extracted for examination following the next irradiation period.

\begin{tabular}{|l|l|}
\hline \multicolumn{2}{|l|}{ Distributed Partnership at a Glance } \\
\hline ATR NSUF and Partners $\quad$ Facilities \& Capabilities \\
\hline MIT & Reactor \\
\hline Team Members/Collaboration \\
\hline - $\quad$ MIT - Mujid S. Kazimi (principal investigator), David M. \\
Carpenter (postdoctoral fellow), Jacob P. Dobisesky (graduate \\
student), John D. Stempien (graduate student), Uuganbayar \\
Otgonbaatar (undergraduate) \\
- $\quad$ INL - Mitchell Meyer (principal investigator) \\
- $\quad$ Westinghouse Electric Company - E. Lahoda (collaborator) \\
\hline
\end{tabular}

G11-2494-13a 


\section{Introduction}

With the growing interest in developing a new generation of advanced nuclear energy systems, both fission and fusion, designed to operate at higher temperatures and extremely greater radiation levels, the search for superior radiation-tolerant materials has taken on new importance. Bulk nanocrystalline (nc) polycrystals whose ultra-fine grains have diameters of less than $100 \mathrm{~nm}$ are promising radiation-resistant structural materials. Their high-volume fraction interfaces can
The search for superior radiationtolerant materials are important to the development of new generation advanced nuclear energy systems. act as sinks to radiationinduced defects. Nanocrystalline materials possess very desirable properties for reactor construction. High strength and superior wear resistance have made them the subject of intense theoretical and experimental studies.

\section{Project Description}

This project investigates the responses of the mechanical properties and microstructures of nanostructured metals/ alloys - including nc-copper, nc-nickel, ODS alloys (MA956, MA-754), and ultrafine carbon steel—when subjected to neutron irradiation. While low neutron-fluence irradiation experiments are being conducted in the PULSTAR reactor at NCSU, higher neutron fluences are more easily achieved at the ATR) at the INL.

It should be noted that all irradiation experiments for this project include the conventional counterparts of the materials mentioned above.

\section{Accomplishments}

PIE of the nc-copper samples irradiated at NCSU has been completed. Investigations of mechanical properties and

\begin{tabular}{|l|l|}
\hline \multicolumn{2}{|l|}{ Distributed Partnership at a Glance } \\
\hline ATR NSUF and Partners $\quad$ Facilities \& Capabilities \\
\hline $\begin{array}{l}\text { INL } \\
\text { North Carolina State University }\end{array}$ & $\begin{array}{l}\text { Advanced Test Reactor, PIE facilities } \\
\text { PULSTAR Reactor }\end{array}$ \\
\hline Team Members/Collaborators \\
\hline - $\quad \begin{array}{l}\text { North Carolina State University - K.L. Murty (principal } \\
\text { investigator); Walid Mohamed (Ph.D. candidate) }\end{array}$ \\
- $\quad$ INL - Doug Porter (co-principal investigator) \\
- $\quad \begin{array}{l}\text { University of Idaho - Indrajit Charit (collaborator); } \\
\text { Ramprashad Prabhakaran (Ph.D. candidate) }\end{array}$ \\
\hline
\end{tabular}

microstructures show that irradiation induces softening and concurrent grain-growth in nanograin-structured copper.

Nanostructured nickel and ultrafine carbon steel irradiated at NCSU are still undergoing cooling, and researchers expect to begin PIE on these samples by fall 2011. All samples irradiated at ATR were discharged and are currently undergoing PIE at either the HFEF or other laboratories at MFC.

Hardness measurements of irradiated conventional grainsized copper clearly revealed radiation hardening

(Figure 1), while nc-Cu showed decreased hardening with neutron radiation fluence (dpa). The hardness of nc-Cu following irradiation to $2 \mathrm{dpa}$ is essentially identical to that of irradiated conventional copper. The grain size of the 2-dpa-irradiated $\mathrm{nc}-\mathrm{Cu}$, however, has not been measured to date, so no comparisons are available.

Tensile tests were completed on both conventional $\mathrm{Cu}$ (Figure 2) and $\mathrm{nc}-\mathrm{Cu}$ (Figure 3) for all fluences to $2 \mathrm{dpa}$. The expected radiation hardening and embrittlement in conventional $\mathrm{Cu}$ (Figure 2) along with the formation of a distinct yield point were noted following 2-dpa irradiation. In contrast, $\mathrm{nc}-\mathrm{Cu}$ exhibited radiation softening with slight hardening at the highest fluence level (Figure 3).

Microstructural studies on samples irradiated to $1 \mathrm{dpa}$ revealed radiation-induced grain growth, with the data following the Hall-Petch relation (Figure 4). Interestingly, the data seem to reveal - as indicated by the slopes of the graphs - decreased source hardening (per the Petch unpinning coefficient) with increased neutron fluence, although only two data points that correspond to conventional copper and $\mathrm{nc}-\mathrm{Cu}$ are available.

The microstructural work did not proceed as expected. Various trials to prepare foils for TEM at the MFC, either via FIB or the traditional jet-polishing, were unsuccessful. Both procedures, however, worked successfully for the low-dpa samples at NCSU.

\section{Future activities}

Initially, PIE of nc-Cu was to be completed by the end of 2010; however, problems with the microstructural investigation caused researchers to extend the deadline to May 
2011. It will be interesting to study the radiation effects on $\mathrm{Cu}$ as a function of grain size to see how they affect the trends in the Hall-Petch relation (Figure 4).

To date, these studies have been made only on copper. However, PIE of irradiated Ni would be of immense interest since the limited amount of literature on the subject in-

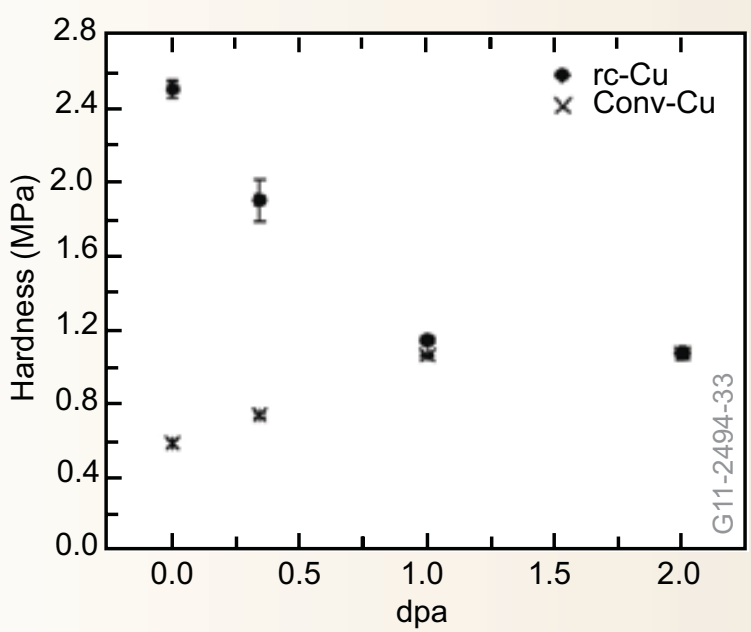

Figure 1. Hardness vs dpa

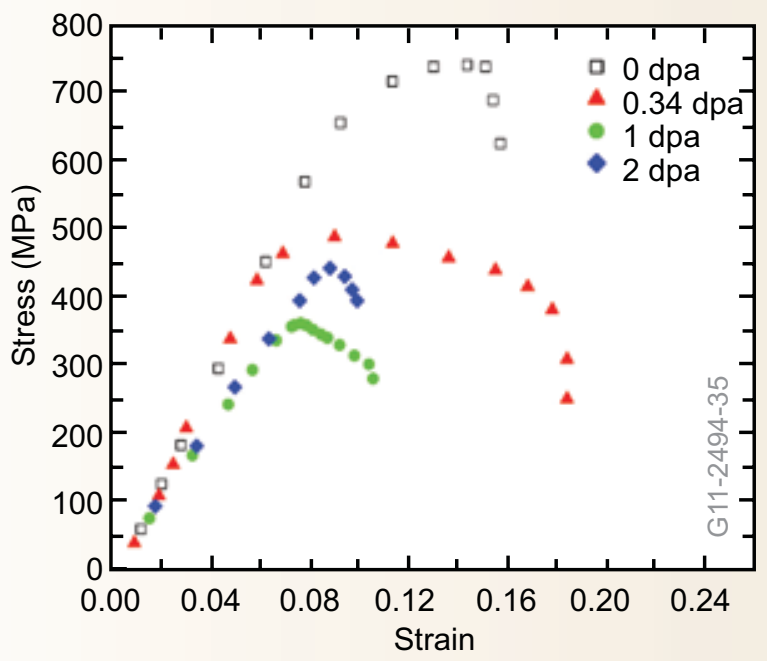

Figure 3. Stress-strain curves of nc-Cu dicates grain shrinkage in $\mathrm{Ni}$ - in contrast to $\mathrm{Cu}-$ following radiation exposure. In addition, the effects of radiation on ultra-fine-grained steel would be of both technological (structural alloy) and scientific (yield-point phenomena) importance. These seem like perfect research projects for a new graduate student.

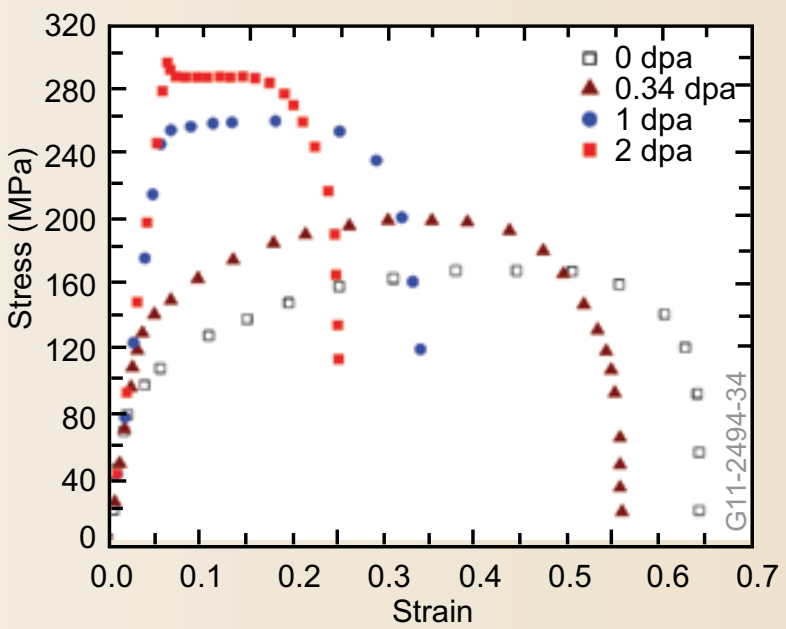

Figure 2. Stress-strain curves of conventional $\mathrm{Cu}$

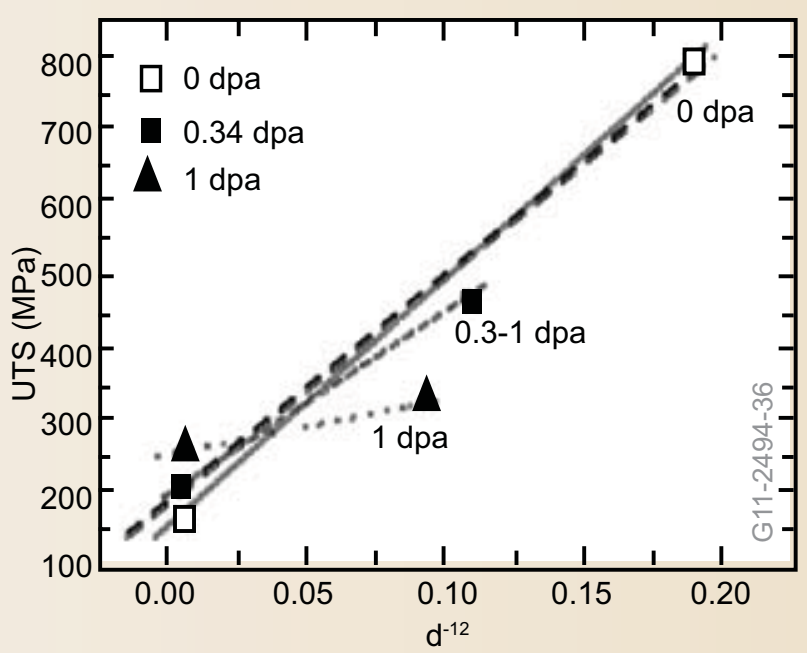

Figure 4. Hall-Petch plot 


\section{Introduction}

The worldwide inventory of radiotoxic weapons- and reactor-grade nuclear waste, such as plutonium $(\mathrm{Pu})$, neptunium (Np), americium (Am) and curium $(\mathrm{Cm})$, is growing rapidly. Disposing of this waste in safe, secure, ecologically responsible and economically sensible ways is a national and international priority.

One way to reduce the amount and the threat of radiotoxic waste is through transmutation in nuclear reactors. Transmutation converts the radioactive constituents of the waste into more stable elements, such as iodine $\left({ }^{131} \mathrm{I}\right)$, barium $\left({ }^{140} \mathrm{Ba}\right)$, and Cerium $\left({ }^{140} \mathrm{Ce}\right)$. However, the transmutation of mixed-oxide-based (MOX) fuel, which itself is made of weapons-grade $\mathrm{Pu}$, leads to the generation of new radioactive transuranium actinides. A more promising alternative is burning the $\mathrm{Pu}$ and other transuranic elements in an inert-matrix fuel, which generates much less radioactive waste.

\section{Project Description}

The Nuclear Energy Research Initiative awarded a project to the University of Florida that expands on the INL efforts to develop magnesium oxide $(\mathrm{MgO})$-based, ceramic-ceramic (cercer) inert-matrix materials. ${ }^{1}$ The university's researchers investigated the synthesis and thermophysical properties of potential inert-matrix materials: magnesium oxide-neodymium zirconate cercer composites $\left(\mathrm{MgO}-\mathrm{Nd}_{2} \mathrm{Zr}_{2} \mathrm{O}_{7}\right)$ and single-phase magnesium-based spinel compounds (Table 1$)^{2}$.

The objectives of this project are to:

- Investigate the behavior of $\mathrm{MgO}-\mathrm{Nd}_{2} \mathrm{Zr}_{2} \mathrm{O}_{7}$ cercer composites as an inert matrix in irradiated environments

- Investigate the behavior of single-phase, Mg-based spinel compounds as an inert matrix in irradiated environments
- Characterize the effects of irradiation on the microstructure and thermophysical properties of the irradiated materials.

Ceramic disc samples of the two materials were irradiated at approximately 350 and $700^{\circ} \mathrm{C}$ to dose accumulations of 1 and $2 \mathrm{dpa}$ (Table 1). Post-irradiation analyses of the materials are being performed at INL's Materials and Fuels Complex.

\section{Accomplishments}

The project team has completed the following procedures:

- Capsule A2 was disassembled, and samples were categorized in January 2010

- Post-irradiation examination of $\mathrm{MgO}, \mathrm{MgAl}_{2} \mathrm{O}_{4}$ and $\mathrm{MgO} \cdot 1.5 \mathrm{Al}_{2} \mathrm{O}_{3}$ of capsule $\mathrm{A} 2$ began in May 2010

- TEM samples were prepared and characterized (Figure 1)

- Pellets were fractured and the cross sections examined using SEM.
The reduction of radiotoxic waste is a national and international priority.
The fracture SEM revealed that the irradiation caused the microstructure to become brittle (Figure 2). Polished and thermally etched samples examined by SEM are needed to identify if any microstructural changes such as grain morphology occurred during irradiation.

In addition, X-ray diffraction (XRD) showed that irradiation caused no phase changes in the materials, although changes in the color of the samples were traced to the irradiation. Sample densities were also measured; and thermal diffusivity indicated that irradiation damage caused the diffusivity to decrease, while the high-temperature measurements initiated annealing of the damage.

Table 1. Irradiated materials and capsule irradiation conditions.

\begin{tabular}{|c|c|c|c|c|}
\hline Materials & & Iden & & \\
\hline $\mathrm{MgO} \cdot 1.5 \mathrm{~A}_{2} \mathrm{O}_{3}$ & Dose (dpa) & \multicolumn{2}{|c|}{ Temperature $\left({ }^{\circ} \mathrm{C}\right)$} & \\
\hline $\mathrm{MgO}$ & & 350 & 700 & \\
\hline $\mathrm{Nd}_{2} \mathrm{Zr}_{2} \mathrm{O}_{7}$ & 1 & A2 & B2 & \\
\hline $\mathrm{Mg}_{2} \mathrm{SnO}_{4}$ & 2 & $\mathrm{C} 2$ & C1 & \\
\hline
\end{tabular}




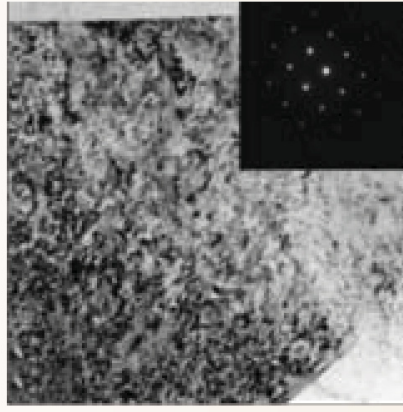

$100 \mathrm{~nm}$

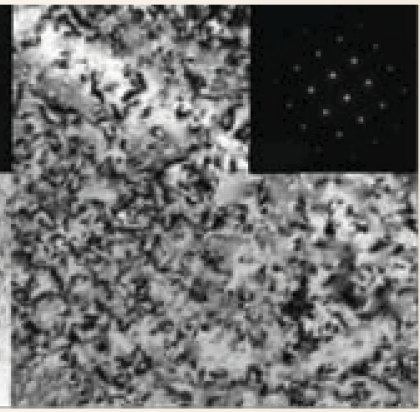

$\overline{100} \mathrm{~nm}$
G11 2494-04

Figure 1. (Left) TEM showing ion damage in nonirradiated $\mathrm{MgO}$ caused by the FIB. (Right) Irradiated MgO has increased dislocation loops due to neutron irradiation. The diffraction patterns indicate that the material's crystal structure did not become amorphous.

\section{Future Activities}

The following actions will be undertaken in 2011:

- Defect formation in neutron-irradiated materials will be characterized

- SEM will be used to characterize grain size, microcracks, voids and other deteriorative microstructural effects, though changes in the samples' microstructures are not anticipated

- Thermal diffusivity of irradiated samples will be measured and correlated with radiation doses, radiation temperature and defect formation

- The mechanism of thermal diffusivity degradation will be studied.

The planned experiments for this project will:

- Measure the thermal diffusivity of gold-coated $\mathrm{MgO}$, $\mathrm{MgAl}_{2} \mathrm{O}_{4}$ and $\mathrm{MgO} \cdot 1.5 \mathrm{Al}_{2} \mathrm{O}_{3}$ samples from capsule $\mathrm{A} 2$ at the INL

- Take SEM, TEM and diffusivity measurements of $\mathrm{MgO}$ and $\mathrm{MgAl}_{2} \mathrm{O}_{4}$ from capsules $\mathrm{C} 1$ and $\mathrm{C} 2$

- Take SEM, TEM, and diffusivity measurements of $\mathrm{Nd}_{2} \mathrm{Zr}_{2} \mathrm{O}_{7}, \mathrm{MgO}-\mathrm{Nd}_{2} \mathrm{Zr}_{2} \mathrm{O}_{7}$, and $\mathrm{Mg}_{2} \mathrm{SnO}_{4}$ from capsule A2

- Measure thermal diffusivity of pre-irradiated samples.

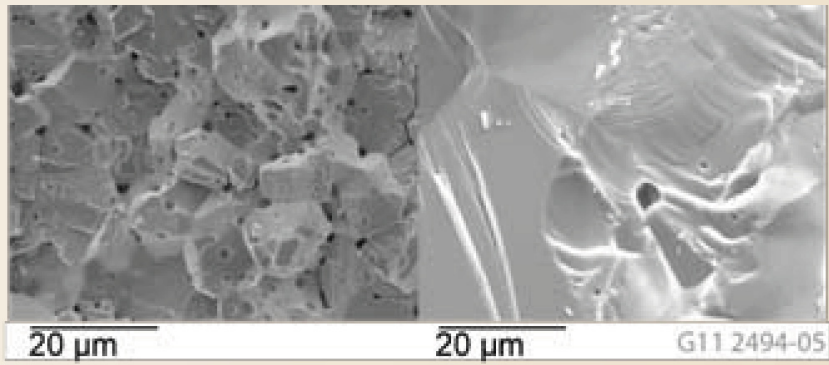

Figure 2. The nonirradiated MgO SEM image (left) shows intergranular fractures through pores on the grain boundaries. The irradiated MgO SEM image (right) shows transgranular fracture, which can be attributed to the irradiation, which caused the grains to become more brittle than the grain boundaries.

Completing the post-irradiation examinations of $\mathrm{MgO}$ and $\mathrm{MgAl}_{2} \mathrm{O}_{4}$ in capsules $\mathrm{C} 1$ and $\mathrm{C} 2$ will enable researchers to compare the effects of irradiation dose and temperature on the materials' properties.

\section{Footnotes}

(1) P. G. Medvedev, S. M. Frank, T. P. O'Holleran and M. $\mathrm{K}$. Meyer. "Dual-phase $\mathrm{MgO}-\mathrm{ZrO} 2$ ceramics for use in LWR inert-matrix fuel," Journal of Nuclear Materials, Vol. 342, pp. 48-62. (2005).

(2) J. C. Nino, NERI final technical report DE-FC07O5ID14647, "Optimization of oxide compounds for advanced inert matrix materials," Report No. DOE/ ID/14647-Final (2009).

\begin{tabular}{|l|l|}
\hline \multicolumn{2}{|l|}{ Distributed Partnership at a Glance } \\
\hline ATR NSUF and Partners $\quad$ Facilities \& Capabilities \\
\hline INL & Advanced Test Reactor, PIE facilities \\
\hline Team Members/Collaborators \\
\hline - $\quad$ University of Florida - Juan Nino (principal investigator); Donald \\
Moore (graduate student) \\
- INL - Pavel Medvedev (co-principal investigator); \\
Gregg Wachs (project engineer); Collin Knight (project manager) \\
Collaborators: Mitchell Meyer, Robert Hergesheimer, \\
Paul Murray, Joseph Nielsen, James Parry
\end{tabular}

G11-2494-04b 


\section{Introduction}

One of the great challenges in developing advanced sources of nuclear energy is predicting the structural integrity of the materials used in key components. Creating a large library of irradiated advanced fission and model materials will go a long way toward addressing a number of scientific questions and engineering issues regarding the degradation of the materials' microstructures and mechanical properties caused by irradiation.

Micro-hardness measurements on a large set of alloys will enable the creation of an unprecedented database on the hardening and softening effects of irradiation. Testing many samples after side-by-side irradiations provides a unique opportunity to develop models on these effects to aid future studies.

Creating an unprecedented database on the hardening and softening effects of irradiation.

\section{Project Description}

The University of California, Santa Barbara (UCSB) and the INL collaborated on a recently completed, side-byside, alloy irradiation experiment which tested a total of 44 structural and model alloys including:

- Tempered martensitic steels

- Nanostructured ferritic alloys

- Stainless steel

- Mn-Mo-Ni bainitic pressure vessel steels

- Simple model alloys .

The database created from the materials tested will provide a unique understanding of the effects of using metallurgical variables on the properties of the materials used in the study. The majority of the 1,380 specimens used were disc multi-purpose coupons, however, irradiated samples also include:

- Sub-sized tensile specimens

- Disc compact tension fracture

- Deformation and fracture mini-beam

- Chevron notch wedge fracture

- Cylindrical compression specimens.

The alloy samples were loaded into 11 specially designed capsules and irradiated at temperatures ranging from $300^{\circ} \mathrm{C}$ to $750^{\circ} \mathrm{C}$ up to a range of 1.5 to 6 displacements per atom (dpa). The unique design of the capsules features axial insulating sections that force radial heat transfer through a single interface regulated by a gas gap. Varying the thickness of the gas gap between the sample packets and the cooled capsule wall effectively maintains the precision isothermal temperatures (Figure 1).

Micro-hardness measurements will be the primary method used to assess strength changes. Fracture studies will also be carried out on a subset of materials, including compact tension (CT) tests measuring shifts in the reference temperatures. The CT tests are further supplemented by mini-bend bar tests on other alloys.

In addition to the mechanical property tests, studies were conducted on the micro-structural character of the irradiated alloys using a large suite of state-of-the-art tools. In-situ helium implantation studies are also included in the experiment, along with diffusion multiples that offer the very exciting aspect of a "lab on a chip" characterization by providing a unique look at both thermo-kinetic parameters and phase fields in a combination of materials under irradiation.

\section{Accomplishments}

Between January and June of 2009, UCSB scientists prepared documents, collected materials, and fabricated and assembled capsule parts and specimen packets. The packets were shipped to INL, along with detailed documentation, in July and the irradiation began in August 2009. One irradiated capsule was opened in March 2010, and the samples were recovered and identified (Figure 2), and PIE preparations began.

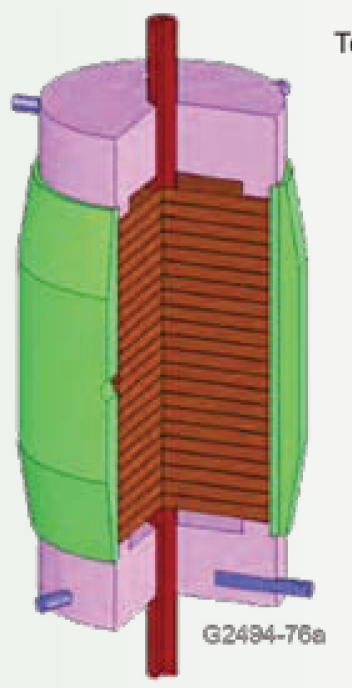

Temperature scale is $270^{\circ} \mathrm{C}-303^{\circ} \mathrm{C}$

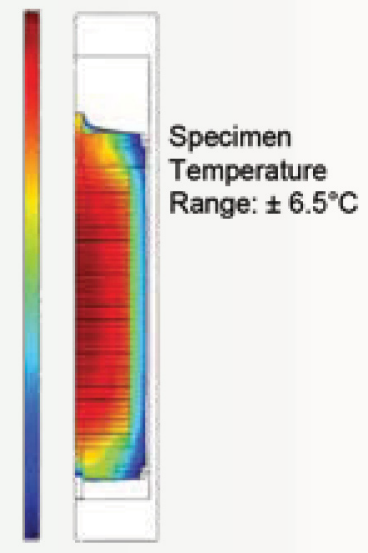

Figure 1. An example of a $300^{\circ} \mathrm{C}$ isothermal temperature packet. 


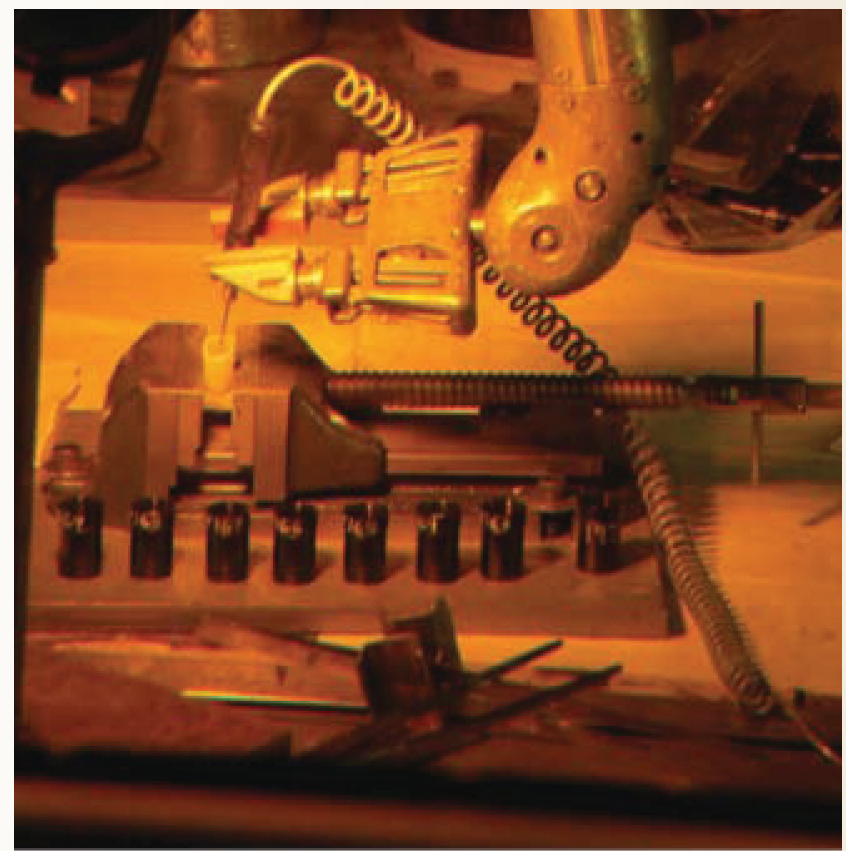

Figure 2. The vacuum removal tool in HFEF removing specimen discs from an irradiation capsule.

\section{Future Activities}

In late 2010, a team of research engineers from Boise State University (BSU) will visit UCSB to discuss construction of new facilities for evaluating activated materials. The facilities would be added to the existing laboratories at the Center for Advanced Energy Studies (CAES) in Idaho Falls. CAES is a research and education partnership between INL, BSU, ISU and the University of Idaho which makes a variety of laboratories available to researchers across the country.
This project offers the very exciting aspect of a "lab on a chip" characterization.

Activities planned in 2011 include a team from UCSB visiting the CAES microscopy facility, and attendance at The Minerals, Metals \& Materials Society's (TMS) annual meeting in San Diego to discuss the UCSB experiment and solicit interest in additional collaborations for PIE studies.

Actual PIE is anticipated to begin in the summer of 2011, much of which would be conducted at INL and the proposed new CAES facility. Plans call for preparing more micro-machined specimens with the FIB and distributing them for testing at UCSB and a number of other universities and research institutions around the world.

\section{Distributed Partnership at a Glance}

\begin{tabular}{|c|c|}
\hline ATR NSUF and Partners & Facilities \& Capabilities \\
\hline $\mathrm{INL}$ & PIE facilities \\
\hline \multicolumn{2}{|c|}{ Team Members/Collaborators } \\
\hline \multicolumn{2}{|c|}{$\begin{array}{l}\text { - University of California, Santa Barbara - G. R. Odette (principa } \\
\text { investigator); David Gragg, Doug Klingensmith, Ben Sams, } \\
\text { Takuya Yamamoto (co-principal investigators) } \\
\text { - INL - Jim Cole (co-principal investigator); Paul Murray, } \\
\text { Gregg Wachs, Tony Walters (project engineers) } \\
\text { - Los Alamos National Laboratory - S. Maloy (collaborator) } \\
\text { - Oak Ridge National Laboratory - R. Nanstad (collaborator) } \\
\text { - Pacific Northwest National Laboratory - R. Kurtz, M. Toloczko } \\
\text { - } \quad \text { (collaborators) } \\
\text { - University of California, Berkeley - B. D. Wirth (collaborator) }\end{array}$} \\
\hline
\end{tabular}

G11-2494-40a 

(ATR) Irradiation Facility for Light Water Reactor Vessel Life Extension

\section{Introduction}

Our nation's energy stability depends on the safe operation of our current fleet of pressurized light water reactors. Making sure they can operate safely at extended lifetimes of up to 80 years will require a greater understanding of the long-term effects of radiation on reactor pressure vessel steels.

We already know that neutron flux and fluence have very complex effects on transition temperature shifts (TTS) in these materials, which is known as irradiation embrittlement.

\section{This project will fill a major gap in the} existing database.

There is currently no data on low flux TTS at the high fluence levels needed for life extension. Flux is the rate of neutron impingement on a material and fluence is the corresponding total number of neutrons experienced over time. TTS are caused by irradiation hardening that can be monitored by micro-hardness and tensile tests. Most notably, current embrittlement models systematically and significantly under predict TTS in the existing high fluxfluence database. However, this may be an artifact of high flux irradiations that are greatly accelerated compared to actual pressure vessel conditions. To resolve these issues, a test rig for carrying out neutron irradiation experiments is currently under construction. The database to be generated from these experiments will greatly enhance understanding of the effects of irradiation on the properties of reactor pressure vessel steels, and will lead directly to more accurate predictions of TTS in these materials for realistic low flux, high fluence conditions.

\section{Project Description}

The objectives of this project are to:

- Develop a new ATR test rig for intermediate flux irradiations of pressure vessel steels

- Examine the irradiation effects on 1,675 samples of 186 different reactor pressure vessel steels and model alloys to increase our knowledge regarding the effects of composition, flux, fluence and temperature on embrittlement.

This project will fill a major gap in the existing database on reactor pressure vessel TTS. High fluence data at an intermediate flux will then be linked with other data on many of the same alloys that was generated over a much wider range of conditions to resolve flux effects and a number of other important embrittlement issues. The combined databases will then be used to refine and validate advanced TTS models.

The project will focus on:

- Assessing flux effects at high fluence, including the use of post-irradiation annealing, to evaluate the contributions of various hardening features as a function of flux, as well as other embrittlement variables

- Identifying conditions leading to the formation of "late-blooming" phases in irradiated alloys that could lead to severe embrittlement currently unaccounted for in regulations

- Conducting extensive microstructural characterization and mechanism studies on the irradiated materials

- Conducting extensive post-irradiation annealing recovery experiments as a potential strategy for embrittlement mitigation

- Irradiating a number of new reactor pressure vessel alloys, including candidates for use in advanced reactors

- Evaluating the master curve method for measuring fracture toughness at high fluence in sensitive alloys

- Addressing the surrogacy issue associated with alloy conditions in the actual vessel, which typically differ from nominally limiting steels for particular reactor vessels.

\section{Accomplishments}

Reactor pressure vessel irradiation will provide flux-fluence bridging in a variety of sample types (Figure 1).

Comparison of Measured and Calculated Temperatures

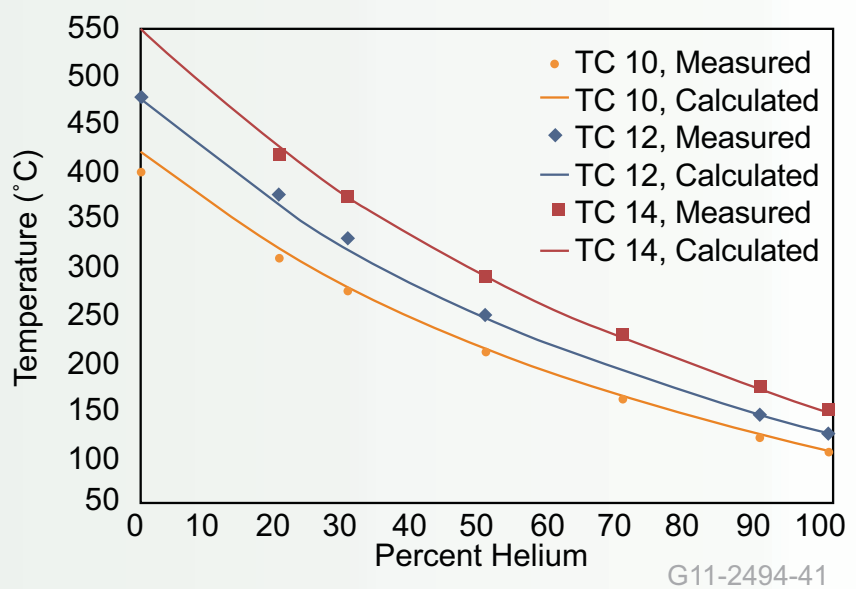

Figure 1. Measured vs. calculated temperatures using a variable He/Argon gas mixture for control. 
"When coupled with the IVAR and other databases, the UCSB ATR-2 experiment is by far the largest and most comprehensive study of irradiation effects on structural alloys that addresses critical engineering issues ever carried out in the world. This research will lead to new models of embrittlement that will provide a rigorous and objective basis to assess safety margins for extended reactor pressure vessel life."

G. R. Odette, Ph.D. Professor, Mechanical Engineering and Materials, University of California, Santa Barbara.

The list includes 186 different materials in a total of 819 alloy/irradiation condition combinations. Most are steels previously irradiated over a wide flux range. For example, the experiment includes reactor pressure vessel alloys irradiated in the UCSB Irradiation Variable Facility at the University of Michigan's (UM) Ford Reactor. Materials used in this project also include surveillance alloys, as well as a large set of about 60 new alloys with a wider range of composition than is represented in the current database.

The specimens include:

- Disc multipurpose coupons

- Disc compact tension fracture specimens

- Diffusion multiple specimens

- Subsized tensile specimens.

A team of INL design engineers visited UCSB during FY 2010 to review and finalize details for an experimental test rig. In order to fully understand and effectively control the thermal characteristics of the facility, a mock-up was fabricated and tested at INL. The final design encompasses six discreet flux/temperature zones. Each is highly instrumented and uses profiled gaps containing a mixture of helium and neon gases to account for axial variations in heating. A gadolinium thermal neutron shield sleeve was used to minimize sample activation, which will vastly increase the possibilities for post-irradiation testing.

\begin{tabular}{|l|l|}
\hline \multicolumn{2}{|l|}{ Distributed Partnership at a Glance } \\
\hline ATR NSUF and Partners $\quad$ Facilities \& Capabilities \\
\hline INL & Advanced Test Reactor, PIE facilities \\
\hline \multicolumn{2}{|l|}{ Team Members/Collaborators } \\
\hline - UCSB - G. R. Odette (principal investigator) \\
- INL - M. Meyer (co-principal investigator) \\
- ORNL - R. Nanstad \\
- Rettis Atomic Power Laboratory - M. G. Burke \\
- Japls Royce Marine - T. Williams \\
- Industry - N. Soneda \\
\hline
\end{tabular}

\section{Future Activities}

The massive task of fabricating and documenting the matrix of more than 1,600 specimens and loading them into thin-walled holder cups is expected to be complete by March 2011. Materials were provided by UCSB, ORNL, Rolls Royce Marine, Bettis Atomic Power Laboratory and the Japanese Central Research Institute of Electric Power Industry in Japan. In addition, a number of surveillance steels from the actual reactor pressure vessel have been provided by the U.S. nuclear industry.

INL engineers will complete the test rig in May 2011, with a tentative date of May for insertion into the ATR reactor. 


\section{Synchrotron X-Ray Diffraction Measurements of Spatially Resolved Strain Fields in Nuclear Fuel Plates}

\section{Introduction}

Throughout the world, nuclear reactors that use highly enriched uranium fuel are gradually being converted to reactors that utilize low enriched uranium (LEU) fuel for non-proliferation purposes. The development of these advanced LEU fuels is one of the missions of the Reduced Enrichment for Research and Test Reactors (RERTR) program. In the case of high performance research reactors, such as the ATR at INL or the High Flux Isotope Reactor at Oak Ridge National Laboratory, nuclear fuels with a high fission density are necessary.

The fuel under development for these applications is a monolithic fuel consisting of a uranium-10wt. $\%$ molybdenum (U10Mo) alloy foil encased in 6061-aluminum (Al) alloy cladding. The technique currently used to fabricate such a plate is hot isostatic pressing (HIPing). During the fabrication process residual stresses are introduced to the plates. Because the thermal expansion of U10Mo is roughly half that of the Al cladding, a significant residual stress is anticipated after cooling from the HIPing temperature. These stresses may affect the performance of a fuel plate during irradiation. It is therefore of interest to quantify the residual stresses present in the monolithic fuel after HIPing.

\section{Project Description}

The objective of this study was to utilize synchrotron X-ray diffraction (XRD) to quantify the spatially resolved residual stresses in the monolithic mini fuel plates that result from HIPing. Two of the benefits of using synchrotron XRD are: (1) it is a non-destructive technique for measuring residual stresses, as opposed to a mechanical method such as hole drilling or sectioning, and (2) a high degree of spatial resolution can be achieved. A range of process parameters were evaluated, including varying HIP cooling times, as well as U10Mo foil annealing treatments.

The specimens that were analyzed included depleted U10Mo clad foils (mini fuel plates, $\sim 150 \mathrm{~mm} \mathrm{x} \sim 50 \mathrm{~mm}$ $\mathrm{x} \sim 1.5 \mathrm{~mm}$ ) which were cooled at slow and fast rates at the end of the HIPing procedure. Bare depleted U10Mo foils that served as controls were also examined.

This project was a collaboration of INL, LANL, IIT and ANL. The bare depleted U10Mo foils and HIPed depleted U10Mo clad foils were fabricated at INL and then shipped to ANL for examination. The specimens were encapsulated and placed in requisite sample contain- ers prior to shipment to ANL since they contained radioactive materials. The synchrotron XRD measurements were performed at the Advanced Photon Source at the Materials Research Collaborative Access Team (MRCAT), beamline 10-ID (Figure 1) at ANL. This experiment allowed the team to develop new capabilities (e.g. larger spatial scanning area) at beamline 10-ID. It was also the first experiment of its kind since synchrotron XRD measurements have never before been performed on monolithic mini fuel plates.

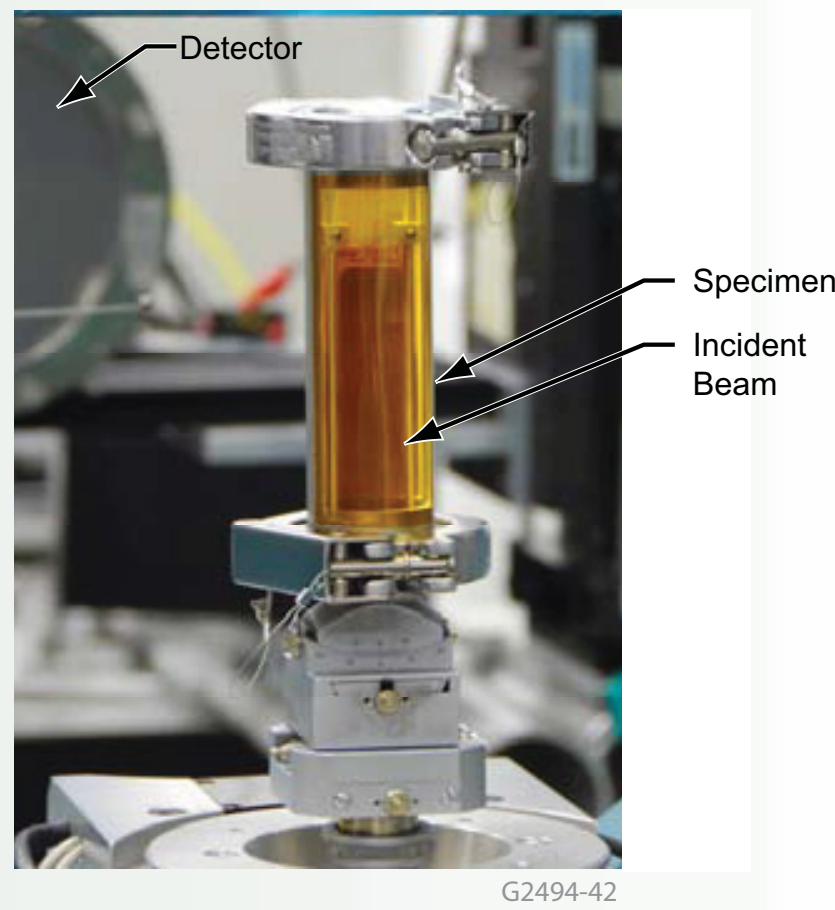

Figure 1. Bare depleted U10Mo foil mounted at beamline 10-ID

\section{Accomplishments}

The diffraction measurements were conducted in transmission geometry with $\sim 90 \mathrm{keV}$ X-rays. A typical Debye ring pattern and the resultant diffraction pattern are shown in Figure 2 for a depleted U10Mo clad foil. The patterns were collected at five sample orientations with respect to the incident beam to allow for the determination of the full stress tensor as a function of position in the sample. Two samples, fast HIP cooled and slow HIP cooled, were examined. During the course of the experiment, a number of line traces in increments of $0.5 \mathrm{~mm}$ were measured along the horizontal and vertical mid-planes of the specimens. 


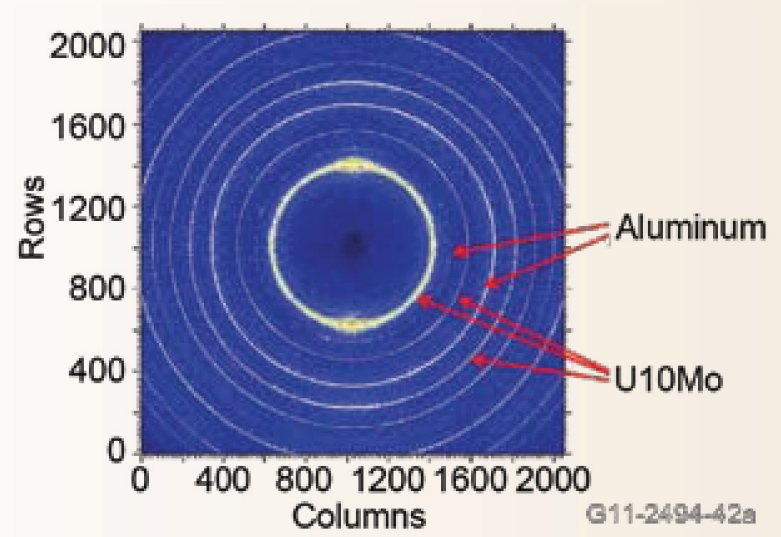

Figure 2. Typical diffraction results illustrating the Debye rings (left) and a corresponding diffraction pattern (right)

The beamline 10-ID results led the researchers to pursue the project in additional detail. It was determined that a higher intensity beam would be required to obtain the spatial resolution of the plate in a timely manner. A subsequent experiment was proposed and awarded in late 2010 on another beamline (1-ID) at the APS.

The experiments at beamline 1-ID were conducted using a spatial resolution of $0.1 \mathrm{~mm}$. One full quadrant of the mini fuel plate was measured (Figure 3). The data was obtained using an area detector to measure the entire Debye rings for multiple U10Mo (body centered cubic) peaks, which were "caked" into 24 diffraction patterns. The measurements were obtained with the specimen normal to the beam, as well as at $45 \mathrm{o}$ and $60 \mathrm{o}$ about the vertical axis to determine the full strain, as well as the stress tensor. Inplane compressive stresses of greater than $150 \mathrm{MPa}$ were observed in the U10Mo mini fuel plate (Figure 3).

\section{Distributed Partnership at a Glance}

\section{ATR NSUF and Partners}

Illinois Institute of Technology

\section{Facilities \& Capabilities}

MRCAT at Advanced Photon

Source, Argonne National Laboratory

Team Members/Collaborators

- Idaho National Laboratory - Maria Okuniewski (principal investigator); Barry Rabin, Blair Park, Steve Steffler, Mike Chapple, Glenn Moore (collaborators)

- Illinois Institute of Technology - Jeff Terry (co-principal investigator); Dan Olive, Yulia Trenikhina, Hasitha Ganegoda (Ph.D. candidates)

- Los Alamos National Laboratory - Don Brown (co-principal investigator); Levente Balogh (post-doctoral researcher)

- Argonne National Laboratory - John Okasinski (collaborator)

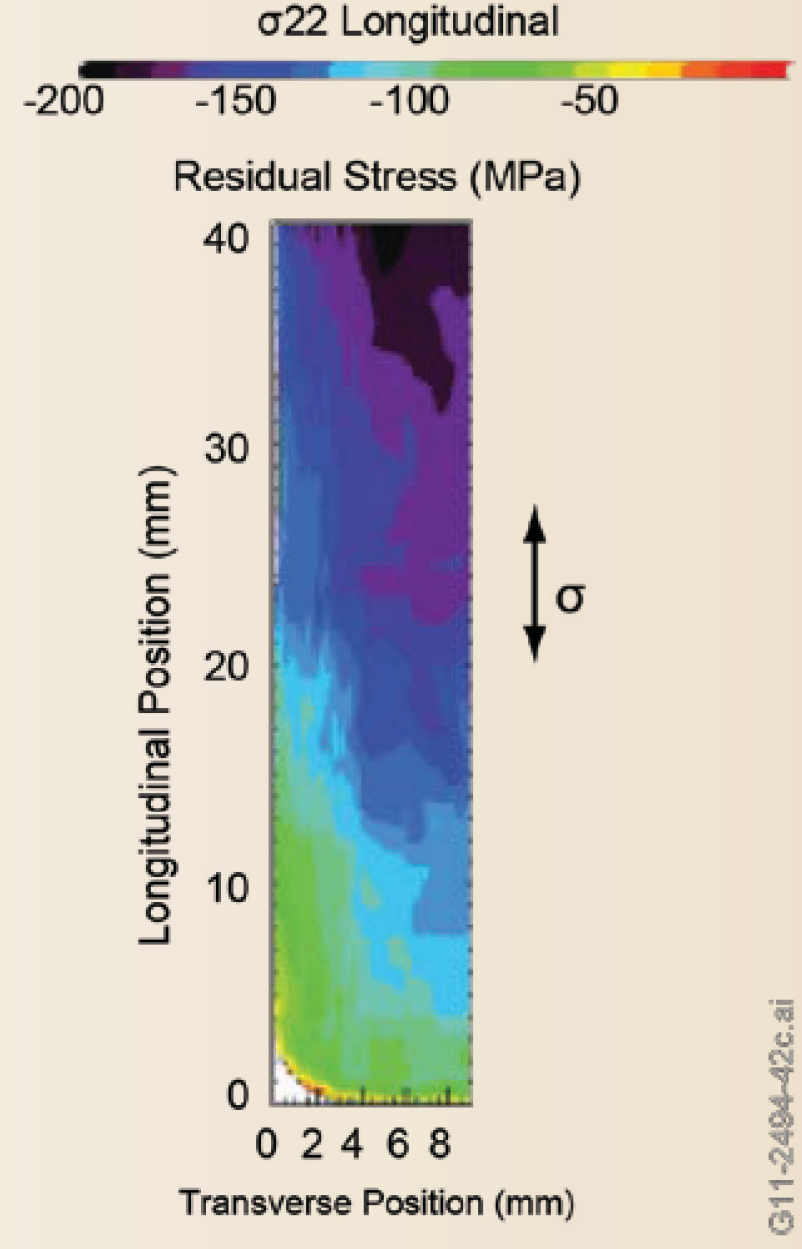

Figure 3. Longitudinal residual stress ( 22 ) in depleted U10Mo mini fuel plate.

\section{Future Activities}

Measurements to examine additional mini fuel plates on beamline 1-ID are planned at APS in spring 2011. A finite element analysis code has also been developed to determine the residual stresses in the fuel plates following various processing conditions. Results from the synchrotron XRD measurements will be utilized to validate this model. Once validated, this model could be used to optimize the processing conditions. 


\section{Introduction}

Incorporating hydride fuel elements into the current fleet of light water reactors (LWR) offers a number of improvements. The addition of hydrogen neutron moderation within the fuel, along with the thermally-induced hydrogen up-scattering that accompanies Doppler Feedback, can improve safety and eliminate plutonium more efficiently than with a mixed oxide fuel (MOX).

Incorporating hydride fuel elements into the current fleet of light water reactors offers a number of improvements.

\section{Project Description}

The objectives of this research are to study the materials associated with the use of a hydride fuel for power production in LWRs, and to explore the use of a liquid metal (LM) as a replacement for helium in hydride fuel elements. The feasibility and benefits of this process have been previously investigated using neutronic and thermal hydraulic calculations, and laboratory scale materials experiments. ${ }^{1}$ Recognizing the necessity to shift from the laboratory to more relevant environments, an irradiation experiment is underway to evaluate the feasibility of the LWR hydride fuel concept.

This experiment is supported by the DOE's ATR NSUF program at the INL. An irradiation spot has been designated in the MITR for fuel irradiation, with PIE scheduled to be conducted at INL's Materials and Fuels Complex.

\section{Accomplishments}

Five mini-fuel rod assemblies have been fabricated at the University of California, Berkeley, Department of Nuclear Engineering, for irradiation in the MITR. Four were configured with LM and one with a helium-filled gap to act as a control. Each of the four LM-bonded fuel elements consists of a $75 \mathrm{~mm}$-long cladding of Zircaloy-2 tubing capped at the bottom with a zirconium plug and at the top with a zirconium Conflat mini-flange (Figures $1 \& 2$ ). The cladding has been loaded with five $\mathrm{U}_{0.17} \mathrm{ZrH}_{1.6}$ pellets approximately $1 \mathrm{~cm}$ in height, with $19.7 \% \mathrm{U}^{235}$ enrichment. The pellets were extracted from a Training, Research, Isotopes, General Atomics (TRIGA) fuel element provided by INL, courtesy of the Reduced Enrichment for Research and Test Reactors (RERTR) program. They were prepared by core drilling to the approximate size and then by centerless grinding to achieve high tolerance on the desired diameters.
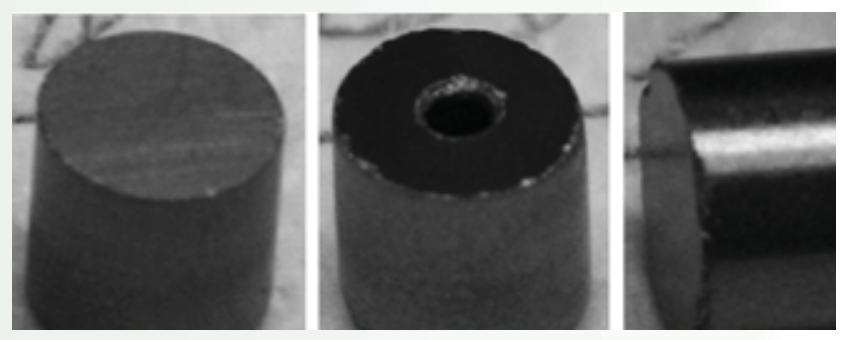

Figure 1. Fuel pellets prior to insertion in cladding. Some of the pellets have centerline holes to accommodate a thermocouple.

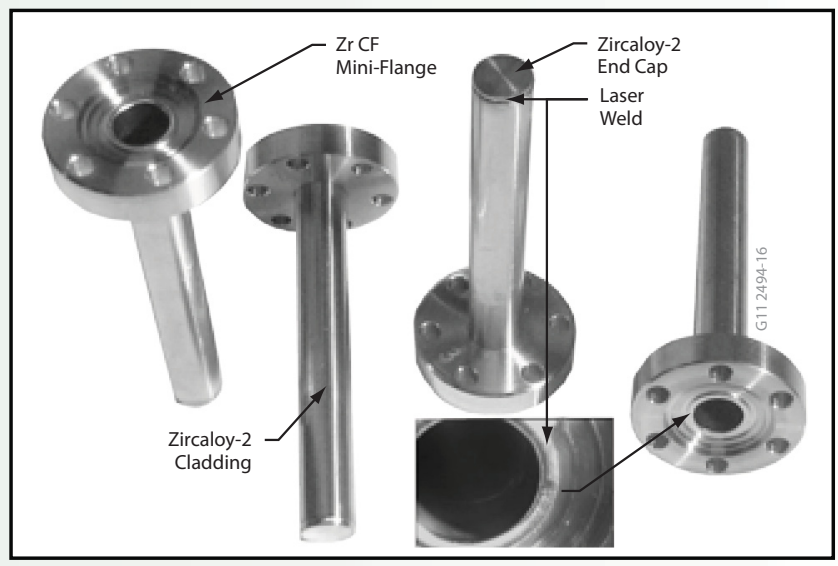

Figure 2. Fuel pellets inserted into Zircaloy-2 rods that are capped off on one end and welded to a zirconium flange.

Alumina spacers were placed on the top and bottom of the hydride pellet stacks. The pellet-to-pellet interfaces, as well as the pellet-to-cladding gaps, were filled with eutectic lead-bismuth alloy (Bi- $44 \mathrm{wt} \% \mathrm{~Pb})$. On four of the fuel rods a K-type thermocouple was inserted in the centerline of the middle fuel pellet. A second thermocouple was clamped against the cladding outer diameter (OD) by spot welding a zirconium sheet to the cladding. One fuel element was equipped with a developmental INL thermal conductivity probe, which will utilize hot wire transient dynamic techniques to record simultaneous temperature and conductivity measurements.

The Monte Carlo N-particle (MCNP) transport code has been used to calculate the volumetric heat-generation rate in the fuel. A simulated column of irradiation capsules was placed in a designated position, and the input code for the MCNP calculation captured the entire MITR core. The details of the mini-fuel rod components and capsule design were accounted for in the input code and a set of coupled conduction, heat-transfer and thermal-hydraulic calculations determined the temperature drop from the fuel to the coolant flowing in the channel. 
'The Hydride Fuel Irradiation experiment led by UC Berkeley and designed in collaboration with MITR staff is currently undergoing irradiation without any major challenges. The ATR NSUF program, in addition to supporting the entire effort, has played a critical role in establishing the synergies between UCB and MIT'

Mehdi Balooch. Ph.D., Research Scientist, University of California, Berkeley

The irradiation capsule was designed and constructed by the MIT group to perform the following functions:

- Act as a fission product release barrier in the event of a mini-fuel rod failure

- Control the thermal resistances in the heat flux path from the fuel to the coolant so that the desired fuel temperature can be reached

- Provide the means for the instrumentation wires to reach outside the reactor core

- Enable gas sampling at the plenum region of the capsule above the mini-fuel rod in order to detect fuel failure.

Titanium was chosen as the capsule material due to its good corrosion properties, ease of machining and welding, and reliable operational experience in the MITR. A set of iterative calculations were required to refine the capsule geometry (Figure 3). The fuel-centerline and cladding OD temperatures of each capsule will be monitored by the thermocouples throughout the irradiation. MIT's Reactor Safeguards Committee approved a maximum fuel-centerline temperature of $650^{\circ} \mathrm{C}$. Since the cladding OD temperature is to be kept below $450^{\circ} \mathrm{C}$, reactor power is adjusted to keep the central capsule within these limits.

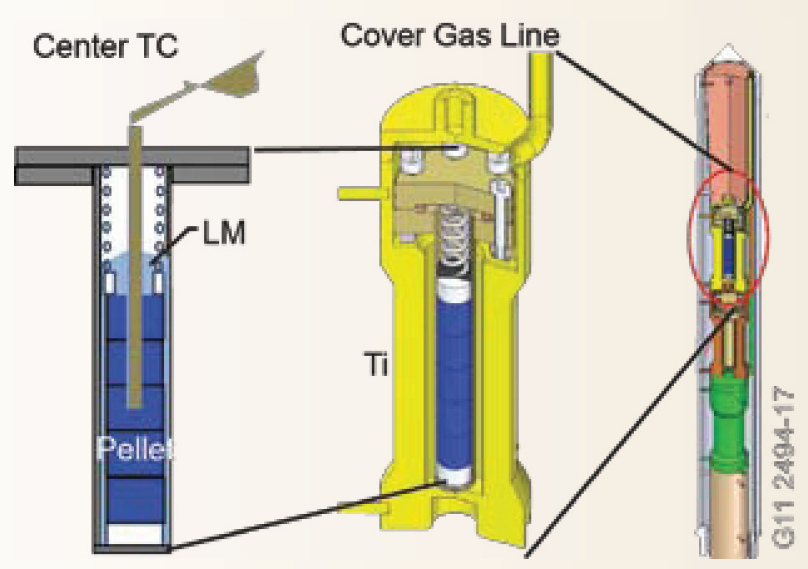

Figure 3. Schematic of mini-fuel element, titanium capsule and an assembly for holding three fuel elements

\section{Future Activities}

Two of the hydride mini-fuel rods and one dummy, mounted in irradiation capsules, are scheduled to be inserted into the MITR in March 2011. Every four months, one of the three will be withdrawn, placed in the MIT fuel-storage pool for cooling and replaced by an unirradiated assembly. The last min-fuel rod will be removed from the core after approximately one year, providing a snapshot of fuel conditions and behavior at three different burnups.
This project will also explore the use of a liquid metal (LM) as a replacement for hellum in the gap for hydride fuel elements.

After cooling, the rods will be shipped to the MFC at INL for PIE. This is expected to take place in FY 2012. The extent of fission gas release from the fuel through the LM gap filler will be examined, as will the redistribution of hydrogen in the fuel and the condition of the Zircaloy cladding. The fuel swelling mechanism will be investigated to determine whether it is due to solid fission products, fission gas bubbles or other defects. The possibility of gas bubble formation in the LM bond will also be checked, as it would compromise the high thermal conductivity of the gap. PIE will also involve characterization techniques previously demonstrated on as-fabricated hydride fuels. Transmission and scanning electron microscopy, $\mathrm{x}$-ray diffraction and mass spectrometry, among other techniques, will be utilized as well.

\section{Footnotes}

(1) Full issue, "Hydride Fueled LWRs," Nuclear Engineering and Design, Vol. 239 (2009), pp.1373-1570.

\section{Publications}

(1) K. A. Terrani, M. Balooch, W. Siekhaus, D. R. Olander, "LWR Hydride Fuel Rod Irradiation," Proceedings of 2010 LWR Fuel Performance/Top Ful/WRFPM, Orlando, Florida, September 26-29, 2010, paper \#86.

\begin{tabular}{|l|l|}
\hline \multicolumn{2}{|l|}{ Distributed Partnership at a Glance } \\
\hline ATR NSUF and Partners $\quad$ Facilities \& Capabilities \\
\hline $\begin{array}{l}\text { MIT } \\
\text { INL }\end{array}$ & $\begin{array}{l}\text { Reactor, neutron radiography } \\
\text { PIE facilities }\end{array}$ \\
\hline Team Members/Collaborators \\
\hline - & $\begin{array}{l}\text { UCB - Donald Olander and Mehdi Balooch (principal } \\
\text { investigators) }\end{array}$ \\
- $\begin{array}{l}\text { MIT - Sung joong Kim, Tom Newton, Gordon Kohse, Lin-wen Hu } \\
\text { (collaborators); David Carpenter, (post-doctoral student) }\end{array}$ \\
- $\begin{array}{l}\text { INL - Mitchell Meyer (co-principal investigator); Joy Rempe } \\
\text { (collaborator) }\end{array}$ \\
- $\quad$ ORNL - Kurt Terrani, (collaborator) \\
\hline
\end{tabular}

G11-2494-17a 


\section{Introduction}

The next generation of nuclear reactors will operate at much higher temperatures, therefore increasingly heat resistant materials will need to be used in building the reactor cores. There is also a need for nondestructive, in-situ tools to assess accumulated radiation damage in potential structural materials. Using electronic and elastic (ultrasonic) sensors in combination with a knowledge base of structurally damaged materials, it is possible to establish a calibrated sensor for a given reactor core material.

\section{Project Description}

This research began with four primary objectives:

- To establish a sufficient relationship between radiation damage and aging

- To monitor and record structural damage to the Silicon Carbide ( $\mathrm{SiC})$

- To distinguish between slow and fast neutron effects using $\mathrm{SiC}$ samples coated with cadmium

- To develop these correlations into analytical practices.

Now in its second year of collaborating with INL and ATR NSUF partner MITR, the Colorado School of Mines (CSM) project team is focusing on the possibility of using silicon carbide $(\mathrm{SiC})$ containing ceramic sensor materials to monitor radiation damage.

Neutron transmutation doping (NTD) offers the nuclear power industry a method to more easily evaluate radiation damage to nuclear core components. The process, in which high purity silicon is irradiated with a thermal neutron flux, causes a reaction that produces a phosphorousdoped semiconductor in which the atoms are capable of providing extra conduction electrons to the host material. This allows for electronic measurements of in-situ aging in reactor core materials that not only indicates the neutron fluence, but also its effective damage to the materials.

\section{Accomplishments}

The use of contact property measurement probes, thermoelectric power sensors and high-frequency impedance measurements show both electronic and structural property changes in $\mathrm{SiC}$ resulting from irradiation (Figure 1). Hall coefficient measurements recorded an increase in the carrier density in samples subjected to increasing radiation levels (Figure 2), and gamma spectroscopy revealed higher levels of ${ }^{60} \mathrm{Co}$ isotopes. A sharp decrease in the amplitude of resonance modes was noted with increased fluence levels (Figure 3), indicating microstructural damage to the lattice structure during irradiation. This supports the increase in electronic impedance despite the increase

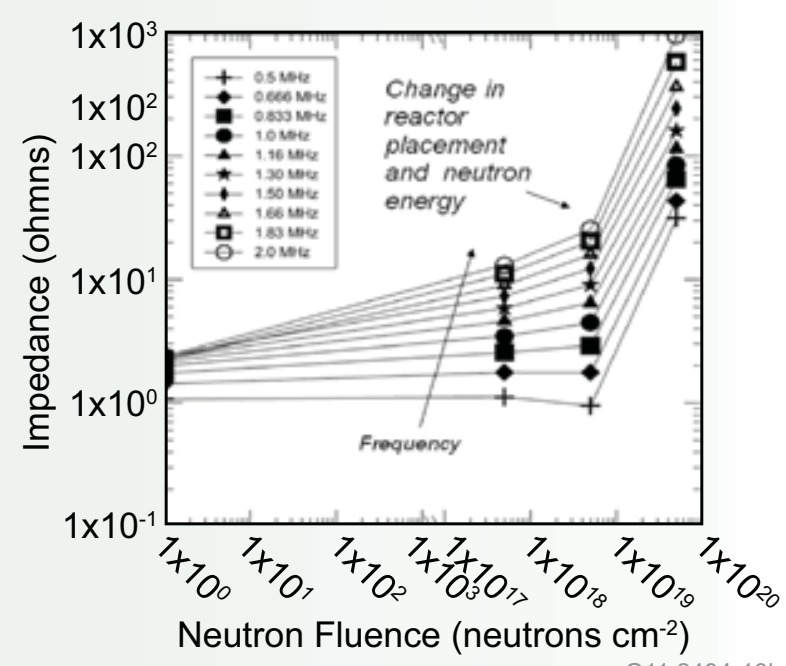

G11 2494-18b

Figure 1: Impedance Results from Silicon Carbide Samples Subjected to Varying Levels of Neutron Fluence.

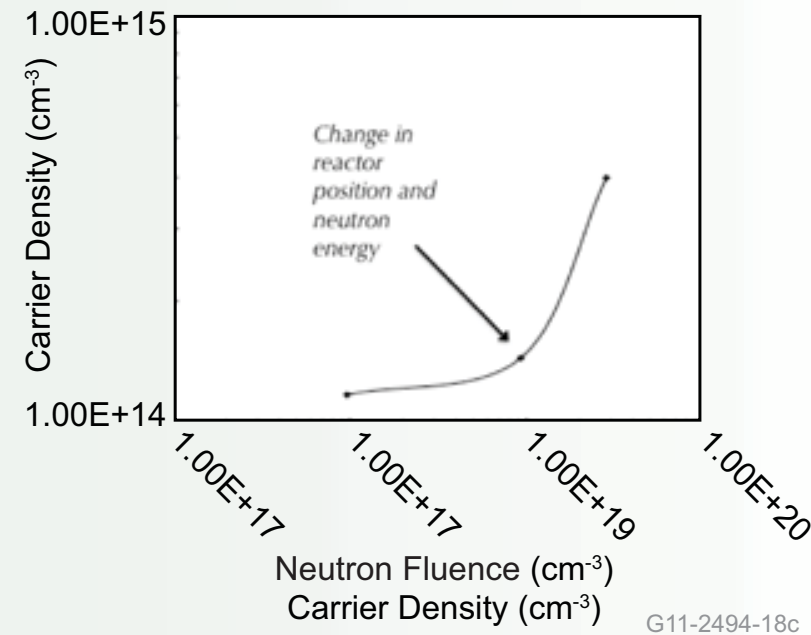

Figure 2: Carrier Density Results as Measured Using Hall Effect from Silicon Carbide Samples Subjected to Varying Levels of Neutron Fluence.

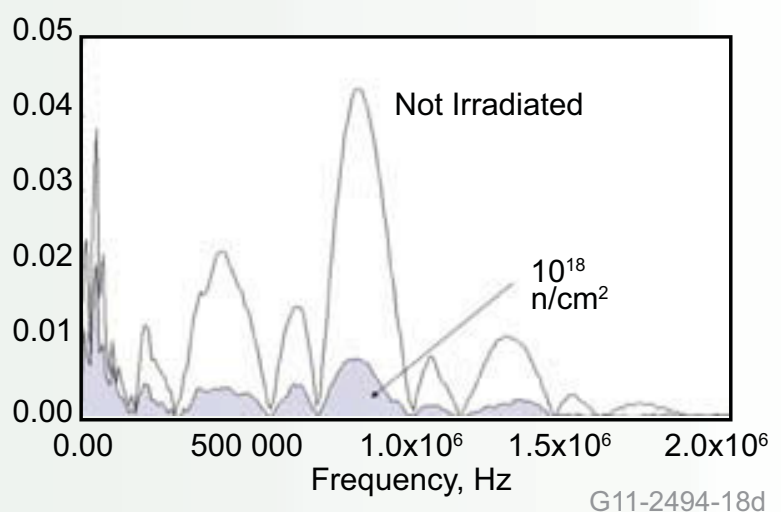

Figure 3: Ultrasonic Resonance Amplitude Results from Silicon Carbide Samples Subjected to Varying Levels of Neutron Fluence. 
in carrier content. Preliminary results also show an excellent correlation between these types of tests and radiation damage in silicon carbide.

MIT's reactor group has become a crucial partner in this preliminary investigation by providing the semiconductorgrade silicon carbide. CSM is currently collaborating with INL and MIT in conducting electronic backscatter diffraction to further monitor the lattice structure damage that occurs during irradiation. It is also apparent that impedance measurements show better correlation with neutron fluence levels at higher frequencies. Initial tests show a great deal of promise, indicating further research and development of the $\mathrm{SiC}$ concept will produce a successful in-situ damage sensor tool (Figure 4).

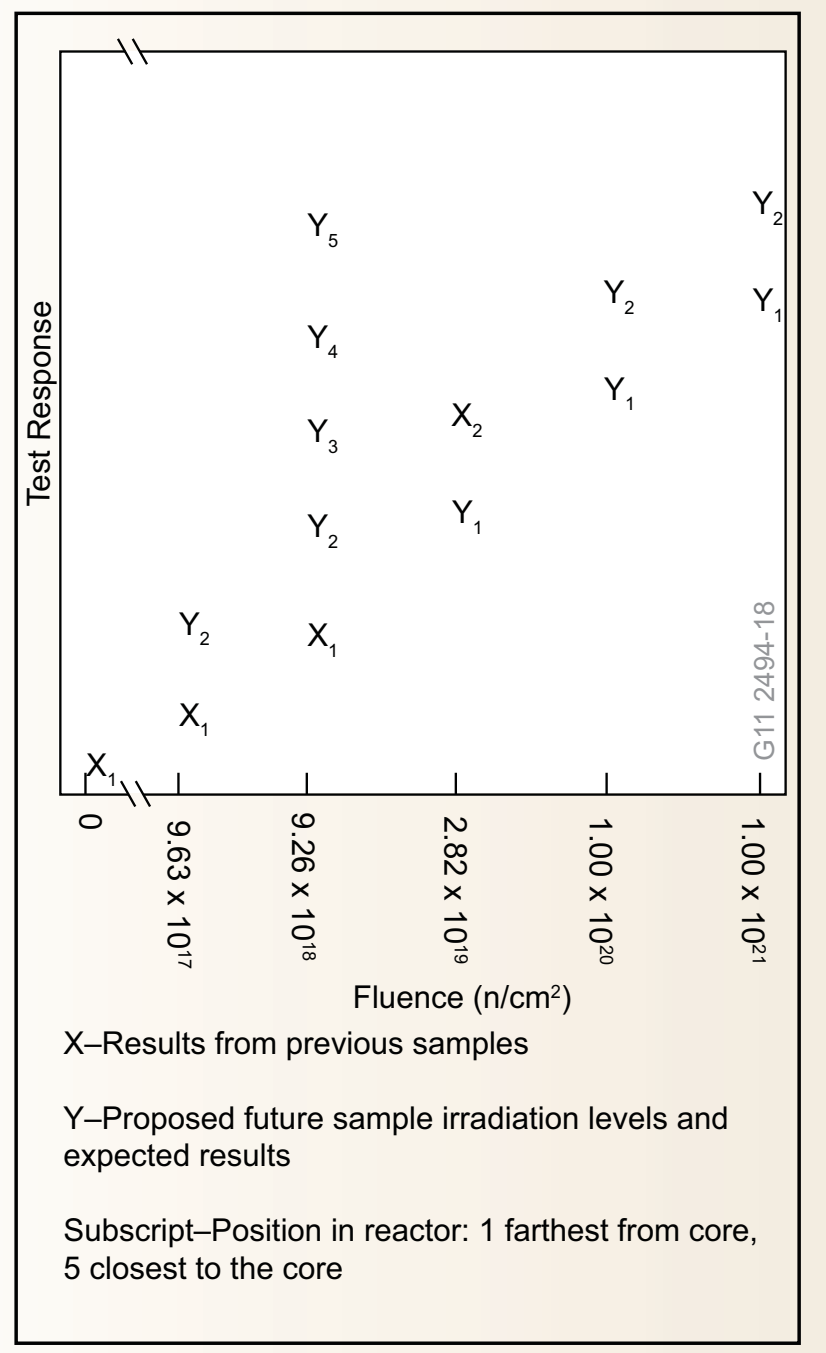

Figure 4. Proposed test matrix for future $\mathrm{SiC}$ samples to be irradiated and expected test responses.

\section{Initial tests show a great deal of prom- ise in silicon carbide as a successful damage sensor tool.}

\section{Future Activities}

The project team intends to work closely with the advanced sensor group at INL, while continuing to build its connections with MIT to assure that the laser ultrasonic probe for this tool will be compatible and consistent with other tools currently being developed. Further investigation into the nature and effects of the microstructural damage is needed. After the microstructures of the irradiated samples have been fully assessed, the same samples will be heated to relieve internal stress and cooled slowly, then re-examined to determine the effects of that process on the crystal structure.

\section{Publications}

T. W. Koenig, D. L. Olson, B. Mishra, J. C. King, J. Fletcher, L. Gerstenberger, S. Lawerence, A. Martin, C. Mejia, M. K. Meyere, R. Kennedy, L. Hu, G. Kohse, and J. Terry, "Advanced Non-Destructive Assessment Technology to Determine the Aging of Silicon Containing Materials for Generation IV Nuclear Reactors," in Review of Progress in QNDE, edited by D. O. Thompson and D. E. Chimenti, American Institute of Physics, Melville, NY, in press.

\section{Distributed Partnership at a Glance}

\section{ATR NSUF and Partners Facilities \& Capabilities}

\begin{tabular}{|l|l|}
\hline MIT & Reactor \\
\hline
\end{tabular}

\section{Team Members/Collaborators}

- CSM - David L. Olson (principal investigator); Professors Jeff King, Brajendra Mishra and Michael Kaufman (collaborators); Travis Koenig (graduate student); Jordan Fletcher, Louis Gerstenberger, Samantha Lawrence, Alexandra Martin and Christopher Mejia (Senior Design Team)

- MIT - Lin-Wen Hu (co-principal investigator); Gordon Kohse (collaborator)

- INL - Mitchell Meyer, Rory Kennedy and Jim Cole (collaborators) 


\section{Introduction}

The increasing use of salt beds as disposal sites for nuclear waste makes it necessary to develop accurate models for the solubility of actinides, such as plutonium $(\mathrm{Pu})$, in the brines that develop at these sites. The effects of iron on this process are critical to overall repository performance due to its prevalence in the waste stream, and its ability to reactively impose a reducing environment that leads to lower actinide solubility. A key goal of the nuclear industry is to ensure the long term safety of waste repositories. This requires a detailed scientific basis for modeling the fate and transport of actinides in the environment. By improving these models this research will address issues concerning the back end of the nuclear fuel cycle, as well as potential inadvertent environmental release situations.

\section{Project Description}

Understanding the role iron plays in changing the oxidation state and solubility of the actinides is vital to accurate modeling. The complex nature of the brines that form in the salt beds makes it difficult to infer the mechanism of this iron chemistry, so experiments have been conducted on $\mathrm{Pu}$ in brine solutions containing various iron phases. $\mathrm{X}$-ray spectroscopy was used to determine the oxidation point of the plutonium at both short and long times.

\section{Accomplishments}

In earlier Pu brine studies, $\mathrm{x}$-ray absorption near edge spectroscopy (XANES) measured a rapid reduction of

\begin{tabular}{|l|l|}
\hline \multicolumn{2}{|l|}{ Distributed Partnership at a Glance } \\
\hline ATR NSUF and Partners $\quad$ Facilities \& Capabilities \\
\hline $\begin{array}{l}\text { IIlinois Institute } \\
\text { of Technology }\end{array}$ & $\begin{array}{l}\text { MRCAT at Advanced Photon } \\
\text { Source, Argonne National } \\
\text { Laboratory }\end{array}$ \\
\hline \multicolumn{2}{|l|}{ Team Members/Collaborators } \\
\hline - LANL - Donald Reed (principal investigator) \\
- IIT - Jeff Terry (collaborator); Daniel Olive (Ph.D. candidate)
\end{tabular}

$\mathrm{Pu}(\mathrm{VI})$ to $\mathrm{Pu}(\mathrm{IV})$ over a time scale of days. In this study a longer time scale was used to examine the chemistry. The corrosion products were recovered after approximately four years in an oxygen-free nitrogen glove box.

Using x-ray absorption spectroscopy, samples were analyzed where $\mathrm{Pu}(\mathrm{VI})$ had interacted with $\mathrm{Fe}(0)$ coupons and magnetite $\mathrm{Fe}(\mathrm{II} / \mathrm{III})$ powder. Initial results indicate that in the presence of iron the plutonium-in-solution will be rapidly reduced to $\mathrm{Pu}(\mathrm{IV})$, and over longer time scales will eventually be reduced to $\mathrm{Pu}(\mathrm{III})$ at long timescales (Figure 1).

\section{Future Activities}

In order to understand the underlying thermodynamics of $\mathrm{Pu}$ in complex brine systems, the solubility controlling phases must be identified. Extended x-ray absorption fine structure (EXAFS) spectroscopy is capable of identifying the number and geometries of near neighbor atoms in amorphous materials such as the corrosion products mentioned above. However, these scans require significantly more time to complete on the kinds of low concentration samples typically obtained under environmentally relevant conditions. These samples are also susceptible to changes induced by the $\mathrm{x}$-ray beam, which can complicate the analysis.

The complex nature of the brines that form in the salt beds makes it difficult to infer the mechanism of this iron chemistry. 


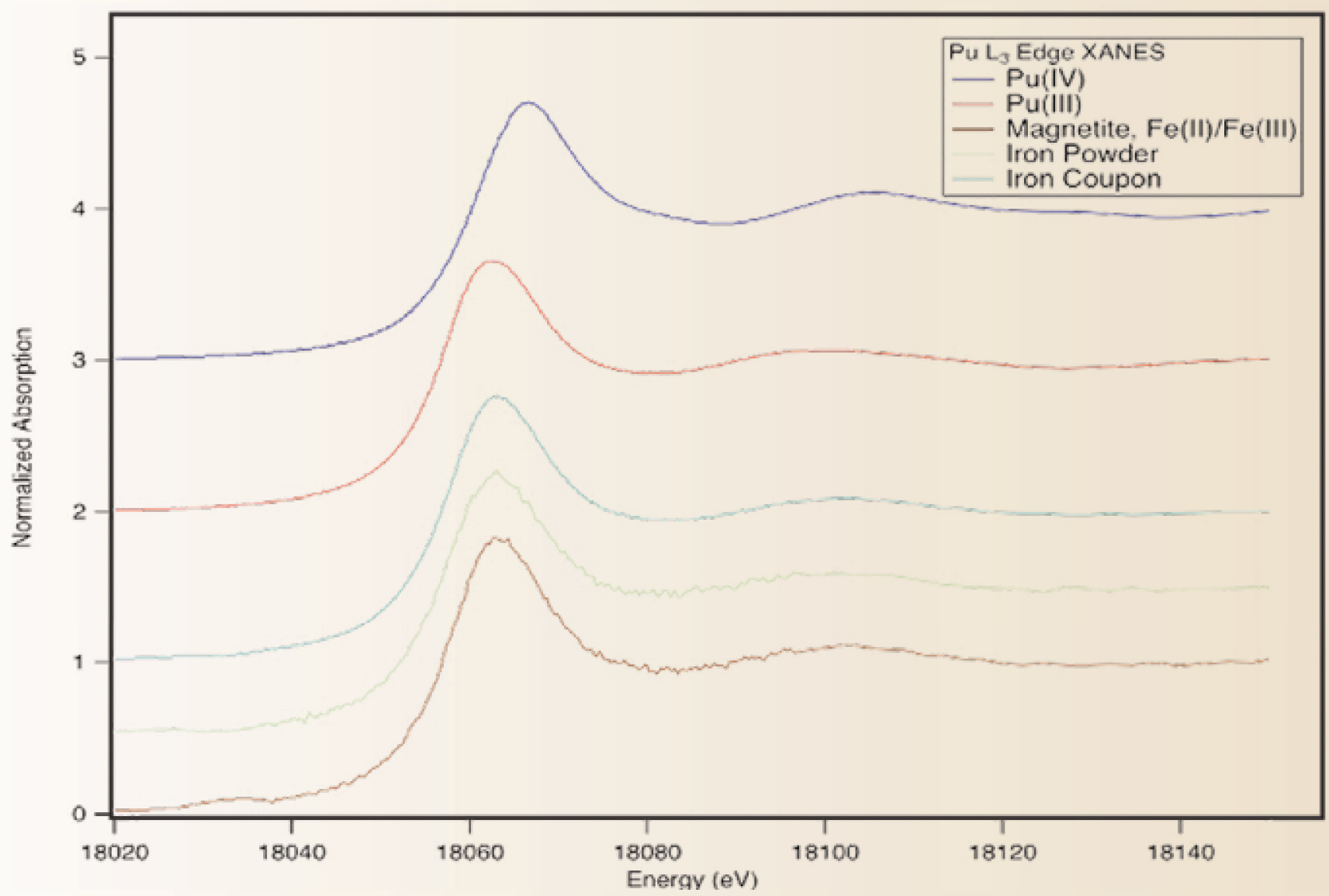

Figure 1. XANES of plutonium associated with iron precipitates/corrosion products from extended equilibration study of Pu(IV) in solution, as shown by comparison with $\mathrm{Pu}(\mathrm{III})$ and $\mathrm{Pu}(\mathrm{IV})$ standards. These results show that $\mathrm{Pu}(\mathrm{IV})$ was largely converted to $\mathrm{Pu}(\mathrm{III})$ under the conditions of the brine experiments.

\section{Publications}

At least two publications are in preparation utilizing the data collected during this experiment.

\section{Presentations}

(1) Daniel Olive, "Investigation of actinide solubility in rines using XAFS," American Chemical Society, 240th National Meeting, Boston, Massachusetts, August, 2010.
(2) Donald Reed, High ionic-strength subsurface chemistry of actinides," American Chemical Society, 240th National Meeting, Boston, Massachusetts, August, 2010 . 


\section{Introduction}

During this pilot project, being undertaken jointly by the ATR NSUF and the University of Wisconsin (UW), neutron irradiations are performed at various temperatures on a broad spectrum of alloys and geometries used in nuclear reactors. The irradiated materials then undergo structural characterization and mechanical property testing.

Irradiation samples were provided by the Pennsylvania State University; Alabama A \& M University; Westinghouse Electric Company; the University of Wisconsin; the University of Michigan; Los Alamos National Laboratory; Oak Ridge National Laboratory, and the Japan Atomic Energy Agency. Samples were prepared and documented at UW, and then loaded into irradiation capsules at the ATR NSUF in June 2008.

The first batch of irradiations have been completed, and materials are being shipped to various U.S. facilities for relevant PIE.

\section{Project Description}

The research team irradiated more than 500 individual samples, some of them virtually, but not completely, identical. For example, by irradiating ferritic steel HT-9 obtained from three separate sources-INL, ORNL, and LANL - the project team hopes to understand the effects minor compositional variations have on radiation response.

\section{The project will advance the state of} knowledge of radiation responses in a wide range of important reactor structural materials.

Ferritic steels with more apparent differences are also being irradiated. They include T91, NF616, 9Cr nanostructured oxide-dispersion-strengthened (ODS) steel, grainboundary-engineered $\mathrm{HCM} 12 \mathrm{~A}, \mathrm{Fe}-9 \% \mathrm{Cr}$ and $\mathrm{Fe}-12 \% \mathrm{Cr}$ binary alloys.

In the austenitic category, irradiation investigations are being conducted on the conventional alloys IN $800 \mathrm{H}$, NF709, and D9, as well as two advanced-concept alloyssuper 304 stainless steel and HT-UPS-AX-6 - that were developed at ORNL.

To investigate their usability in nuclear waste storage applications, five compositions of $\mathrm{Fe}-\mathrm{Cr}$-Mo-B metallic glasses that were prepared through melt spinning at UW are being irradiated. Two ceramics, silicon-carbide (SiC) and $\mathrm{ZrO}_{2}-\mathrm{MgO}$, as well as two pure metals from Westing- house, $\mathrm{W}$ and $\mathrm{Ag}$, and Mo-ODS are also being irradiated.

All irradiations are being performed at 300,400, 500, and $700^{\circ} \mathrm{C}$, at dose levels of 3 and $6 \mathrm{dpa}$. Samples were placed on 3-mm TEM disks; miniature, 16-mm-long tensile sample rods; and $\mathrm{SiC}$ rods.

Given the large number of materials being investigated, researchers are using an array of PIE techniques, including:

- High-resolution transmission electron microscopy (HRTEM)

- Atom-probe analysis

- Small-angle neutron scattering (SANS)

- Tensile testing

- Shear punch tests

- Micro-hardness testing.

\section{Accomplishments:}

Irradiation began in September 2008, and most of the 3-dpa irradiations were completed in July 2010. All 6-dpa and 3-dpa irradiations will be completed in 2011, and PIE on the 3-dpa samples has begun.

At UW, the Characterization Lab for Irradiated Materials (CLIM), which includes a TEM with energy dispersive spectroscopy, has been established exclusively for PIE.

At UNLV, a high-resolution TEM that can handle radioactive samples was used to examine ion-irradiated ferritic (Fe-Cr) and oxide-dispersion-strengthened (ODS) steels (Figure 1).

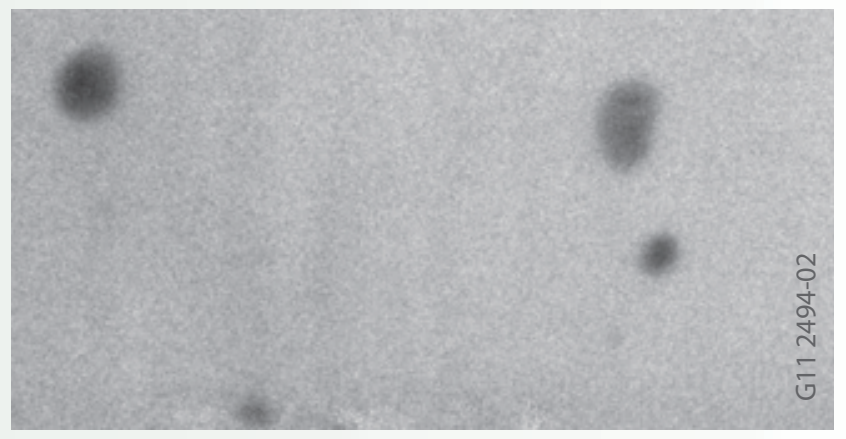

(a)

Figure 1. High-resolution TEM image of 14YWT oxide-dispersion steel showing nanometer-size scale oxide particlesResearchers used SANS analysis at the National Institutes of Standards and Technology (NIST) in Washington, D.C., for PIE work on $9 \% \mathrm{Cr}$ ODS steels 
Kevin Field, (Ph.D. candidate) University of Wisconsin - Madison

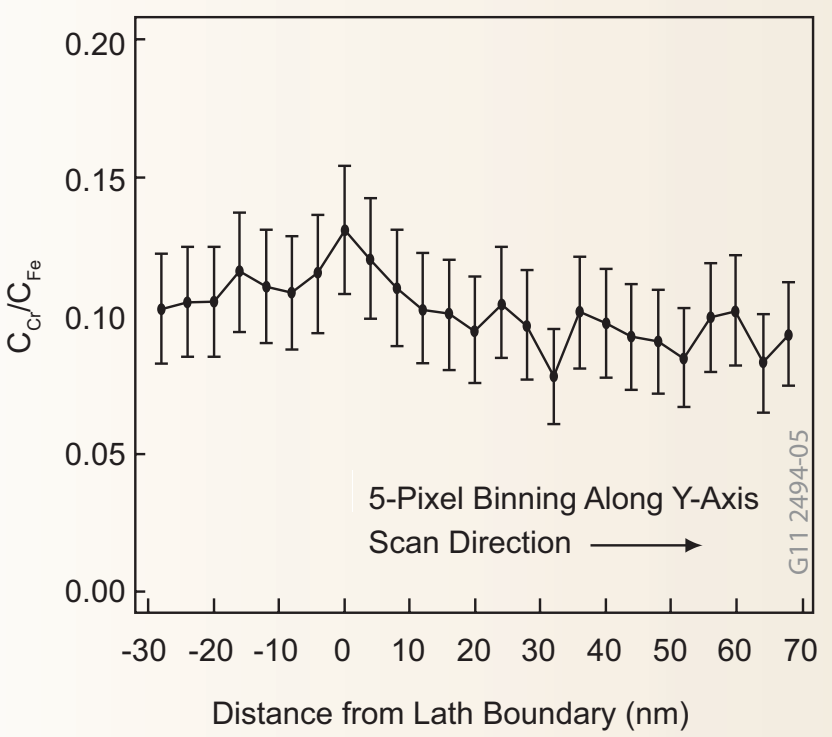

(b)

Figure 2. Chromium distribution map of a $100 \mathrm{~nm} \times 100 \mathrm{~nm}$ region of interest that contained a grain boundary in a Fe- $9 \% \mathrm{Cr}$ model alloy

Researchers used SANS analysis at the National Institutes of Standards and Technology (NIST) in Washington D.C., for PIE work on $9 \% \mathrm{Cr}$ ODS steels (Figure 2) irradiated to $3 \mathrm{dpa}$ at $500^{\circ} \mathrm{C}$ as well as unirradiated ODS samples. In addition, irradiated samples of ferritic HCM12A steel underwent SANS analysis at LANL.

Under a Shared Research Equipment (SHaRE) project, awarded by ORNL in February 2010, a FEG-TEM/STEM and local electron atom probe were used for structural characterization of the samples. Samples of IN 800H and grain-boundary-engineered IN 800 alloys irradiated to $3 \mathrm{dpa}$ at $500^{\circ} \mathrm{C}$ have been sent to ORNL for PIE.

At INL, a tensile testing machine in the hot cell is evaluating the mechanical properties of the irradiated samples.

Shear punch and micro-hardness testing equipment is also being utilized.

A TEM and atom probe, along with the focused ion beam (FIB) system, have been installed at CAES and will be available to project researchers.

\section{Future Activities}

The primary focus of project-related research in FY 2011 will be the PIE work on the 3-dpa samples that were irradiated in FY 2010. The analysis of irradiated IN 800H and grain-boundary-engineered IN $800 \mathrm{H}$ steels will be performed at ORNL. Project researchers will also use the newly enhanced FIB and TEM capabilities at CAES for PIE on ferritic model alloys and steels. Irradiation of 6-dpa samples and the remaining 3-dpa samples will also continue.

Tensile testing of the irradiated alloy samples will be performed at INL, and their properties will be benchmarked against those of the unirradiated samples. Additionally, shear punch and micro-hardness tests will be performed on some of the 3-mm disks.

\section{Publications, Presentations and Patents}

(1) K. Sridharan, T. R. Allen, Y. Yang, P. Xu, L. Tan, and T. Gerczak, H. MacLean, and J. Foster, "ATR-NSUF Pilot Project: Irradiation of Reactor Structural Materials," FCRD Advanced Materials Development Working Group Meeting, Santa Barbara, CA, 2010.

(2) J. L. Rempe, K. G. Condie, D. L. Knudson, and L. L. Snead, "Comparison Measurements of Silicon Carbide Temperature Monitors,” IEEE, TNS-00048, 2010.

(3) J. L. Rempe, K. G. Condie, and D. L. Knudson, "Silicon Carbide Temperature Evaluation Monitors," INL-PLN-3473. 2010.

\section{Distributed Partnership at a Glance}

\begin{tabular}{l|l}
\hline \multicolumn{1}{|l}{ ATR NSUF and Partners } & Facilities \& Capabilities \\
\hline $\begin{array}{l}\text { Idaho National Laboratory } \\
\text { University of Wisconsin }\end{array}$ & $\begin{array}{l}\text { Advanced Test Reactor } \\
\text { PIE facilities }\end{array}$ \\
\hline \multicolumn{2}{|l}{ Team Members/Collaborators } \\
\hline
\end{tabular}

- University of Wisconsin - Kumar Sridharan (principal investigator); Yong Yang (collaborator); Yina Huang, Peng $\mathrm{Xu}$ (post-doctoral students); Kevin Field, Alicia Certain, Tyler Gerczak (Ph.D. candidates)

- Idaho National Laboratory - Heather Chichester (co-principal investigator); Ram Prabhakaran (Ph.D. candidate); Mitch Meyer, Joy Rempe (collaborators)

- University of Michigan - Gary Was (collaborator); George Jiao (post-doctoral student); Janelle Wharry (Ph.D. candidate)

- Pennsylvania State University - Arthur Motta (collaborator)

- University of Nevada, Las Vegas - Longzhou Ma (collaborator)

- Alabama A \& M University - Claudiu Muntele (collaborator)

- Los Alamos National Laboratory - Maria Braga (collaborator)

- Oak Ridge National Laboratory - Jeremy Busby, Lizhen Tan (collaborators)

- National Institute of Standards and Technology - John Barker (collaborator)

- Japan Atomic Energy Agency (JAEA) - Shigeharu Ukai (collaborator) 


\section{Introduction}

In recent years, ferritic alloys have emerged as strong candidate materials for the construction of advanced nuclear power systems. Compared to traditional materials like austenitic stainless steel, ferritic alloys possess excellent resistance to void swelling, better thermal conductivity, lower thermal expansion and acceptable mechanical strength at high temperatures. Iron-chromium $(\mathrm{Fe}-\mathrm{Cr})$ is considered the leading ferritic alloy system for a variety of advanced reactor components and applications.

\section{Project Description}

This project undertakes of a set of experiments using PIE and analysis to gain significant new insights into the radiation performance of the ferritic alloys proposed for advanced reactor applications. Through the cooperative efforts of no fewer than six research institutions, this project will subject $\mathrm{Fe}-\mathrm{Cr}$ model, commercial and developmental alloys to a set of common irradiation conditions. The data collected during these experiments will provide the foundation for developing materials and material modeling that will enable researchers to better understand the radiation performance of the entire $\mathrm{Fe}-\mathrm{Cr}$ alloy system.
No fewer than five research institutions are contributing to the success of this project.

At the same time, it will aid the development of modeling capabilities that will enable scientists to more accurately predict future alloy performance.

The study will examine two sample geometries:

1. Samples for transmission electron microscope analysis

2. Samples for measuring tensile strength

The samples will be placed in the ATR and subjected to irradiation temperatures of 300,450 , and $550^{\circ} \mathrm{C}$ (Table 1).

Irradiations with low target doses of 0.01 and 0.1 displacements per atom (dpa) will be performed using capsules in the ATR's B-7 position (the hydraulic shuttle irradiation system or "rabbit"). The high-dose irradiations $(0.5-10$ dpa) will occupy ATR position A-11 (Table 2).

Table 1. Test Matrix (12 materials, 3 irradiation temperatures, 6 doses)

\begin{tabular}{|l|l|l|l|}
\hline Alloys & Temperature $\left({ }^{\circ} \mathrm{C}\right)$ & Dose $(\mathrm{dpa})$ & Specimen Types \\
\hline Model Alloys: & $300,450,550$ & $0.01,0.1$, & $0.5,1.0,5.0$, \\
Fe, Fe-9Cr, Fe-9Cr-0.1C, Fe-9Cr- & & 10 & \\
0.5C, Fe-12Cr, Fe-12Cr-0.2C, & & & \\
Fe-12Cr-0.5C, Fe-14Cr*, Fe- & & & \\
19Cr* & $300,450,550$ & $0.01,0.1$, & TEM, Miniature tensile \\
\hline Commercial Alloys: & & $0.5,1.0,5.0$, & \\
T91, HT-9 & $300,450,550$ & $0.01,0.1$, & TEM, Miniature tensile \\
\hline Developmental Alloys: & & $0.5,1.0,5.0$, & \\
MA-957 & & & \\
\hline
\end{tabular}


"The ATR experimental facility provides the first real opportunity for university programs to plan and lead reactor irradiation experiments in the U.S. This adds a whole new dimension to our understanding of radiation effects in reactor materials and provides the training ground for students who will become the next generation of researchers in this area."

J. F. Stubbins, Ph.D., Professor and Department Head, Nuclear, Plasma and Radiological Engineering, University of Illinois

Table 2. Irradiation Cycle and Capsule Arrangement at position A-11

\begin{tabular}{|c|c|c|c|c|c|c|c|c|}
\hline Cycle & $145 A$ & 145B & $146 \mathrm{~A}$ & 146B & $147 \mathrm{~A}$ & 147B & $148 \mathrm{~A}$ & 148B \\
\hline $\begin{array}{l}\text { Cycle Time } \\
\text { (EFPD) }\end{array}$ & 56 & 49 & 56 & 49 & 49 & 14 & 56 & 49 \\
\hline \multicolumn{9}{|c|}{$\begin{array}{r}\text { Distance from Core } \\
\text { midplane (inches) }\end{array}$} \\
\hline 20.375 & & UI-0.5-300A & & UI-0.5-450A & UI-0.5-550A & & & \\
\hline 13.875 & & UI-1.0-300A & & UI-1.0-450A & UI-1.0-550A & & & \\
\hline 5.500 & UI-5.0-450 & UI-5.0-450 & UI-5.0-450 & & & & & \\
\hline 2.500 & UI-10-450 & UI-10-450 & UI-10-450 & UI-10-450 & UI-10-450 & & UI-10-450 & UI-10-450 \\
\hline-0.500 & UI-10-550 & UI-10-550 & UI-10-550 & UI-10-550 & UI-10-550 & & UI-10-550 & UI-10-550 \\
\hline-3.500 & UI-10-300 & UI-10-300 & UI-10-300 & UI-10-300 & UI-10-300 & & UI-10-300 & UI-10-300 \\
\hline-6.500 & UI-5.0-300 & UI-5.0-300 & UI-5.0-300 & UI-5.0-550 & UI-5.0-550 & & UI-5.0-550 & \\
\hline-15.875 & & UI-1.0-300B & & UI-1.0-450B & UI-1.0-550B & & & \\
\hline-22.625 & & UI-0.5-300B & & UI-0.5-450B & UI-0.5-550B & & & \\
\hline
\end{tabular}

\section{Accomplishments}

As of this writing, all high-dose irradiation capsules have been inserted into the reactor. Capsules whose irradiations have been completed have been transferred to the Hot Fuel Examination Facility at the Idaho National Laboratory for unloading and post-irradiation examination.

Titanium capsules have been designed for the low-dose irradiations. Fe-Cr samples that will be inserted into these capsules were machined at the University of Illinois. Delays in the startup of the rabbit system at the ATR have led to corresponding delays in the low-dose irradiation schedule.

In 2011, ATR will add a new hydraulic shuttle system and this experiment will be the first to use this brand new capability.

\section{Distributed Partnership at a Glance \\ ATR NSUF and Partners Facilities \& Capabilities \\ INL \\ Advanced Test Reactor, PIE facilities \\ Team Members/Collaborators \\ - University of Illinois - James Stubbins (principal investigator) Carolyn Tomchik (graduate student) \\ - INL - Jian Gan, Maria Okuniewski (co-investigators); Gregg Wachs (project engineer) \\ - Georgia Institute of Technology - Chaitanya Deo (collaborator) \\ - General Electric Company - Eric Loewen (collaborator) \\ - Los Alamos National Laboratory - Stuart Maloy (collaborator)}

\section{Future Activities}

In spring 2011, the titanium capsules for low-dose rabbit irradiations will be loaded with $\mathrm{Fe}-\mathrm{Cr}$ samples at the University of Illinois. They will then be shipped to the ATR to be inspected, tested and loaded into the rabbit system. When the low-dose irradiations are completed, the capsules will be transferred to the HFEF for preparation of the samples for examination. Post-irradiation work is expected to be completed by September 2011. 


\section{Introduction}

As the nuclear power industry develops its Generation IV reactors, Tristructural-Isotropic (TRISO) particles have emerged as the proposed fuel of choice for the U.S. Department of Energy's Very High Temperature Reactors (VHTR). With their small size, ceramic construction, and spherical shape, TRISO particles possess a very high mechanical strength, which allows them to safely contain all but the smallest traces of fission byproducts. However, it has been observed that, when exposed to radiation and elevated temperature, intact TRISO fuel particles can release two of these byproducts, ${ }^{110 \mathrm{~m}} \mathrm{Ag}$ and ${ }^{137} \mathrm{Cs}$. This reduces the lifetime of the fuel and can adversely affect reactor safety and maintenance. To ensure the VHTR operates safely, efficiently and to its full potential, the kinetics and mechanisms of the $\mathrm{Ag}$ and $\mathrm{Cs}$ releases must be understood.

\section{This project will help ensure that} VHTRs operate safely, efficiently and to their full potential.

\section{Project Description:}

The project will measure the diffusion of $\mathrm{Ag}$ and $\mathrm{Cs}$ in single-crystal and polycrystalline silicon carbide ( $\mathrm{SiC})$ and the effect irradiation has on the diffusion kinetics and solubility.

In the initial stage, researchers at the Michigan Ion Beam Laboratory, working through the ATR NSUF at the INL, will implant $\mathrm{Ag}$ and $\mathrm{Cs}$ into $\mathrm{SiC}$ substrates to create diffusion couples of $\mathrm{Ag} / \mathrm{SiC}$ and $\mathrm{Cs} / \mathrm{SiC}$. They will then expose the couples to temperatures of up to $1600^{\circ} \mathrm{C}$ to induce the thermal diffusion.

In the second stage of the project, which will be performed at the University of Wisconsin Ion Beam Laboratory User Facility, researchers will investigate the effect of irradiation on $\mathrm{Ag}$ and $\mathrm{Cs}$ diffusion by bombarding the implanted samples with high-temperature $\left(1200^{\circ} \mathrm{C}\right.$ $-1400^{\circ} \mathrm{C}$ ) protons using a specially designed hot stage.
Subsequently, depth profiles of the diffusion couples will be completed using secondary ion mass spectroscopy (Figure 1). Depth profiling of the ion implantation samples will reveal the manner in which the implanted concentrations of $\mathrm{Ag}$ and Cs have been redistributed by the irradiation, thus providing data on the sample's impurity diffusion.

\section{Accomplishments}

When completed, the project will provide depth profiles of irradiated and unirradiated diffusion couples. Comparing these samples will illuminate the effects of irradiation on diffusion and solubility in $\mathrm{Ag} / \mathrm{SiC}$ and $\mathrm{Cs} / \mathrm{SiC}$ systems. Using scanning transmission electron microscopy-energy-dispersive spectrometry, researchers will investigate how the dispersion of $\mathrm{Ag}$ and Cs influences specific defects. They will also observe the boundaries of individual $\mathrm{SiC}$ grains to learn how they contribute to irradiation-induced defects.

The project will also provide insight into the active diffusion mechanisms responsible for the release of $\mathrm{Ag}$ and $\mathrm{Cs}$ from the TRISO particles as well as enable the measurement of diffusion coefficients that will allow researchers to accurately predict fuel lifetimes.

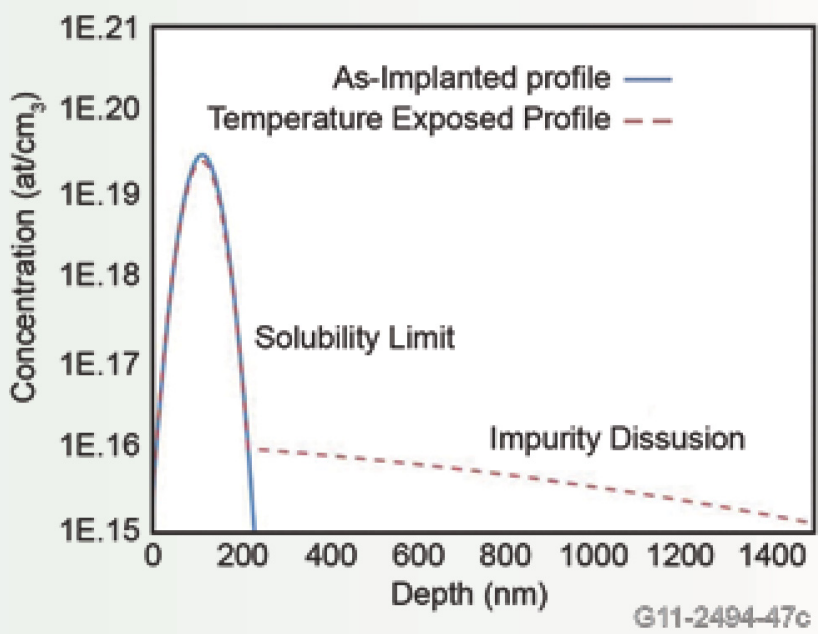

Figure 1. Schematic of an ion implantation diffusion couple depth profile 


\section{Future Activities}

As of the writing of this report, no implantations have been performed. The research has been centered on the preparation of silicon carbide samples, which are expected to be ready for implantation in spring 2011. The project team expects that all objectives described in this report will be completed in 2011.

\begin{tabular}{|l|l|}
\hline \multicolumn{2}{|l|}{ Distributed Partnership at a Glance } \\
\hline ATR NSUF and Partners $\quad$ Facilities and Capabilities \\
\hline University of Michigan & lon Beam Laboratory \\
\hline Team Members/Collaborators \\
\hline - University of Wisconsin - Izabela Szlufarska \\
(principal investigator); Tyler Gerczak (Ph.D. candidate) \\
- INL - Jim Cole (co-principal investigator); Paul Murray, \\
Gregg Wachs, Tony Walters (project engineers) \\
- University of Wisconsin lon Beam Laboratory - Kim Kriewaldt \\
(collaborator) \\
- Michigan lon Beam Laboratory - Ovidiu Toader (collaborator) \\
-Pacific Northwest National Laboratory - Zihua Zhu (collaborator) \\
\hline
\end{tabular}

G11-2494-50 


\section{Introduction}

High-temperature gas-cooled fast reactors will require advanced materials that demonstrate good stability under higher temperatures. Some ceramics appear to be good candidates. Examining the microstructural evolution of these ceramic materials under neutron radiation at high temperatures could provide a better understanding of their potential stability in gas-cooled reactors.

\section{Advanced materials are need- ed for high-temperature, gas- cooled reactors.}

\section{Accomplishments}

Post-irradiation examination (PIE) showed the irradiated microstructures for the $\mathrm{ZrC}, \mathrm{ZrN}$, and $\mathrm{TiC}$ are all decorated with a high density of dislocation loops. Rel-rods streaks were also clearly observed in the diffraction condition for those specimens (Figure 1). The relrods' dark field images further confirm the existence of the faulted dislocation loops in those samples.

\section{Project Description}

The objective of this project is to examine the impact of neutron irradiation on the microstructure of proposed candidate ceramics - zirconium carbide $(\mathrm{ZrC})$, titanium carbide (TiC), zirconium nitride $(\mathrm{ZrN})$ and titanium nitride (TiN) - that were irradiated in the Advanced Test Reactor (ATR) to $1 \mathrm{dpa}$ at $800^{\circ} \mathrm{C}$.

The samples, 3-mm discs and 20-mm long rods, were prepared at the University of Wisconsin, and will be examined using TEM. The goal of the TEM is to understand the effect of irradiation on lattice stability, phase change, void growth and development of other microstructural features, such as dislocation loops and stacking fault tetrahedral.

PIE activities also include microhardness tests and immersion density measurements.

\section{Distributed Partnership at a Glance}

ATR NSUF and Partners Facilities \& Capabilities

University of Wisconsin PIE facilities

Team Members/Collaborators

- University of Florida - Yong Yang (principal investigator);

Clayton Dickerson (graduate student)

- INL - Jian Gan (collaborator)

- University of Wisconsin - John McCarthy (Ph.D. candidate)
TiN displays a very different irradiated microstructure than other ceramics. This difference was also observed in proton-irradiated gas fast reactor (GFR) ceramics. The details of the irradiation-induced features in TiN are yet to be investigated.

Generally, microstructures resulting from neutron irradiation of the selected GFR ceramics are very similar to those seen with proton irradiation at the same temperature. However, the size, density and nature of the defects - which can be observed through further systematic characterizations - can vary slightly.

\section{Future activities}

A request was filed with ATR NSUF to extend the project contract through September, 2011. Based on the preliminary TEM results, the project team realized that a TEM with a higher resolution was needed to view important features that are beyond the capability of current equipment.

Once the protocol is approved and the relevant hardware upgrades are completed, all TEM specimens will be re-examined to provide a lattice resolution analysis of irradiation-induced features. Negotiations are underway to perform the microhardness test and density measurement experiments at the INL.

\section{Publications}

Abstract accepted by TMS 2011, and the presentation titled with "Radiation Stability of GFR Candidate Ceramics" is scheduled. 
"The low-dose neutron irradiation from the Advanced Test Reactor offers a valuable opportunity to benchmark the accelerator-driven, ion-irradiation experiments performed daily on the university campus. "

Yong Yang, Assistant Professor, Nuclear and Radiological Engineering, University of Florida

$\mathrm{ZrC}$

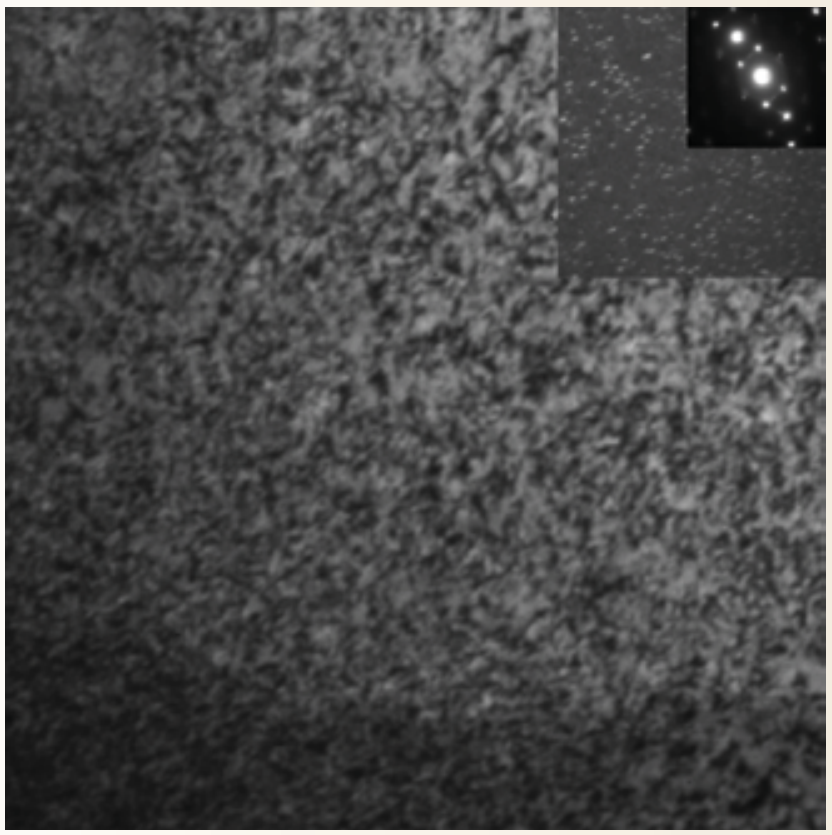

TiC

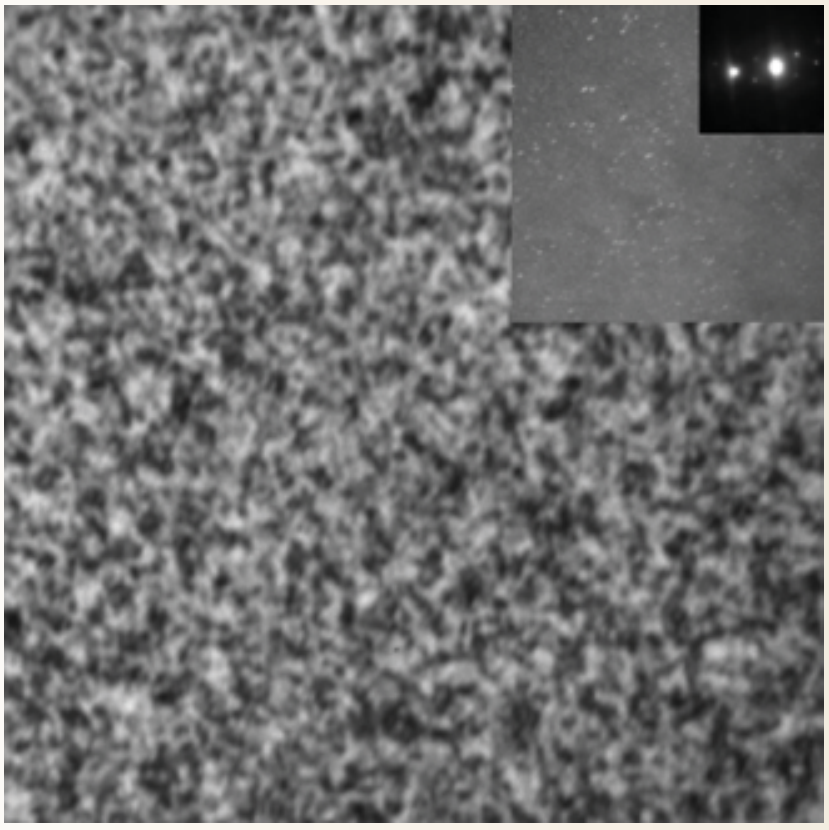

Figure 1. Irradiated microstructures of $\mathrm{ZrC}, \mathrm{ZrN}, \mathrm{TiC}$ and $\mathrm{TiN}$
$\mathrm{ZrN}$

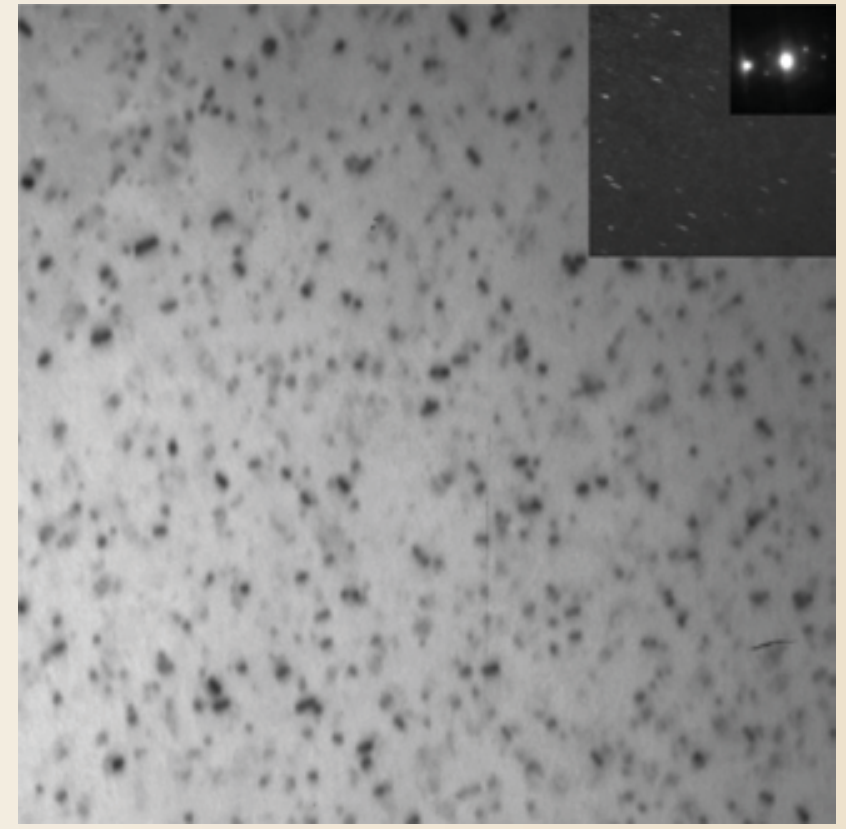

TiN

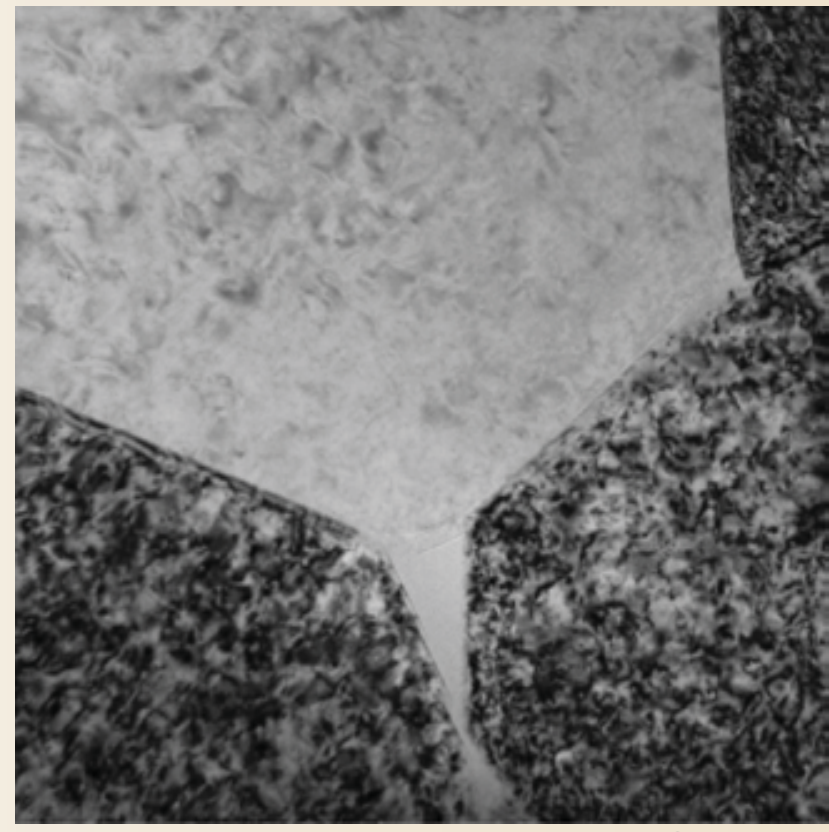

G11 2494-19 


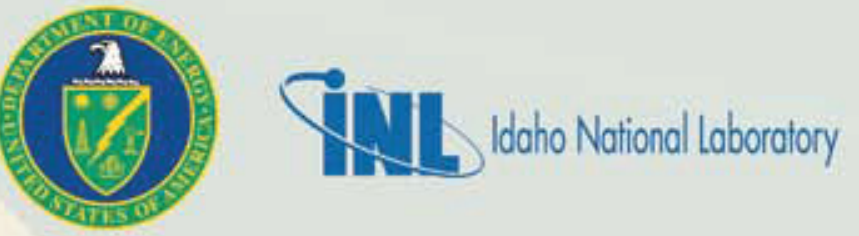

